
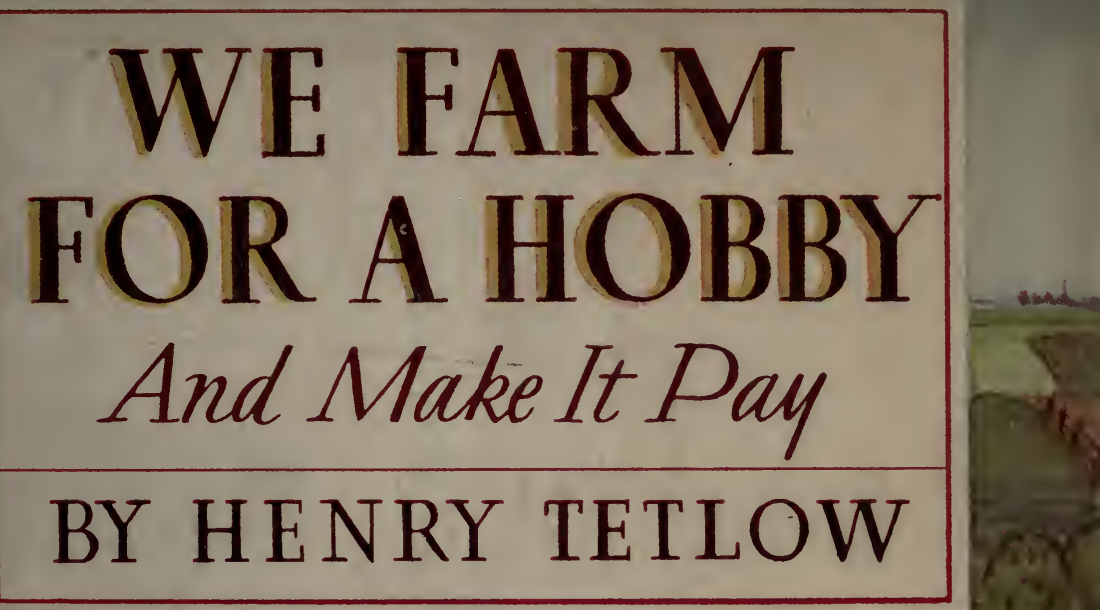

ex $t=1-x$

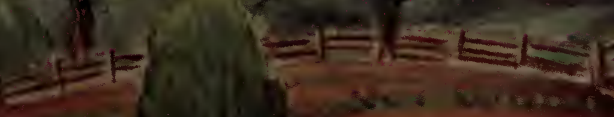

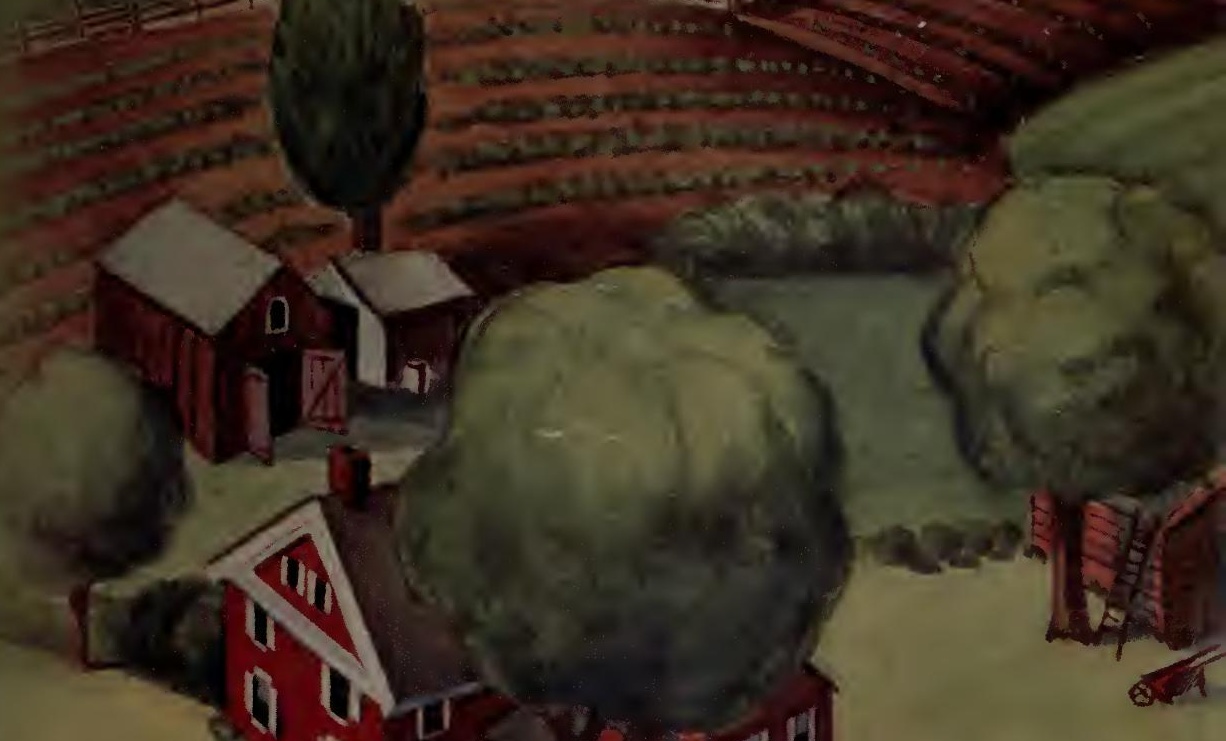

te Q 0 N

$90^{10}$ 
For all its charm and humor, this book is far from the idyllic, nostalgic back-to-the-land sort of thing. It is a book with facts and figures by a hard-headed Philadelphia business man who decided that, instead of feeding his farm, his farm should feed him.

\section{WE FARM}

\section{FOR A HOBBY}

\section{And Make It Pay \\ By HENRY TETLOW}

Henry Tetlow has a job that means the office every day. He, his wife, and two children live on a small farm near Philadelphia. In $193^{2}$ he decided that a few acres of good land could-and would-feed a family. Everyone told him he was crazy: that, next to owning a yacht, "farming a farm" was the most expensive luxury in the world.

Mr. Tetlow has proved that it can be done.

Except for a few staples, everything the Tetlows now eat comes off their farm. They live well, bounteously (the author has the utmost contempt for (continued on back flap)

AND PUBLISHED BY MORROW 
From the collection of the

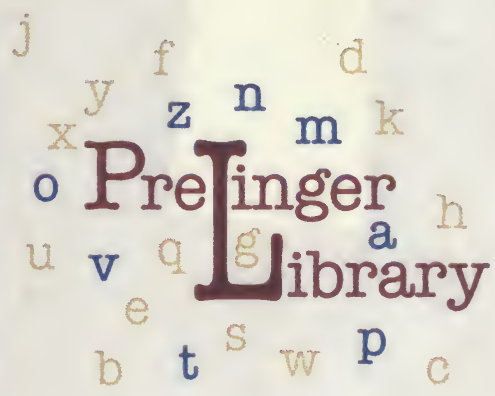

San Francisco, California 2007 



\section{WE FARM FOR A HOBBY}

$$
\text { and make it pay }
$$





\section{WE FARM FOR A HOBBY}

\section{and make it pay}

\section{BY HENRY TETLOW}

\section{$193^{8}$}

WILLIAM MORROW \& CO.

New York 


\section{WE FARM FOR A HOBBY}

COPYRIGHT - 1938

BY HENRY TETLOW

All Rights Reserved

This book, or parts thereof, may not be reproduced in any form without permission of the publisher. 


\section{THIS BOOK \\ IS DEDICATED TO \\ HAREBELLE}

who has put seventeen years of her career

into Medlock Farm, without foregoing any

of her charm, her grace, her gayety 
"What though I am not wealthy in the dower Of spanning wisdom; though I do not know The shiftings of the mighty winds that blow Hither and thither all the changing thoughts Of man: though no great minist'ring reason sorts Out the dark mysteries of human souls To clear conceiving: yet there ever rolls A vast idea before me, and I glean Therefrom my liberty." 



\section{O N T EN T S}

CHAPTER

PAGE

1. The Problem, the People, the Place

2. Pitfalls of Accountancy

3. The Expectation of Plenty

28

4. Farm Drudgery: A Myth

40

5. Where to Find Out How

49

6. Making Plans That Work

61

7. Must You Keep a Cow?

74

8. Poultry: A Success Story

88

9. Where Pigs Is Profits

102

10. The Garden and Orchard

116

11. Planning Side-Line Produce

12. The Household Chores

13. A' Babbled of Green Fields

154

14. Selling the By-Product

166

15. Some Conclusive Comparisons

180

Bibliography

193

Index 


\section{Preface}

NEAR the completion of his book the author, if he dare relax, sits back, and calls all the sad captains of memory to name those who came from the varying shore of the world to make his book for him. He battles the temptation to write scores of dedications. For he knows he has created little; rather, collated the "sifted wisdom" of his progenitors. To dedicate a book a dozen times is to quarrel with convention: the preface remains the author's outlet for his gratitude. There the living customarily take precedence of the dead. Yet the person before all others who must shoulder responsibility for my book is the late Jay E. House. He not only guided my early, wavering auctorial steps; at a time when others looked down their noses at my experiments in home-use farming he, out of his practical experience on the land, endorsed and encouraged them.

From the long list of the living I present these representative names: John Heilman, who combines with a natural gift for part-time farming the spirit and ability to carry on his shoulders the 
work I talk about doing; my neighbor William F. Hangstorfer, who epitomizes his own indirect definition of the perfect neighbor: "I aim to leave my neighbor alone unless he needs my help"; and my friend and classmate Howard Swiggett. He has kept me devoted through thick and thin to the "life beyond life."

"Quem fors dierum cumque dabit lucro adpone."

\section{Henry Tetlow.}

Tavern House, Medlock Farm,

Centre Square, Pennsylvania.

New Year's Eve, 1937. 


\section{WE FARM FOR A HOBBY}

$$
\text { and make it pay }
$$


CHAPTER ONE

The Problem, the People, the Place

UNLESS your memory is abnormally short you recall that 1932 was the year the roof of the world nearly fell in. Civilization appeared to be crumbling to bits. The least pessimistic could foresee some such crisis as that which culminated in the "bank holiday" of 1933. I have never been a bull on the United States nor, in fact, of bullish temperament. My way is to expect the worst and prepare for it. So it was in the fall of 1932 that I took serious thought of what $I$, and my family, could do to hedge against the economic and social disaster that appeared about to engulf the nation.

It needed no second sight, no preternatural vision to see the first and most important thing was. to trim our financial sails as closely as possible. My business had already taken a serious beating. I was. convinced, and had forecast in an article in The American Mercury in December, 1931, that things. would get worse before they got better. There were a number of different ways we could cut down on our living expenses. The problem was to decide which way was best. 
We live in the country, twenty miles north of the point in Philadelphia where I run the business founded by my great-grandfather eighty-nine years ago. We are four in family: Mrs. Tetlow, our daughters Margaret and Martha, and myself. Ours was a wartime marriage. Our oldest daughter was born about the time my outfit was moving up from the Haute Saône to a position northwest of Verdun in the Argonne jump-off line. Martha, the younger, joined us after the tumult and the shouting had died, and the captains and the kings had gotten the bum's rush. When I came back from the wars in the summer of 1919 we went to live in an apartment in Germantown. I stuck it out for more than a year. You have noticed that when two or three dog owners are gathered together sooner or later someone will say they would like nothing better than to have a dog, but an apartment is no place to keep one. What is not fit for a dog is not good enough for me or my family. Before the year was out I had Mrs. Tetlow, who was city raised, converted. We had searched for and found Medlock Farm. We moved out to it in the spring of 1921.

So when the crisis of 1932 arrived we were not beginners at country living. For Mrs. Tetlow the country had lost its strangeness: The girls, then fourteen and eleven-"going on" fifteen and twelve -had, like myself, practically never known anything else. As far as the records show there is not 
a trace of bucolic blood in their ancestry on the distaff side. On the Tetlow side it is different. There is a family tradition that the Tetlows introduced the use of soap from the civilized Baltic basin into the wilds of north England some six hundred years ago. I researched this as carefully as possible when I was at Yale. There is no doubt all my more recent forebears were soapmakers; but the meager written records prior to the early eighteenth century indicate that from the earliest times up until then they were all farmers. So perhaps it is not surprising we live on a farm.

Medlock Farm is not a suburban residence in a suburban community: it is a real farm, surrounded by farms, on Skippack Pike at its junction with the old post road from New York to Lancaster. The farmhouse that is our home appears on the maps used by Lord Howe and Sir Henry Clinton, during the Revolution, as White Horse Tavern. We have a near neighbor whose grandmother saw General Washington and his staff ride back up the pike after the battle of Germantown. She was four years old. She waved to the General and he waved back. The Lutheran church a-top the first rise north of Medlock Farm was used as a base hospital after Germantown. From our bedroom windows you can see Valley Forge.

For a variety of reasons we had not cultivated our forty acres seriously for nearly a decade prior 
to 1932. Six acres were-and are-in timber; another acre in young orchard, part of which was set out in the spring of that fateful year. Nearly another acre is in lawn and buildings. All the rest, save for a small fraction of an acre dedicated to a summer vegetable garden, we had let run to second-growth timber. It made fine game cover; but a half-dozen pheasants and as many rabbits are not much annual return out of thirty-eight acres. There was no other livestock on the place.

In spite of this reduction of farm property to its minimum uses there was still, as anyone who has ever owned any kind of real estate knows, a certain amount of work to be done all the time merely to "keep the place up," as it is called. For this purpose I had for the last eight years employed a man three days a week the year around. In summer he mowed the lawn and tended the garden. In winter he did painting, cleaning, wood-cutting -anything that came to hand. It was sometimes a problem to find work enough to keep him busy from one growing season to the next.

There was therefore the possibility of laying him off and saving his wages. I could cut the grass and tend the garden myself. There were times when I had done it. But reasons other than the prospect of weeding the onions and pushing the lawn-mower made this course distasteful. My man is a family man. Furthermore, when any man has 
THE PROBLEM, THE PEOPLE, THE PLACE

been with you eight years you hesitate to let him go: steady men are not easy to find. This one is such that I had little fear he would end up "on the county"-those were the days before the more abundant handout-if I let him go. Yet it would mean one more job closed to the six to sixteen millions variously estimated jobless. In those days the least public-spirited would have agreed with me that, assuming any conceivable alternative, such a course lacked constructive merit. And while it was admittedly a good idea to save all the money possible, yet what should we do if a time came when there was no money, or when the money we had was worthless? I was in Vienna in 1923, at the tail end of Austria's post-war inflation and had seen something of the dire consequences of currency depreciation. Again, in November, 1929, I heard a stock broker say, in his office in Wall Street: "Thank God I still know how to milk a cow." I lived to see him go back to doing just that. My concern was not only that we should pull in our financial neck but also that come what might we should not starve. There were plenty of other ways we could cut down cash expenses. Since we had forty fallow acres underfoot why not keep the man on and start producing our own food? Even should it prove more expensive than buying it ready-made, if the crash came we still would have three meals a day. 
I had always lived in the country. I was born in Germantown and brought up in Chestnut Hill when those two suburbs of Philadelphia were distinctly rural. I was used to a way of life that presupposed a vegetable garden, a flock of chickens, a cow or two, and a closetful of canned goods and preserves down cellar. Nevertheless I still subscribed in a vague, lukewarm way to the theory that it is cheaper to buy milk than to keep a cow, although my business experience had long since convinced me that in industry the theory never works out in practice. It now presented itself for practical demonstration on the homestead.

Earlier in 1932 I had interested myself in the problem of how a relief subject fared on a food order of five dollars a week. I had some experience both with army rationing and provisioning myself for canoe trips three or more hundred miles beyond the end of steel into the sub-arctic. It seemed to me one should eat perhaps not well but sufficiently on five dollars a week. Yet when I kept book on our own expenditure for food for several weeks that year I found that even with the help of a summer vegetable garden, and of relatively low store prices for food, our weekly bills averaged seventeen dollars, a good deal for four people who lived as simply as we did. Could we, perhaps, by producing the greatest possible amount of our own 
food on the farm cut down that weekly food bill enough to justify keeping our man on?

It was worth a try.

Our aim would be to produce as much of everything that could be grown here as we could consume at home-and no more. Thus we should have an edge on the ordinary commercial farmer, for everything we used would be at a saving of some part of the seventeen-dollar food budget. We would in effect be selling our own produce to ourselves at top retail prices; all the "spread" between producer and consumer, about which there is so much tohu bohu, as the French call it, would be clear profit for Medlock Farm. There would be no thought of production for sale. I could see no profit in selling. When we reached the point in any agricultural activity where we were producing all we could reasonably use at home we would level off production, and stick to that rate. Despite a lifetime in the country I still did not know that is the one most difficult thing to do: you can not regulate nature the way you would a production line.

How nearly we have succeeded in attaining our objective this book will show. The results are substantial if not spectacular. After two years I began to keep book on the enterprise; at first it was enough to know we were obviously saving more 
than we spent. By the end of 1934 we realized we had something. The next year we recorded not only farm expenses, but what we spent for food bought in stores. The total bill for food actually purchased ready for use in 1935 was $\$ 179.03$, an average of $\$ 3.44$ per week. Whatever else we did, we had knocked the tar out of that item. Since we seemed to entertain much more than when all the food had to be bought in stores I checked the actual number of meals eaten in the house and found that week-in-week-out, deducting meals eaten away from home by all four members of the family as well as adding the extra places laid for our guests, we were providing for an average of five people instead of the actual four numbered in family.

Of course this is only one side of the story; it is incomplete until you know how much more it cost to operate the farm in 1935 than it did in 1932. There are two extreme views of farming costs. Most people cling to the conviction fostered by manufacturers, as well as by the type called "gentleman farmer" who is-at least in this country -seldom either one or the other, and who has been known to boast that a glass of milk costs him more than a glass of champagne, that it is cheaper to buy anything than it is to make it or grow it yourself; that whatever advantages may accrue to country life, its great disadvantage is its high cost. 
THE PROBLEM, THE PEOPLE, THE PLACE

The other extreme-the roots-and-berries schoolassumes successful farming can be done without expense. These wishful thinkers see in country life a return-rather, a retrogression-to pioneer if not primordial conditions.

My own way, I-perhaps fondly-believe, is the auream mediocritatem, the golden mean between these extremes. It is not true that it is cheaper to buy it than it is to make it or to grow it. On the other hand, it can not be made or grown for nothing. While I view with distaste large farms run for tax purposes, yet I do not hold with the eaters of bark and grubs: I am for comfort, convenience, and a civilized life first, last, and all the time. Nothing but dire necessity could induce me to put out the furnace fire and try to cook and keep warm at the fireplaces.

In addition to confusing discomfort with simplicity, the roots-and-berries school usually leans toward vegetarianism or some other dietary crotchet. I had a strong, healthy great-uncle who killed himself in the prime of life with such notions. His brother, my grandfather, thought he was a vegetarian too: he always said he was. Yet for the twenty-eight last years of his life, during which I knew him, he ate prodigiously of meat at least twice, more often three times, a day. He was well and strong enough to take up farming when he was over seventy and make a small fortune from it in 
the ten last years of his life. To a normal human there could be no more repellent prospect than a meatless existence. Back in 1932 the problem of meat supply looked like the most difficult one we should have to face. It was certainly the one of which we knew least. It was the first one we tackled, and we solved it satisfactorily.

But we still buy meat from time to time. Not because we should otherwise go meatless but because we fancy a kind or cut of meat not immediately available on the farm. In putting Medlock Farm on a production-for-sustenance basis we have not bound ourselves to an ideological wheel. If we were to carry out our program to immoderate extremes we could make a better showing on paper. There were two weeks last summer while our daughters were away that, just to check up on ourselves, Mrs. Tetlow and I lived on a total outlay of thirty-eight cents-for two pounds of coffee. Lest the too hasty skeptic assume we did so at the expense of existing inventories let me add that our food purchases for four weeks before and four weeks after that fortnight were below average for the year. Furthermore, we entertained two lots of dinner guests and one week-end couple. No one complained of the fare. But as a general proposition we are not out to establish new highs or alltime lows.

It is more fun to be not too damned efficient. 
THE PROBLEM, THE PEOPLE, THE PLACE

If food cost us seventeen dollars a week in 1932, when prices reached a record low for my generation, it is fair to assume the weekly average for the previous five years must have been at least twenty-one dollars. In 1932 butter sold at thirty-two cents; milk was less than eleven cents a quart, eggs nineteen cents a dozen; while six cuts of pork averaged less than sixteen cents a pound. Prices were actually much more than twenty per cent lower in 1932 than in 1928 , or even 1930. There were times in the five years 1927-1931 when food cost us more than thirty dollars a week. But rather than draw the long bow let us take twentyone dollars per week as the five-year average. In the same years, that is in the years before we started the experiment recounted here, the incidental expenses of farm operation and upkeep, including vegetable seeds and commercial fertilizers, plus the three days' services of the hired man ran to nineteen dollars and twenty cents a week. Our total budget for food and the farm was, therefore, at least \$40.20 per week.

By 1935 , three years after we started Medlock Farm on its career of production for home-use, the weekly budget had dropped to $\$ 25.62$, despite increased farming expense. In the first nine months of 1937 the net weekly budget for all food and expenses of farm operation was exactly $\$ 23$ even though the part of our budget which went for 
boughten food had risen to an average of $\$ 5.90$ per week. As the government figures on the cost of commodities cited in the previous paragraph suggest, this increase is practically all price-not kind or quality; the higher cost of living imposed on us as a cure for poverty. All materials and supplies used cost more than they did five or even three years ago and we employ two days more labor.

In these figures every dollar that went into the farm is reckoned as expense although a good many such dollars were in fact either capital investment or prepaid expense: the cost of fencing a pasture or planting a hay field should properly be spread over five or ten years. No account is taken of the vastly improved physical condition of Medlock Farm; nor of the inventory which from a fourhundred-dollar beginning has grown to an "absolute auction" value of twelve to fifteen hundred dollars.

Conversely, if we had chosen to lay off the hired man and save his wages, where would we be today? If the increased prices of the foodstuffs we still have to buy are an indication we would be spending twenty-eight to thirty dollars a week for food. Even if the incidental maintenance expenses of the property remained the same, we would now be saving only a part of the man's wages andwe would have nothing to show for our pains or his lost time. However, it is a certainty that with- 
THE PROBLEM, THE PEOPLE, THE PLACE

out the man, other expenses could only be kept constant at the risk of further depletion of capital. Tilth is a prime factor in rural real estate values. We had already let thirty-two of our forty acres backslide.To neglect the remaining eight would have been to sacrifice some part of that proportion of the basic investment.

Now turn to glance at the aforementioned inventory with me. As this is written we are close on to Thanksgiving. In the barn are two milch cows yielding a daily superabundance of tuberculin- and blood-tested whole raw milk. Beside them are two bred heifers and two female calves. In the next twelve months we can count on four more calves, at least one of which will be a vealer (its mother tossed her cap, not over the windmill but the party-line fence). Alongside these are three sheep that will turn into lamb some time this winter; and when I say lamb I mean lamb, not the goat meat so frequently fobbed off on the innocent public as lamb. There are nineteen pigs, four of which will go to the butcher before Christmas, while three will stay at home to provide us with ham, bacon, lard, sparerib, sausage, scrapple, and souse. There are one hundred and ten hens producing more eggs than we can eat. Before next spring we shall have culled out thirty or forty of the low producers and salvaged them in potpies. These, with the twenty ducks in excess of the brood 
flock, will supply us with fowl twice a week for the next six months. Currently, until the end of the gunning season, they give place to rabbit and squirrel, pheasant and quail.

Overhead in the hayloft are fifteen to twenty tons of hay and corn fodder, while out in the corn crib are some six tons of corn with which to feed the livestock through the winter. Although the year's growing season is supposed to be over, the garden still produces lettuce, celery, leeks, broccoli, spinach, and cauliflower; while in the cellar or outdoor pits are carrots, beets, cabbages, turnips, potatoes, apples, and pears. There are two hundred and fifty quarts of canned fruits and vegetables in the red-room closet, and no one knows how many jars and glasses of jellies, jams, relishes, and preserves (we can always garnish the dining table with the traditional "seven sweets and seven sours" of Pennsylvania Dutch cuisine). The two kegs of sauerkraut will be ready to use by the time the first set of pig knuckles comes into the kitchen. In the north attic, where the tobacco crop is curing, are enough onions to see us through until next spring's scallions.

Even if it did not "pay" I would still like it. 


\section{Pitfalls of Accountancy}

NO indirect expenses that can legitimately be charged to rent are included in the figures set forth in the last chapter. We must have a place to live. Whether we pay a lump-sum rent or a variety of installments called interest, taxes, insurance, and upkeep on the dwelling is immaterial. The important point is that if we moved to town we should pay much more rent for the housing we presently enjoy in the country-with none of the attendant production facilities.

How rural rents here compare with those in the neighborhood of other large cities I can not say. My unsupported opinion is the ratio anywhere will be about the same as Philadelphia to its environs. In the absence of other specific data let me tell you what we get for how much, and then make some invidious comparisons. Tavern House-it is so nominated in the colonial deedsis a two-and-one-half-story brick building made with the same kind of brick, and in the same architectural school, as the State House (Independence Hall) in Philadelphia. It probably antedates the 
State House. From the end of the north wing to the front door it is sixty-three feet long. The wing is thirty-three feet long and thirty feet wide; the main body of the house is thirty by forty-five. On the ground floor are two living rooms, my study, dining room, kitchen, and pantry; on the second floor five bedrooms, dressing room, and three baths. There are three attic bedrooms, bath, and store room. And-to be sure!-there are four "practical" fireplaces and a secret staircase.

The total cost for interest at five per cent, insurance, taxes, and average repairs for the last three years is exactly thirteen hundred and twentynine dollars a year. The property pays part of the interest, so what I actually put out is $\$ 689$ per year. Add the five-year-average year bill for heat, light, and power, and our "rent" is exactly one hundred dollars a month. It is incredible it should work out at an even figure. I am always suspicious of even figures; if you are not you ought to be, too: if they do nothing else, more often than not they reveal the superficial, inexact mind. Nevertheless, there it is. . . . And to add artistic verisimilitude: in the three-year-average repair bill included in the even hundred dollars there is one item of $\$ 93.18$ for opening and connecting a longunused well one summer when our water supply was low.

Thirty years ago my father, for a brief season, 
rented in Chestnut Hill. He had an acre of ground, with carriage-house and stabling for four horses (I forget we have a three-car garage, thrown in at no extra cost). In addition to this he had fourteen rooms and two baths in a house that ate coal faster than it could be mined-and still was never warm in winter. The rent was one hundred dollars a month. In my own brief apartmental experience I paid one hundred and twenty dollars a month for six rooms and two baths; but that was right after the war. You can rent a two-story house, six rooms and bath, in a fairly good suburban neighborhood today for fifty or sixty dollars-and find your own heat. Of course, in the country we must find not only heat but also water supply, hot water, and sewage, garbage, and trash disposal, and all such basic services. It is an easily demonstrated fact that all these cost much more when supplied by a city government and paid for in taxation than when you furnish them yourself.

Part of the water pumped at our own expense (included in rent) from our own wells is consumed by the livestock, or otherwise used on the farm. Conversely, the labor of painting the exterior of the house is not included in the abovementioned maintenance bill because it has already been put down in the cost of farm operations for 1937. In a word, it is neither practical nor necessary to separate all costs to a nicety. No more is it 
when we come to segregate departmental farm accounts. Consider the corn crop now in the crib. Part will be used in the kitchen as corn meal. Most of it will be fed to the livestock. And who shall say what share of it goes to milk, beef, and veal, how much into pork or poultry? To attempt such refinements of bookkeeping would be to smother the homestead under a mountain of paper work, of which there is plenty now. And there is a still better reason for abstaining from it. The aim is not to limit production to those things that pay on paper alone. The aim is a well-balanced diet and as varied a ration as possible. Ducks offer a good illustration: they are carried at a loss. They are voracious feeders, grow rapidly, and having once made their weight at an early age must be killed or sold to avoid financial loss because they keep right on feeding voraciously without adding any more meat to their bones. But we are not out for a money profit on ducks; what we want is a change from chicken.

Here let me warn the laymen, of whom I am one, against the pitfalls of accountancy. Do not let the intricacies of farm operations beguile you into those deadfalls. There are as many ways to skin a bookkeeper's cat as there are certified public accountants. This was strikingly revealed last winter when I undertook to figure out the profit and loss on my poultry department in 1936. I calcu- 
lated them a half dozen different ways with as many different net results. Then I took the figures to town and had my treasurer, who is an expert accountant, see what he could make of them. He reached a result undreamed of in my figuring. So we took the data to our C. P. A. His findings in no way resembled either mine or the treasurer's. We finally agreed to call the ensuing debate off on the grounds that any one of us might be right; and that as long as we were all on the right side of the ledger it did not matter a great deal.

Which reminds me to explain how it is that when my rent is $\$ 1329$ a year I only have to pay $\$ 689$ of it per year. Well, the Federal Department of Agriculture, with that phenomenal ingenuity for figuring heads-I-win-tails-you-lose fashion commonly esteemed the peculiar gift and province of the Internal Revenue Bureau has succeeded in interpreting that which many consider an operating expense, as income. The Department made a study of a group of Maryland farms, to determine how much income-in-kind they contributed to their owners. The experts defined interest on the owner's equity in his property as the property's contribution toward the owner's total rent. Maybe that is right; I am not an expert and would not know. All I know is that $\$ 640$ is the interest on my equity in Medlock Farm, and that if I had not put the principal where it is when I did, the 
chances of my enjoying any income from it now would be tolerably slim.

In this same study everything consumed on the farms was weighed, measured, counted, and priced as it was brought in the house, a procedure that must have entailed endless detail work and that at best could never be absolutely accurate. Too many things must be processed too often before they reach the ultimate consumer to permit absolute accuracy. Should we reckon that part of the corn consumed on the farm at so much per bushel, or should we wait until it appears in the house as raw milk before entering it as a credit? And if we do the latter, shall we calculate it as so many quarts of raw milk, or as milk, cream, and butter? What shall we do about that part of the raw milk which goes sour and would be wasted were it not made into smear case? Or about the skim milk that comes out of the separator and goes into the pig trough?

From a practical standpoint it is just as useful and a lot easier to ignore the whole question of the value of the products consumed at home; to concentrate accounting vigilance on two sets of figures about which there can be no possible doubt or argument: the costs of those things that must be bought, and the receipts from sales. For the alert reader will have observed that in spite of 
the original intention to produce only for home use, we sell a good deal. We were forced into it. As has been said it is almost impossible to regulate production exactly to fit your needs. The measures that must be taken to insure sufficiencies frequently produce surpluses which must either be given away or be sold if they are not to go to waste. Sometimes it is harder to give a thing away than to sell it: the number of anyone's friends who could accept a fresh cow or a prime pig as a gift is limited; while to one accustomed to the intricacies of modern, high-pressure selling, the ease with which first-class farm produce can be sold is almost terrifying. In either case the devotée of the produce-for-use thesis enjoys an inestimable benefit denied the producer for sale: he does not need to worry about the production cost of the goods he sells. Whatever the money crop may be it is all velvet. My potato crop of 1936 is a good example.

Precisely the same quantity of the same kind of seed potatoes, planted and cultivated exactly the same way as any year for the last ten, produced an unexpected bumper crop. Instead of the normal twelve or fifteen bushels-enough to last through the winter into May or June-we found ourselves possessed of about thirty-five; which meant that after setting aside our own supply we had twenty 
bushels to sell. If we had sold them at a dime a bushel we would still have had a profit. In fact, we averaged $\$ 1.25$ a bushel.

It is obvious that since we do not charge rent against production we should not consider the basic capital investment in land and buildings as a factor in the cost sheets. Capital costs, as here applied to the farm, are those outlays necessary to change what is otherwise actually a commuter's home into a producing farm. The distinction is important because even after one has paid for land and buildings (of no matter what kind or condition) there is scarcely any limit to the amount of money that can be poured into a farm-if one has it to pour. Observation tells me that those who have, often spend too much, get disgusted, and move back to town. It is neither necessary nor desirable to invest a great deal of money in farm production, nor-and this is at least equally important-to do it all at once. Unless time is the vital factor, most of the investing can be left to nature. It is possible, for example, to start in the poultry business with one setting hen and a clutch of eggs. How much more one should invest depends on how quickly one wants to get results. Instead of the hen and eggs one could start by buying a flock of matured pullets that are ready to lay. They are cheap today at $\$ 1.25$ apiece, hereabouts.

In my case it was not necessary to invest any 
money in horses, or in heavy-and expensivemachinery. There are disadvantages to hiring heavy work done on contract, but so far I have been able to manage that way, and probably will be for some time to come. The only tools I had to buy that are not normal home equipment are:

Set of butchers' tools-knives, saw, cleaver, block and tackle for hoisting carcasses, lard press, sausage stuffer.

Hand-operated cream separator.

Small motor-driven mill for grinding cereals.

A spraying outfit mounted on a hand barrow.

A pressure cooker: absolutely necessary for canning all meats and some vegetables.

An eighty-four-egg electric incubator.

Two electrically lighted and heated brooders for small chicks.

One "finishing battery" brooder for birds six to sixteen weeks old.

Miscellaneous feed troughs for chickens and pigs. Sixteen galvanized iron trap nests.

Five galvanized iron ash cans to store stock feeds out of reach of rats.

Two scales: one for grading eggs by weight, and one for weighing milk in the barn.

I also have an apparatus for testing the butterfat content of milk. Aside from that, the only dispensable article in the list is the mill. Grain can be ground cheaply and easily at the local mills, but for human consumption I prefer it freshly- 
and home-ground. This vast array of new and improved farm machinery cost me altogether about one hundred and ninety-eight dollars. It was not all bought at once. My original poultry investment was seven dollars-for an oil-burning incubator, a gallon of kerosene, and a setting of eggs. I could give you the price paid for each article in the list, but all prices have varied up or down since I bought them; if you are interested the current prices may be obtained from a mail-order catalog. There you will see there is nothing in the way of farm tools and machinery-even prefabricated barns and outbuildings-that you can not buy from the mail-order houses, and buy on time, if you are, like Sary Gamp, so dispoged.

It would probably pay me to buy a lot of new equipment, even on time; neither my dairy barn nor poultry housing are of the finest. But my disposition is to take the slow, cautious way. It has worked well enough so far. We were less than two years getting substantial results, and we have taken almost no risk at all. Thus, I might have spent a hundred or a hundred and fifty dollars for a flock of laying hens-and while I was learning the modern way to feed and handle them, rubbed them out by an ignorant mistake.

In the spring of 1932 I finished setting out an acre of young orchard. I had taken three years to do it, at a cost of about $\$ 150$. An acre of orchard, 
with a few random fruit trees for shade and landscaping, is plenty for a family of four. Aside from poultry, my investment in livestock totalled $\$ 18_{5}$ : $\$ 165$ for a fresh cow and a half-grown heifer, $\$ 10$ for a pair of weaned pigs, and $\$ 10$ for a ram and two ewes. Reckoning my basic poultry investment at seven dollars for eggs and incubator, the grand total outlay was then about five hundred and fifteen dollars-considerably less than the price of a cheap car after you have paid the so-called "freight" from Detroit. Unlike the cheap car, after five years' hard use my tools and machinery give every appearance of being good for another ten to fifty years-although, of course, at forced sale they would bring practically nothing. The fruit trees are there to stay; they will ultimately liquidate as firewood. But crops and livestock are good negotiable securities with daily price quotations in the newspapers. When I mentioned a twelve to fifteen hundred dollar inventory it was them I was talking about. 


\section{The Expectation of Plenty}

A FRIEND of mine was negotiating the purchase of a near-by farm. A doubt was raised whether he would work as much on his farm as I do on mine, and if not whether he could hope to make a go of it.

"Listen," he said. "I don't know how much actual farm labor Henry does, although I suspect you could put it all in your eye. It doesn't matter whether he does any or not. When you drive down the pike, late of a winter night, and see the light on in his study-that is when he is doing the work that makes his farm go."

The point is well taken, however exaggerated. Success in farming, even the kind of part-time farming practiced at Medlock Farm, depends as it does in all other enterprises on formulating a definite plan. It depends, in a word, on the proper exercise and co-ordination of the three great factors that govern every human undertaking: staff work, or planning; executive, or seeing that it gets done; labor, or doing it. Neither function is more important than the others. Often, on the farm as 
elsewhere, one individual combines in himself all three. That all three functions must be exercised in successful farming is a fact that must not be overlooked or forgotten, however many farmers may neglect all or any part of them. When I went to work in the fall of 1932 it was with a definite plan. Because staff work comes first chronologically we will consider it first here.

There are certain mental, psychological, and spiritual prerequisites to the formulation of successful farm plans. I was already conscious of some of these in 1932. Others, either instinctive or the result of youthful exposure to the principles and practices of a suburban farm home-I can not tell -I have reduced to words as time made them patent. I have pointed out that we try to avoid extremes. Yet my knowledge and experience of rationing and feeding convinced me there was one policy we must adopt from the beginning, if we were to make the most out of the farm.

The town dweller decides what he or she wants for dinner-or looks at the advertisements to see what is cheapest-and buys accordingly. On the land the question is not what you would like to eat but what you have to eat. There is always plenty. But if it should happen to be what you do not especially fancy at the moment you must train and govern your appetite to accept it none the less, rather than fly to the store for others that you 
know not of. There is the thing that should give us pause if we are to make the homestead pay off. If you happen to fancy green corn a week or two before yours is ripe, it is no good to go buy it as long as other ripe and edible vegetables are standing in the ground. The point sticks deep in animal as well as human nature. Dr. Stefansson's Arctic studies demonstrate that food habits are among the most difficult in nature to alter.

We had been eating little but store food for ten years. We were not above buying fruit and vegetables that we could and did raise, merely because they appeared in the stores out of season. Could we adapt our tastes and appetites to fit the farm and "the latitude of Philadelphia"? We could. We did. The change is not so hard as you might suppose. It means that when you butcher a pig you must eat pork; when the calf is eight weeks old you must eat veal. But, you may object, it is not easy to eat the same things three times a day for weeks. Possibly it is not. We would not know. We do not do it. For while pork is pork and veal is veal, yet both subdivide into a wide variety of cuts and dishes: chops, hams, bacon, sausage, and scrapple; cutlet, sweetbread, stewing meat, kidney, and liver. All these can always be varied with eggs, poultry, lamb, and game in season. Yet even without variety the superior quality and flavor of home-grown foods-a superiority that simply 
cannot be credited without experience-is enough to neutralize monotony. It is hard to tire of really good food.

With the foreknowledge of what crops are ripening one can conscientiously abstain from its dishes and thus whip up an appetite for them. Although here a certain sweet reasonableness is desirable. We have never put yearling steers on the place to fatten for beef, but we have grown our own beef from dairy calves. We did not forego beef the whole four years it took to mature the first beef critter (real beef: not the tasteless two-yearold stuff, scarcely more than overgrown veal, currently purveyed in Eastern stores and restaurants as beef). But we ate our last boughten roast in November and did not have home-grown beef until January. If you wonder what four people could do with a half ton or more of beef-on-thehoof I can only assure you none of it went to waste. Part of it, of course, was canned and corned. But we cut thirty-six sirloin steaks of varying size off that carcass and four of us ate thirty-three of them. For me it meant the realization of a thirty years' dream: reversion to the "standard American breakfast [vide Tramp Abroad] of beefsteak and coffee."

Although I was dubious, it seemed to me if we were to farm for use successfully we must revise the values of human labor fostered by unions and the time clock. We expected to contribute a good 
deal of our own time to the job of self-maintenance. What value should we put on that time? Well-since it was in no case time taken from other gainful employment, why put any value on it at all? Our objective was not time-saving; it was the production of the means of life. If an hour's labor produced something we wanted or needed it could scarcely matter whether the product was worth five cents or five dollars at retail. Also, since we already had a hired man on the payroll and our secondary objective was to keep him there, we decided the same principle should apply to his time as long as the work he did would not involve the employment of additional paid labor: if he had the time to do a given piece of work we would not stop to ask if it was warranted by his pay rate.

There is probably no economic question under the sun about which there is so much jiggerypokery, tosh-pail, and tingle-tangle as this of the value of time. Consider butter. With fearfully inefficient equipment I can make three pounds of butter out of eighteen quarts of milk, in seventyfive to ninety minutes. Should I esteem the value of the butter at the cost of the milk-which is insignificant-that goes into it, plus the value of an hour and a half of my working time to my business? I make butter of an evening or week-end, in time that would not otherwise be gainfully employed. Is it not then more sensible to say the 
value of the butter is equal to the amount of money I have saved the household in the purchase of store butter? In today's market that would be $\$ 1.38$. Ninety-two cents an hour is pretty good sideline money for otherwise idle time.

Women have been the greatest victims of the time-saving racket. Thirty years ago, admittedly, the average housewife was viciously overworked. If she is today it is because she does not know how properly to manage her time. Yet the time-saving arguments that legitimately apply to the sale of automatic household machinery and other laborsaving equipment break down when it comes to the serving of those ready-made foods which apparently constitute the nation's biggest current business. I have costs on the home-made materialsas well as the store-bought-that go into a dish of cream of tomato soup. The store-bought stuff is, of course, more expensive. But it is so much more so that if we take the difference between storebought and home-made as the measure of the value of a woman's time then, by using a can opener on commercial soup instead of making her own with home-canned tomatoes and real cream, any housewife can fix an up-set value on her time of more than fifteen thousand dollars a year. ... So much for the value of time.

Early in our occupancy Medlock Farm was struck by a tornado. Fortunately it involved no loss 
of life nor even wounds. But it did visit us with nearly every other misfortune flesh is heir to. It tore away our electric wiring. "Where we lay ... the chimneys were blown down"; there was neither light nor fire for cooking or heating the house, for days. We lifted all water from the well by hand. Not only windows, but entire casements were blown out on that side of the house facing the storm. Everything in the living room-and it is a big room, full of furniture-was piled up in one corner. Our neighbor's barn, which was wrecked, checked the full force of the wind. Unhappily there were sixteen tons of loose straw in the barn. Fifteen of them blew into our house. Two sixtyfoot pine trees leaned against the house like toy trees swept over on a nursery floor by a giant skirt. The tool shed and corn crib disappeared with the carry-over of last year's corn and most of the hens. The little greenhouse we had built on the south side of the garage was smashed to atoms. I carried the pieces of the children's bedroom doorand it was no slouch of a door; but hand-hewn and mortised oak-down stairs in a five-eighths basket. The children were not in the room when the storm struck; otherwise they would almost certainly have been decapitated by the flying roof slates that cut the door down to kindling. We were so discouraged and terrified we put a For Sale sign on the place. Thus I learned that such storms are the 
rule rather than the exception in southeastern Pennsylvania-and to carry wind insurance.

Twelve years later we were hit again. Although the damage was not so great it was still bad enough to have dismayed beginners. But twelve years had made a difference in our point of view; ten minutes after the twister passed we were out clearingup the wreckage, not unmindful of the damage that had been done but too intent on repairing it to bemoan our bad luck. We had lived longenough to know that life on a farm is full of such setbacks, perhaps not all-but most-of them severe enough to justify Jerome $\mathrm{K}$. Jerome's definition of farming as "suffering reduced to a science." Shakespeare of course saw deeper into it, and into human nature, than Jerome. It is the Porter, at the opening of the second act of Macbeth who says:

"Knock, knock, knock! Who's there, i' the name of Beelzebub? Here's a farmer, that hanged himself on the expectation of plenty. ...."

What Shakespeare meant is that your typical farmer so loves to dwell on his misfortunes that, given a year so plentiful there was nothing to complain of, he would hang himself for very chagrin. Mind you-there is always wherewithal to give both Jerome's definition and the Porter's stooge a specious justification. In a typical year-1936-I could point out that the leek crop, which is an 
important factor in the winter vegetable diet, failed; or that the well went dry at the peak of the canning season, thus cutting the crop of canned goods short. But I should add, in all fairness to nature, that although the leeks failed the fall crops of lettuce, radishes, and spinach were unusually abundant and long-lasting; and if the water failure stopped canning, yet we had a carry-over big enough to eke out the year's production; and, in a year of almost universal drought, the biggest corn crop we ever produced.

The poorest year on a well-managed farm, diversified and dedicated to home consumption, must inevitably be bountiful. The complainers are those who seek only money crops. Money can be made at farming, even though it is admittedly impossible for a wheat farmer-to cite a typical instance -to make a year's living out of ninety days' work: which is apparently what the wheat farmer expects and the government esteems his inalienable right. But if the wheat farmer could be persuaded to go to work, to raise his own food instead of buying it ready put up at the store, his condition never would become desperate.

The farmer who complains that everything goes against him betrays his own incompetence as surely as the man who cannot hold a job. Of course things are going to go against you. But that cannot deter you. We have been struck not only 
by tornadoes but by late and early frosts. There was a July day when ten minutes' hail cut the corn to ribbons, stripped the grape arbor and peach trees, and laid the half-grown onions down as neatly as though cut back with giant shears. In the subsequent half hour, while the sun got to work, we made highballs with hailstones: I could have shoveled a ton of ice off the lawn. Another autumn the cold rains rotted the corn stover before we got it in the barn. That winter was so severe it killed most of the bearing asparagus. In the last decade two new scourges, the Japanese beetle and the Mexican bean beetle, have come to plague us. One intent on his own misfortunes might say with England's Richard II:

"Of comfort no man speak. ...

For God's sake let us sit upon the ground And tell sad stories of the death of kings."

But why do it? Why dwell on misfortunes? The way to insure defeat is thus to invite it. Yet the truth, so apparent it should be obvious to the most disgruntled farmer, is that in the long run nature must give man the breaks.

If that were not so we should still be living in caves.

Talk to the farmer overwhelmed by the expectation of plenty and you will realize no one could long be subjected to the rain of misfortunes he de- 
lights in-and survive. Without recourse to the revolting optimism of a Pollyanna one may still take a cheerful view of farm life. Instead of hanging yourself in the expectation of plenty, how much better to string along with that ancient orchardist who cried:

"Forward in the name of God: Plant, graft and nourish up trees in your ground; the labor is small, the cost is nothing, the commodity is great; yourselves shall have plenty, the poor shall have somewhat in time of want, and God shall reward your good merits and diligence."

The labor is small, the cost is nothing, the commodity is great. There is a story of the Jewish schoolboy who did homage to the man who invented interest. My obeisance is to the man who thought of putting nature to work for him.

Nature will give you the advantage of one or more bumper crops every year if you give her a chance. The law irreverently limits the phrase "act of God" to disastrous affairs. The farmer who diversifies as much as possible, aiming always first at home use, will find the unexpected acts of God more often than not beneficent. For diversification is a kind of insurance, a division of risk. And if you are to produce for your own use you must diversify. It was no tragedy last year that all but eight young ducks perished in a sleet storm on the 
very brink of the roasting pan; we had plenty other kinds of meat, yet a duck a week for eight weeks would still be a pleasing variety. But if all Medlock Farm had been gambled on ducks and we had lost two-thirds of them on the way to marketthat would have been big trouble; we should have had nothing but a diminished number of dollars to trade for other kinds of food. God rewards the diversifier with "great commodity." Each season brings its unexpected bounty, its unanticipated bumper crop. "The expectation of plenty" is the normal viewpoint for those who practice farming for use.

So, with revised ideas of what we should, must, or can eat; with a sane concept of the value of labor, and an intelligent determination not to let failure get us down, we are finally in proper frame of mind to draft a plan. 


\section{Farm Drudgery: A Myth}

I HAVE discussed the operation of Medlock Farm with many of those who yearn to go and do likewise. Long before we get to definite plans the objection invariably arises that it is all very well for me-I am my own boss: for me, within rational limits, time is no object nor obstacle, but for anyone dependent on a job the whole scheme is hopelessly unattainable. It is true I am master of my own time: which merely means instead of having someone else tell me where to be and what to do I have to tell myself. However, that is another matter. The point here is that my kind of farming can be done whether one is master of his own time or not.

It would be perfectly possible for me to do all my own farm work with no extra help beyond the necessary contract labor done with teams or tractors and heavy machinery. I do not do it because there are other things I would rather do; and because it would prevent my secondary objective: keeping on my hired man.

A normally active and intelligent man-or 
woman-can feed and water half a dozen cattle, as many pigs and sheep, and any number of fowl up to, let us say, two hundred head, and can milk at least three cows-all in less than an hour. At Medlock Farm we have to carry all the livestock's drinking water; with automatic cups and fountains the time could be cut nearly in half. An hour and a quarter would give me plenty of time to do all these chores, clean up and change into my store clothes. After the morning chores are done there are a milk bucket, strainer, and separator to wash and sterilize. It is easiest done right after they have been used. At that time-with plenty of hot water-the job takes twenty minutes. But if time presses it can safely be left until evening, when it will take a little longer.

All these chores having been repeated at evening, an end is made of all routine work on the farm. (Need I explain, in passing, that there is nothing in the cow's anatomy that requires milking her at the ungodly hours chosen by most farmers? It is all right with her if you milk her at noon and midnight, provided you stick to that schedule.) Everything else is a "job," and three-fourths of all the jobs can be timed to fit one's convenience. Even such pressing work as canning perishable fruits and vegetables will bear with a little postponing. Not nearly all the work requires daylight. Indeed much of it, like canning and butcher work 
is better left until that time of night when there is no further possibility of interruption.

My hired man comes twice a day four days a week to milk and feed. The other three days he works eight hours. Deducting the six morning and evening chore hours from these days it will be seen his total time for all other work is a net eighteen hours a week-most weeks. For there are times when legal holidays cut his working week to two days. On my part, these holidays would augment my total working time. It should be easy to find eighteen hours a week over and above chore time in evenings, week-ends, and holidays, not overlooking the fact that if I were working for someone else instead of myself the chances are it would be a job that carried two weeks annual vacation: in those two weeks I should be able to do work that now takes my man four.

Nor does my hypothesis overlook the fact it might not be convenient to put in eighteen hours a week every week. Farm work does not go that way. In the course of years I have clocked my man's time, if not with the nicety of my whilom neighbor, the late "Speedy" Taylor, at least closely enough to make practical allocations possible. Reckoning that the occasional overtime he contributes-when for instance the hay must be got in-cancels the time lost through holidays or other causes, I would divide his thirty-two hours a week, fifty-two weeks a year, about as follows: 
Cows -728 hours, average fourteen a week, the year round. This is not all spent at the rate of an hour each morning and night. Milking and feeding the cows alone does not consume the entire chore hour. It allows time for cleaning the barns, taking the cows to be bred, hauling corn to the mill in winter, and so on.

Poultry-104 hours. He feeds and waters the chickens in the morning, and waters them at night, in the chore hour. Other poultry chores-caring for the growing stock, collecting eggs, etc.-are done by Mrs. Tetlow and myself. The major share of the man's two hours a week is taken up with cleaning the laying house and in butchering.

Pigs and sheep-208 hours. A little of this is used in the chore hour, most of it in cleaning, in veterinary and breeding work, and in butchering.

Lawn-mowing -78 hours. Say, three hours a week for six months. Some years dry weather cuts this down. A good growing summer will run it up. It would always be possible to cut it down permanently by reducing the lawn area.

Cleaning, running errands, painting, and other strictly household tasks-104 hours. Probably an underestimate. The average, on a basis of two hours a week, would be about one hour a week in summer, three in winter.

Woodcutting -52 hours. This is all winter work. Firewood, fence posts, and other timber requirements are anticipated, to make it so.

Haying-26 hours. Since hay harvesting is a job for outside contract labor and equipment, my man's part in it is only that of an extra hand at pitching and stowing. 
Harvesting corn-104 hours. But it depends on how good the crop is. It is autumn work.

Garden and orchard-26o hours. A bit of this is winter tree-trimming and spraying, but so little that it can be safely regarded as ten hours a week through the six summer months.

All this divides itself up according to seasons. Of course it never runs into an exact division or routine because nature does not work that way. What with gardening and haying, the long hours are in the summer; but then, with the sheep and cows at pasture, there is no work of keeping their stables clean. And the long summer days provide the necessary light for the extra outdoor work. With the exception of woodcutting the winter work is indoor work, and can be done by artificial light.

That there is other work to be done on the farm beside what my man does is obvious.

"What," you will probably ask, "do you do?"

Well, mostly I superintend. Huck Finn might have said of me as of Tom Sawyer: "He could outsuperintend any boy I ever see." There is little actual labor-bossing to be done; a man who needs it is no good to you on the farm-"nur nowurs else." If I were doing the work, the time now spent on supervision would be eliminated entirely, and most of the planning now done at a desk could 
be done in my head while at work. To say, however, that the quantity of actual labor I now do is an important factor in the total would be to exaggerate. As time goes on I find myself doing less and less of it. In winter and spring I run the incubator and tend the growing birds, do the meat canning and pickling, make lard and sausage, and otherwise bear a hand at the butchering. In summer I do most of the fruit and vegetable canning. I make butter, and feed the hens once a day-some days-a job that is a matter of five minutes feeding and fifteen or twenty studying the hens. In sugar time I collect the sap for boiling. I harvest and cure the tobacco, pick strawberries and other small fruits, and keep the records. But checking over the week just ended (as these words are written), I have not put in, altogether, a full hour at farm work, unless you count gunning for pheasants, or picking water cress and wild mushrooms, as work. I could easily work the farm in my spare time. But I could not simultaneously write a book about it. And I do not think it would be much fun.

You remember my saying we have hired two days a week more time on the farm this year. This was not needed to keep the work caught up. We saw that an extra two days would pay off in bigger and better crops and sales. There are times when, in the schedule outlined above, the work will pile up to a disadvantageous degree. A sea- 
son of good growing weather grows weeds as fast as fruit and vegetables. Eventually you can catch up with the weeding, but it is far better for the crops if their growing is not checked by weeds at all. When hay is to be got into the barn or corn into the crib other jobs must wait-and it is not always well to let them wait. The extra two days' labor has justified itself this year and will show up in better results next year. But I got along without it for four years and could get along without it now. On the other hand, like the man who raised onions because he had eleven children to weed them, if it were possible to compete with government hand-outs I could-in season-use five to a dozen extra hands.

The allusion to child labor on the farm (where, by the way, most of the child labor in this country is used-without any agitation to stop it) reminds me that no discussion of the farm labor problem is complete without a glance at the contention that farm life is all work and no play. It would be idle to say there is no hard work on a farm. Outside the routine housework common to city and country there are many farm tasks of which the city dweller is forever free-at a price, in money and in atrophied independence. Some of them are tiresomely monotonous. Yet that is no reason why strong men should shudder or lovely women's chins should tremble at the very thought of doing 
farm work. Nearly all the prejudice against it can be traced to those who, raised as backwoods drudges, have had the wit to escape to the city. Wherever electric power, the internal combustion engine, gas, and oil can penetrate-and where can they, where have they, not?-drudgery can be relegated to that limbo in which dwell the fabled loneliness and isolation of the farm. Of which it may be said dogmatically that one of the real problems of a modern farm is how to get a little time to yourself. What with the telephone and the automobile, country life near a large city is, as Frank Sullivan said of life in the French Cabinet, not unlike keeping house in a revolving door.

However monotonous it can be, farm work has compensations to be found nowhere else in these times. There is great and fortifying satisfaction in the assurance you can feed yourself and your family. There is good mental and nervous discipline in the tempo of the work, which must be slow if it is to accomplish much: a good plough team "moving seems asleep." And there is ever the quiet elation that comes only from creative work. One's own products take on new values. Even spinach is highly palatable if you grow it yourself. Unlike most so-called sports or adult games farm work for home use is strictly non-competitive and -therefore-the healthiest kind of exercise. And while it may not tax the highest reaches of a human 
wit, still it compels the research of so many of the myriad activities contributing to the maintenance of human life and civilization that it cannot but "cultivate the waste places of the mind" to a degree nothing else does. To anyone forced to spend eight or ten hours a day in the highly competitive roar and turmoil of the city it is not work at all; it is the finest, most complete relaxation and diversion.

Nevertheless I should not like to do it all the time, nor would I recommend such a course to anyone. There is more to be gotten out of country life if one has time to sit down and think about it-to plan. (We simply must get on with this business of planning!) It is a good way to begin. By doing the work one learns what ought to be done, and what can or cannot be done. No one who has tried it would ask a hired man to pitch hay all day and can vegetables all night; or to spray fruit trees in freezing weather, or to work four straight hours in a truck patch under a hundred and thirty degrees of sun. The knowledge gained by such experience is the best possible check on that over-enthusiasm which perennially tempts one to bite off a bigger farm program than he can chaw-and thus invite failure. I could do all my own work, but I should not care to do it, and I should count the necessity to do it a defeat. 


\section{Where to Find Out How}

SOME years ago I went down the Abitibi River to Hudson Bay in a canoe. Half way to Moose Factory I met an employee of the Hudson's Bay Company, with his wife and nine-year-old daughter, coming "out" for their annual vacation. My partner on that trip was a doctor; hence, inevitably, the conversation revealed that when the factor's daughter was born the father had delivered her.

"How in the world did you know what to do?" the doctor asked.

"Oh, that was nothing," the Orkney Islander answered modestly. "I had a book."

Five years later, when we put Medlock Farm into production, I took a leaf from the factor's book. Even though raised on it, I realized there were lots of things about the land I did not know, as well as that a lot of what I did know was not true. But if a man could find out by reading a book how to deliver his own daughter, surely there could be nothing vital to successful farming that could not be learned the same way. And while the 
literature of amateur obstetrics must be small, that on agriculture and allied subjects is the world's largest.

Yet there is too often a hiatus between booklore and practice of every Mystery. By the time one attains the status necessary for bookish authority he is liable to forget the beginner's need for the A-B-C's of his craft. Judge Ferguson once told me his first legal job was to have a man arrested, and that nowhere in his "vast cargo of learning" nor in the curriculum of the law school were there directions for such an elemental chore. The instructions in every craft and profession teem with such deficiencies. Fortunately I knew that to bridge the gap between books and practice there were two other sources of agricultural information: government publications and, in Pennsylvania, the free correspondence courses offered by the State College. The latter, like the "refresher" courses given to line officers behind the front during the last war, are primarily designed to recall to practicing farmers elements in their agricultural schooling that they may be overlooking or neglecting; they are true extension courses. At the same time, they have been written with a mental eye on the farm rather than the classroom.

There are thirty-two courses offered in the State College Correspondence School, in four to sixteen lessons apiece. Up to date I have taken all or part 
(lessons are sent only as you answer the question paper of the previous lesson) of ten of them:

Fertilizers and Farm Manures

Sheep-Husbandry

Stock Feeding

Beef Production

Swine-Husbandry

Dressing and Curing Meats

Home Vegetable Gardening

Butter Making

Farm Forestry

Farm Bookkeeping

Some of them-notably Fertilizers and Farm Manures, Farm Forestry, and Dressing and Curing Meats-I found extremely useful and informative. Others, for a variety of reasons, were not so helpful. The difference in climate between Montgomery County in the southeastern and State College in the northwestern parts of Pennsylvania is enough to lay the course in Home Vegetable Gardening, for example, open to the need for experimental verification. Again, none of the courses I have taken has been edited down to date since it was first drafted, twenty or thirty years ago. In some cases this does not matter, in others it could result in more harm than good. I have not taken the course in Poultry Keeping, but if the instruction it gives is based on the poultry practice of my childhood it is worse than useless. Poultry 
practice has not only altered profoundly in the last thirty years, it is changing-and improvingall the time.

The state courses generally share a defect common to all government publications (and our national farm policies) and to many books: they are written namely for or at the commercial or money farmer. In principle commercial farming and farming for home use are essentially the same. In practice they can, and usually do, differ radically. The capital investment needed for even a modest commercial enterprise is generally quite beyond the reach of one designed to pay out only a living in kind. This is not a fatal defect, since anyone with a modicum of imagination can adapt the teachings of commercialism to his amateur ends. Altogether the state courses have been worth much more to me than the time and postage spent on them. For they not only taught me a lot I did not know; they revealed-mainly by indirection-plenty more that I did not realize was to be known. And they saved my feet from many erroneous pitfalls.

The beginner's tendency is to create what he fondly supposes are startling new and revolutionary theories of procedure. Except for what is predicated on new scientific findings there is practically nothing under the sun-agriculturally-that has not been tried and tested somewhere, sometime. The state courses helped me to a fuller appreciation 
of this truth; they discouraged flights of fancy, saved me a lot of waste motion. They even revealed that, on occasion, sloth and indolence can pay off. For years I threatened to get in the woodlot, clean up the undergrowth, put the timber under intensive cultivation. But there was always something else to do; I never got around to it. Ultimately the course in Farm Forestry revealed it would have been precisely the wrong thing to do.

State and federal publications cover "every conceivable subject," as the old-time encyclopedists said of themselves. At first I tried to pick out of the indices all those I thought might be useful. I soon found, however, that where these agencies can help most is in the solution of specific problems. Today, instead of trying to pick out the proper pamphlet in anticipation of a problem, I write a letter when the problem turns up. The answer always includes at least a reference to the most useful bulletins on the subject. For example: I have a number of cook books that tell how to make dill pickles. Year after year I tried to make them because cucumbers, like a lot of other farm produce, come in bunches: unless you pickle them, a lot may go-not to waste-to the pigs and chickens. But evidently none of the authors of my cook books ever made dill pickles because they do not tell how to preserve them after they are made; within a few weeks, if left in the open brine, they go soft. 
Finally I asked the Bureau of Home Economics, U. S. Department of Agriculture, what to do. The reply was Farmers Bulletin Number 1438, wherein the mystery stands revealed. This bulletin, by the way, also gives a good recipe for making sauerkraut, a job which is usually done free-hand by semi-pros in this part of the country, and which is another of the things like dill-pickle preserving and the proper way to boil crustaceans (my copy of Fannie Farmer starts a shrimp recipe with "remove shrimp from can"!), conspicuously absent from my collection of cook books.

Government bureaus often supplement the printed word with a letter. A couple of years ago the notion beset me that my man was overfeeding the cows. My childhood recollection was that whatever you fed a cow above a certain limit went to fat instead of milk. I wrote the State Bureau of Animal Industry and got, in addition to a flood of informative printed matter, a letter pointing out that, just as (per the old Montgomery and Stone routine) "you can't skin a manager," so you can't overfeed a cow that has "the true dairy temperament": the more you feed her-or, put it: the more feed she can take-the more milk she will produce. If she is the kind of cow that turns feed into fat, then the quicker you fatten her and find it out the sooner you can get rid of her.

The most disturbing thing about all this in- 
formation-books, pamphlets, lessons, and letters -is its contradiction. One realizes there may be more than one way to do most things, that geography and climate add to the variation. This book, for instance, must be read in the light of the fact that my experience has all been had in southeastern Pennsylvania; a good day's motoring in any direction will run up a seasonal variant of a week to ten days. It is obviously impossible to cover the whole "varying shore" of any agricultural question within the compass of a single book. So much I can understand. But what get me down are such contradictions as that I ran into on corning beef. I got two recipes, from two unimpeachable government sources. My experience in pickling pork and other meats told me one of two things must be true: either the one recipe must produce meat too salty to eat, or else the other one would not preserve meat at all. There was only one thing to do. I made two small batches-instead of one large batch-one by each recipe-and so learned that the stronger brine makes fine corned beef, the weaker one lets the meat spoil. Happily, most of the contradictions involve no greater financial risk when one is practicing maximum diversification for home use.

This same contradiction invades the vegetable world: there is no agreement on how much a given planting should yield. Parenthetically, and under- 
standably, this is the one thing above all others no seedsman or his catalog will discuss. Even to hint that a pound of this or that seed should produce so many pounds of this or that vegetable would open the way for an endless procession of disgruntled litigants. Nevertheless one would suppose there might be a semblance of agreement amongst the experts. Yet their guesses of a given crop will vary-even under the statisticians' standard alibi: "other things being equal"-from three hundred to thirty thousand per cent.

Of books on agriculture and allied subjects the presses have, ever since Thomas Tusser published his Five Hundred Points of Husbandry in 1557, poured forth an endless torrent. I have managed to get this far on a library of twenty-two volumes, at least a third of which have been of little use. In technical books the latest is always the best. There is no telling when something revolutionary may turn up. I await impatiently the lowdown on raising vegetables without benefit of soil or sunlight, in chemical solutions; and on insect control by light and sound: two far-reaching contributions to the sum of agricultural knowledge that are still in the laboratory stage.

Panics and industrial depressions always bring out a flock of back-to-the-land books; most of them highly impractical, the work either of wishful roots-and-berries thinkers or of those enthusiasts 
whose actual experience has just begun: the neophyte is apt to be carried away by the revelation of how.much nature ought to-and, on paper, can -do for him. The panic of 1907 brought forth Bolton Hall and his Three Acres and Liberty and $A$ Little Land and a Living. Their theses, presumably predicated on an experience in the management of the vacant-lot-gardens movement that flourished in our large industrial centers at the time, is that if three hundred and fifty-two square feet of ground will produce ninety-six dollars' worth of celery, an acre should yield twelve thousand dollars' worth. To give Mr. Hall his due, he concedes the difficulty of planting and cultivating an acre so closely and intensively. It can be done-he does not say this-only with slave or peon labor. I was fortunately spared the pitfall of this specious reasoning by the knowledge of a horrible exampleright in my own family. At different times both my grandfathers tackled fruit farming. The one made a famous success; the other, starting from the premise that "if you had ten thousand trees and got only a dollar a tree it would be ten thousand dollars" made as thorough if not so conspicuous a failure.

Like 1907 , the panic that started in 1929 produced its crop of back-to-the-farm books. Ralph Borsodi's Flight from the City is the type specimen. Unless I am mistaken, Mr. Borsodi is the 
creator of the subsistence-homestead idea. It is a good idea, with much to recommend it-especially its sound presumption that under modern conditions of transportation the necessity to live in cities is rapidly diminishing. But it would probably be a failure even though the federal government had not cursed it under the dead hand of bureaucracy. Its fatal weaknesses are that it is based on the wrong kind of people, and that it denies the necessity to sell surpluses to get the best return from a part-time farm. It would be a grand good thing to transplant borderline urbanites to rural homes where production for use, supplemented by two or three days of factory work a week, would guarantee a comfortable living. But with every regard for the thousands of exceptions I seriously doubt that, in the mass, the kind of people who in hard times find themselves forced to the bare-subsistence level of two or three days' factory work a week are going to be the kind who can operate small home farms successfully, or who would even be willing to do the amount of work the job entails. The necessity to sell surpluses is so fundamentally implicit in nature's own production scheme, that government's failure to take it into consideration and Mr. Borsodi's positive denial of it alike indicate to me, at least, a dearth of practical experience in the application of the the- 
ory on which subsistence homesteading must be based.

My need is less for works in the lofty realm of speculation than for those that expound the plain facts and procedures of production for home use. Yet a book like the Shuttle-Craft Book of American Hand-Weaving is of small use to me, as long as there is no book, pamphlet, or correspondence course to tell me what to do with my raw wool to fit it for spinning. Of all the crop the two that have given me most are Gove Hambidge's Your Meals and Your Money, and Clarence Kephart's Camping and Woodcraft. Mr. Kephart spent two years in the Google, or Great Smoky, country, where life-presumably-still goes on much as it did in colonial times. His suggestions and directions are always practical. Yet too often they are patently outmoded. What I want-to return to my muttons-is not someone to teach me how to operate an old-fashioned spinning wheel, but someone who, like Mr. Ham of Bridgeport, will design and build me a motor-driven hand-spinning machine that will turn out ten times more and better yarn than the old-style treadle wheel. A farm like mine cries for a myriad such machines: household sizes of modern factory machinery.

There is one other source of information that, knowing the insensibility of scoffers, I hesitate to 
mention. I am entirely willing to concede that a lot of it may be wrong. Nevertheless I lend an attentive ear to tradition, old wives' tales-well, superstition, if you insist. The data of science are at most the accumulation of a few thousand years. Superstition is the sifted wisdom of fifty, a hundred, five hundred thousand, years. A lot of it can be wrong because it is carried from one country and climate to another, without modification. There are, for example, people in this section who plant only one main crop of potatoes, instead of an early spring and a late fall crop-which can be grown here-mainly because one crop is all that can be grown in the short hot summer of north central Europe. But when the tradition applies to something as definitely American as maize, then it is worth heeding. Perhaps there is no scientific basis for the belief you should not plant corn the first three days of May. All I say is, if you take no stock in it-go ahead and plant your corn on the first, second, or third of May. As for me, I shall continue to pay respectful, if critical, attention to the teachings of the red gods. 


\section{Making Plans That Work}

KEPHART says it is not the man out in the woods in midsummer who is having the most fun: it is the man at home in midwinter, planning next summer's trip. By the same token it is not the fellow weeding the onions in July who is getting the most out of his farm: it is the man who, in January, is planning what kinds and quantities of onions to plant next spring. It is the essence of farm work that, in the awkward phrase of Spengler's translators, it is forever in a state of "becoming" rather than of "being." Farming is never finished, which doubtless accounts for the canard that farmers always work from sun to sun. It may be possible to run a farm well without the help of a carefully worked out plan, but if it is I have never seen it done.

The job of selecting seed corn presents a good illustration of the problems that overwhelm planlessness. Toward the end of February or first of March one goes to the corn crib and picks the best ears for next spring's planting. How much shall be set aside for seed? Apart from how much will 
be needed per acre of sowing, an intelligent answer can only be made when one knows (A) about what the normal crop per acre will be, and (B) how much livestock there will be to feed through the coming winter. How well did the present crop do? Under what conditions? How many head has it fed, and how far into the spring or summer will it last? From the record of past performance an estimate of future needs can be made. Altogether, the complete time cycle contemplated by that one job stretches from a year or more in the past to a year or more in the future.

I was already familiar with this characteristic of farm planning when I set to work in the fall of 1932. I also knew that my land had been worked hard for upwards of two hundred and fifty years, that it was badly run down. I knew that to grow feed for the livestock as well as food for the family it would have to be built up; that land, like old people and horses, is hard to get up once it gets down. I knew that however essential and effective they may be, commercial fertilizers are not a complete substitute for farm manures; the application of organic matter can not be indefinitely deferred. Starting my project in the fall, there would be a small accumulation of manure by spring planting; but how much more would be needed, or what it would cost, or where it could be bought were unanswerable questions. I could have had some help 
from soil analysis, but that is a tricky business: it is not wise to bank too heavily on what it tells you. And I knew, too, that it is not easy to get a proper plant food balance when bought manure is used; as well as that it takes more than one year to render a large part of the food in any manure "available" to growing vegetation.

Lest the reader supposes that here, and elsewhere throughout this book, I belabor the matter of manure too heavily, let us stop right now and consider a statistic on it. Dr. Van Slyke ${ }^{1}$ reckons the average loss from improper storage and treatment of manure is at least two-thirds its value or $\$ 1.25$ per ton at 1912 prices, the year he made that estimate. There is nothing to indicate manure is any better cared for today than it was twenty-five years ago. If we take his figure of the manure production per thousand pounds of live weight, and multiply it by the 1927 census of dairy animals, we find the average annual loss to this one branch of husbandry alone is about four and one-half billion dollars. Again figuring at Dr. Van Slyke's 1912 prices, the value of the manure of my dairy cows was just short of one hundred dollars in 1937.

Since I should have to buy stockfeed well into 1933, and at most could not expect to grow all my feed that first year, it occurred to me to keep

1 Lucius L. Van Slyke, Fertilizers and Crops, New York, Orange Judd Co., 1920. 
right on using bought feed, only offsetting it with home-grown as we were able to do a proper job of crop raising. All that part of the feed which converted into manure would in effect constitute a discount from the feed bill; and a substantial one, since upwards of eighty per cent of what an animal eats goes to manure. I am still working out this program, still buying stockfeeds, and supplementing them with steadily increasing quantities of home-grown. It strikes me as particularly significant that I have achieved the financial results indicated at the beginning of this book on a program that involved the purchase of most of my stock feed at retail prices. In the first nine months of 1937 mill feed still accounted for more than one-third the entire cost of farm operation.

If we were to reckon the manure value of mill feed at forty per cent of the feed bill, then the current net cost of food and farm operations would drop from twenty-three to nineteen dollars a week. Since it is not readily calculable with accuracy I have chosen to ignore it. For it cuts both ways; as it is it shows up in the fact that I am able to maintain more livestock, and sell more farm produce with a disproportionately small increase in operating costs. Its importance is further illuminated thus: when hay, for example, is sold "off" the farm, fully seventy per cent of the price received for it must be returned to the land in com- 
mercial fertilizer merely to maintain the status $q u o$. If the hay is fed to a cow, and her manure returned to the hay field the value of the boughten fertilizer then needed will drop to fifteen per cent -or less-of the sale value of the hay. This percentage can be further reduced if the hay is not fed exclusively to cows, if, in other words, we pay proper respect to the biological farm-balance.

Darwin first described the phenomenon of biological balance. He showed that if there were no house cats in England there would be no clover hay: house cats destroy field mice which, if not thus held in check, would destroy the earth worms that in their turn-or rather, turning, for it is their turning over of tons of soil per acre-keep the clover flourishing. House cats have been domesticated in England since before written history, so they have muscled in on the biological balance. As yet they have no place in the American countryside. As long as there are birds to eat no cat will bother with field mice. Those who write our game laws, at long last realizing this, have finally turned on the cats. Even our farmers are beginning to see-though still as through a glass, darkly-that the birds are our main line of defense against the insects, which, but for an accident of temperature, would long since have extinguished mankind. Yet few farmers appreciate the importance of biological balance in the conduct of their own business. 
It is a mistake to feed all the crops to cows. Cow manure is rich in nitrogen. Without enough phosphorus and potassium, the two other principal plant foods, to balance the nitrogen in cow manure, the farm would go all to leaf and vine.

The proper plant food balance is attained by feeding pigs, sheep, and poultry along with the cows. Hence it was as well for the good of the farm as for variety of diet that I decided to put all four kinds of livestock on at once instead of one kind at a time. Furthermore, I knew pigs and chickens were highly desirable as salvagers not only of garbage and waste garden truck but also of large quantities of skim milk that would otherwise be a total loss.

The crux of the home-farm problem is the question: How much food will a human being eat? The answer is: About three-quarters of a ton a year, roughly ten times his own weight. This sounds like a lot, but compares favorably with the hen, who will eat fifteen times her weight per year. To be sure, man-at least outside show business-does not lay five times his weight in eggs. Back in 1932 I did not know how much a human eats and there were few data to go on, in figuring it out. I had the U. S. Army ration table, the Hudson's Bay Company's ration for voyageurs; Kephart's lists, and my own records, of provisionings 
for the woods. All these were based, however, on the feeding of adult men engaged in strenuous physical labor. With the exception of the Army ration they presumed an almost complete lack of fresh foods. The grub you pack into the woods must be such as will keep indefinitely; and as far as possible the water-which is dead weight-must be squeezed out of it: you do not carry canned baked beans with their supercargo of water and tinplate but a sackful of dried beans-and so on.

I made an infinite number of lists, both of all the things I could think of that we eat and of all those we could possibly produce at home. I checked and cross-checked, balanced and counterbalanced. The final result was a table of food requirements compatible with production facilities surprisingly close to the findings of the government. For it turned out later that the Bureau of Home Economics was doing much the same thing at about the same time. The Department of Agriculture's circular, Diets at Four Levels of Nutritive Content and Cost, was published sometime in 1933 or early 1934 . It is the basis of Hambidge's Your Meals and Your Money which I first read in the fall of 1934. If it had been published two years earlier it would have saved me hours of paper work.

There is one profound difference between my food schedules and the government's. Mine allow 
for a phenomenon with which $I$ have been familiar from childhood: namely, that the quantity of any given food an individual or family will consume is one thing when that food must be bought; it is something else again when it is produced in superabundance at home. I have told of all the sirloin steak we went through when we had it. Everything else goes the same way; such staples as eggs, milk, cream, and butter melt away like the onion snow under an April sun, when you have enough and to spare. Conversely, the optimum diet described by government is by no means the best that can be had at any price but is hedged and limited in every direction by price considerations.

After the food lists were written they still had to be translated into production schedules, which again called for many readjustments. Production so often interlocks. Thus, assuming we should need a certain minimum number of eggs per year, we next calculate the number of hens needed to produce them. The laying flock should be replaced every three years, so one-third its number in pullets should be grown annually. Since eggs hatch about equal numbers of cocks and hens we can therefore anticipate an annual production of broiling and roasting birds. So the matter of egg supply impinges directly on the problem of total meat 
production. As does the dairy, with its concomitant of veal.

When all human needs were accounted for I still had to convert livestock schedules into stock feed plantings. For in 1932 I was looking forward to complete self-sustenance: I wanted to be sure that if necessary we could produce our own stockfeed. The fact that the roof of the world did not fall in, that the monetary system, the economic and social fabrics did not disintegrate completely, making it possible to carry out the boughten-feed policy, was just so much velvet.

All the original scheme, in fact, has been altered and corrected from time to time. Like any sensible set of rules these were made to be broken whenever desirable. Most of the changes have been the result of nature's shoving in her oar. Such an unpredictable phenomenon as the large preponderance of cow over bull calves, for instance, has imposed rearrangement on both the dairy and the meat programs. Miscalculation and improvement in practice have also contributed their share of motivation to the changes. As when I found that two pigs per year are not enough for a family of four; or as the fruit and vegetable canning program has been edited to keep pace with improved production of "winter keepers" and raw winter greens. But once the basic plan was set up there 
was comparatively little to do to it. The rest is mainly a matter of forehandedness. For just as the quantity of seed corn to be selected in February is determined by the livestock population in prospect twelve months hence, so-for example-the household garden planned in midwinter must reckon with the shortage or surplus in last summer's crop of canned goods. Everything depends both on what has been and what is to be.

Which suggests the need for a good system of records.

Now here I am somewhat of a crank. Many people esteem record-keeping a fifth wheel or fancy flourish on the tail end of any undertaking. Yet I never saw the project, however devised or executed, that would not respond to the treatment that can be prescribed on the evidence of the records. No memory can be trusted not alone over long periods of time, but from day to day. The classic example of memory's lack of dependability is, of course, the almost universal belief, in the face of public records to the contrary, that climates are changing perceptibly: "The winters are not as cold as they were 'dans le temps.'" To bring the charge closer home: I recently discovered a growing conviction on Medlock Farm that "the hens are not doing as well as they did this time last year." Yet what are the facts, available to all who wish to consult the day-to-day egg record? 
First, that this time last year the laying flock was ninety per cent pullets, more than half of which had not reached egg-laying maturity. Secondly, that in the current fortnight the hens gave us five times as many eggs this year as they did last. Thirdly, that the basis of this gross error is memory's confusion of last fall's low production level with the following spring's peak.

I have checked milkers' estimates of the cows' productivity and know they bear no relationship whatsoever to the facts that can only be found by weighing each cow's milking and marking it down on the milk record right then and there in the barn. Without records, the guess at the proper time to do a certain job may vary a week to a month, from one year to the next. Memory is guesswork, and like all other kinds of guesswork is always fallible. With a little practice an amateur can learn to cut two, or three, or three and onehalf pounds of meat off a carcass, so close to the desired weight as is no matter. But only yesterday, when I was selling a pair of pigs on the hoof there was a variant between the guesses at the live weight made by two experts-men who have handled more pigs than I have ever seen-of more than fifteen per cent. No man living can guess the weight of a critter on the hoof, or the number of bushels in a heap of potatoes, or the number of acres in a field of alfalfa invariably within ten per 
cent, plus or minus. And the bigger the subject the greater the error.

So we keep records at Medlock Farm. In addition to the egg and milk records there are records of flocks and herds, of breedings and births and deaths, sales records, and financial recordsof a sort. For I never was any great shakes at bookkeeping; I am, as it were, tone-deaf to it. When it is explained to me I can understand the difference between debits and credits; when it comes to deciding which side an entry belongs on I am as the beasts that perish. Yet it is not their complexity that make records difficult. Even the financial ones are as simple as tit-tat-toe. What baffled me for a long time was how to get the records kept, and kept up to date. So much happens on a farm; there are so many things one can overlook until the time comes when one wishes one had the data. I found the solution was partly a matter of habit-forming. But mainly it was a suggestion, contained in a book called Around the Year in the Garden, to keep a farm diary or log. Long ago I conceived the idea of keeping a diary of weather and other natural phenomena; it was easy to slide into the way of keeping it for the farm. A typical day in the diary reads:

"Clear, still, and cold. $9^{\circ}$ at 6 A.M. Maximum 19. Checked laying hens for lice. Sold two pigs out of fall 
litter at agreed weight of 340 pounds@81/4 $\phi$. Note pig left in pasture has bronchial cough. Used last of stored carrots-memo.: store more next year. Broke into first kraut barrel. Medlock Jacqueline bred to Z--'s bull: check for conception this day three weeks. J-— cut and hauled firewood."

Observe the references to first and last things; unless a note is made of the date the last carrots or the first sauerkraut are eaten there is no guessing how many more carrots should be planted or how much earlier the kraut should be laid down next year.

At first my diaries were chiefly notable for omissions. A year or so of hunting through last year's records to see when we did this or ought to do that, and if so how much, supplied the corrective. Year after year the diaries become more valuable. If I had it to do over I should augment them with written orders, like army field messages; I have used them a good deal as it is-a note left beside the milk bucket is quicker and easier than getting up at milking time-but I have not kept a duplicate file. 


\section{Must You Keep a Cow?}

IF you see a poor, run-down farm in this part of the country you need not look in the barn to know there are no cows in it. If there were no other reason for them I would keep cows because they are the backbone of the manure supply system. Not only is manure expensive to buy but, in these mechanized days, it is not easy to find for sale at any price. And there is no substitute for it. Perhaps one reason for this is its insistence; you just have to take it out and spread it on the land to get rid of it. Per pound of live weight the pig is the biggest manure producer of the domestic animals; per capita he runs a poor second to the cows. Five two hundred-pound pigs will produce thirty thousand pounds a year; a single one thousand-pound cow will go to twenty-seven thousand pounds. The horse, by the way, is back among the also-rans both in quantity and in the plant food value of his offal. Five are a good many pigs to carry on a home-use farm; and by the time a pig reaches its mature production peak it is ready to be eaten. But five cows and heifers are a normal 
herd for the same place. The fertilizing superiority of the cow is thus patent. Without cows the land will run down, and do it so unostentatiously that the damage-as in most ills of malnutrition-is done before it is revealed.

Proponents of the nuts-and-berries philosophy have lately backed the goat as a stand-in for the cow on the home-use lot. Goats are easier and cheaper to shelter and to handle at breeding time; per capita they are small eaters. Having said that, you have said all that is good of them. Granted their milk is high-class human food, yet it does not taste that way, and it is unfit for butter. The twicea-day milking chore is one of the bugbears of a home farm. I have heard it argued that goats are easier to milk than cows. I would not know; I have never milked either. Yet they too must be milked twice a day. The difference in actual milking time (the preparation is about the same) is a matter of two or three minutes per head. If milking must be done one might as well get something more than a teacupful for the effort.

Whole raw cow's milk comes close to being the perfect human food. Note I say "whole" and "raw." Whole milk is practically unknown to those who buy their milk ready put up at the store. It is that in which the butter fat content is left intact, just as it came from the cow. Many communities prescribe the legal butter-fat content of differ- 
ent grades of milk. Generally that of the best grades is far below that of the poorest raw milk: either part of the cream is skimmed out, or the raw milk is "sophisticated," as the perfumers say, with water or some other liquid, at the dairy.

This diluted or weakened milk is then pasteurized. That is to say, it is cooked. No one can deny the great blessing the Pasteur process has been to humanity. But it is a wholly negative good: it merely makes a fluid that may otherwise be deadly poison, innocuous and potable. What else it does-how much of the food value of raw milk it destroys-I do not know. What we do know is that raw foods contain more nutriment than cooked. Much has been added to our knowledge in this direction since the practice of pasteurizing began, yet to the best of my knowledge no check-up has been made on raw versus cooked milk. The fact that pasteurized milk is safe has probably obscured the question whether it is beneficial, much as the fact that chlorination renders water harmless has obscured the truth that the chlorine which kills dangerous organisms in water also kills benign enzymes in the digestive system.

If the behavior of cream is an indication, a lot of other things must happen to whole raw milk between the time it enters the modern city dairy and the time it appears on the back step. Bottled cream can be bought in different degrees of-I 
shall not say richness, but-thickness. No matter what its density, whether "table cream," "whipping cream" or what, all store cream remains unchanged in the bottle for an indeterminate time: until it is used up or turns sour. Now you can skim cream of different densities at home, in a separator. But if you stow it in a bottle twelve hours the cream will rise to the top, just as it does on milk. There may be only a quarter of an inch of milk in the bottom of the bottle, but there it will be for all the world to see. Store cream never does this; there is never any need to "shake before using." What the dairies do to it, or say over it, who can tell?

Having decided that for the well-being of both the farm and the family cows were essential, the next thing was to settle on the kind of cows to get. They should certainly be tuberculin- and blood-tested. The cause of tuberculin-testing is pretty well-advanced in Pennsylvania. Blood-testing has not made the same progress, probably because its relationship to human health is not as well-publicized. Both tests can be carried on under state supervision, with indemnities from the state and-of course!-from Washington for the destruction of reactors.

The primary purpose of blood-testing is the elimination of Bang's disease (chronic abortion) in dairy cattle. (By the way: when a cow gives nor- 
mal birth to a calf she is said to "drop" it; when she aborts she is said to have "slunk" and the result is called a "slink," or "slunk.") It is a fairly prevalent and highly infectious disease. It is transmitted to humans through dirty milk as Malta or undulant fever. It is not, I understand, fatal to humans. But it is a long-drawn-out illness. And having seen some cases of it I decided my family could get along without it.

There was no question about whether to get pure-bred or grade cows. An unwritten article of the American Credo says a yellow mongrel cur is the equal or superior of a pedigreed dog. Fiddledee-dee. Don't you believe it. No mongrel or even grade animal is as good as the thoroughbredever. Amazing improvements have been made in milk production in this country in the last twenty years. Between 1917 and 1926 the average yield was upped from 3716 to $5^{208}$ pounds of milk per cow per year. And how? In small part by better feeding and management. Mostly by breeding up, improving the whole nation of cows by the dissemination of pedigreed blood, and by culling in accordance with known records of performance.

As far as cows are concerned the best are the cheapest and most efficient. Records compiled in Hunterdon County, New Jersey, show that cows with production of five hundred pounds of butter- 
fat per year were fed at a cost of seventy-nine cents per hundred pounds of milk (a quart of milk is 2.12 pounds) while those assaying less than two hundred pounds of butter-fat ate a dollar and thirty-nine cent's worth per hundred weight of milk.

The only question in my mind was which of several good breeds to pick. The controlling factor in my decision was this: it does not pay to keep a bull in a small family herd. Even if it did I should not be keen about it. They tell me that in Pennsylvania alone there is an average of a man a week killed by bulls. The place to keep bulls is on big dairy farms where they are in steady use, and where the investment in safe, adequate housing and breeding pens is warranted. The small herd-owner's choice should therefore be of that breed which predominates in his immediate neighborhood. Which is a good point to consider in selecting the breed of any farm animal, for it is usually true that the popular breed is also one that "does well" in the locality.

For me this meant Guernseys. That was all right too: the Channel Island breeds are producers of comparatively small quantity but exceedingly high quality. Beyond a certain minimum of milk, what is wanted most for family use is cream. The less milk that has to be handled to get it the 
better. By good luck I was able to buy cheap a fine cow and a heifer out of a herd that was being broken up by an estate sale.

The cow came in fresh a month after I bought her. She dropped a bull calf that, in the Victorian phrase, we "altered" and raised for beef. Naturally she was at the peak of productivity when the calf was born. The general practice is to breed cows once a year. Their period of gestation is nine months. A month or six weeks before the calf is born the cow is allowed to go dry, to conserve her strength. Dependent on whether her calf is taken from her immediately to be raised, or is left to feed on its mother's milk and fatten for veal, the cow will produce nothing for household use for two to six weeks after the calf is born; for six weeks to three months out of every year the milk factory is shut down. Hence the reason for buying the heifer. For a steady, continuous flow of milk into the home two or more cows should be kept and bred alternately, so that as one is going dry another is coming in fresh.

No "family cow" is as big a producer as a dairy animal: she is not pushed to produce. It is not necessary, for since her product is used in place of boughten milk the family are saving the top retail price on it; success or failure does not hinge on marginal performance. Milk records that are to be made official are kept on all the milk a cow 
produces. Mine are only of what she produces after she is finished with her calf and her milk starts coming in the house. One typical cow yielded 5474.6 pounds in 1936 and 4691.6 pounds in 1937 , a little less than eight and one-half, a little more than seven, quarts a day for the 306 and 312 days she worked for us. Two or three cows that average 2400 quarts a year will supply a family of four.

You may even wonder what one family can do with seventeen quarts of milk a day the year round. Well, as I said, you would be surprised how much more a family can use when there is plenty. We are all milk-drinkers, so we use four to six quarts a day that way. Then there are the two quarts a day the hired man gets. It is easy to use a quart every day or two as junket, which can be made without cooking when the milk is warm from the cow. On Medlock Farm these uses account for six to eight or nine quarts a day. Then there is cream. It takes six or eight quarts of milk, depending on the richness desired, to make a quart of cream. An eight-quart Guernsey cream, if pan raised, you could, as Plupy Shute's father said, "lift out of the pan like a old pare of linen britches"; it is considerably richer than Pennsylvania "whipping cream." What with morning cereal, coffee, fruit in season, and such like uses my family can go through a quart of cream a day like nothing at all. There remain cheese, cot- 
tage cheese (smear case), buttermilk, sour creamfor salad dressings and the like-and butter. Four people can easily use three pounds of good, homemade butter a week; more in the summer vegetable season and if the cook knows her job. For as the author of The Gun Club Cook Book says:

"There is no 'secret' of good cooking; it is the intelligent use of the best materials and the greatest of these is butter. If one uses the finest butter in sufficient quantities, the cooking can hardly go far wrong."

Who has not heard the reverent Frenchman cry that his favorite restaurant cooks "tout en beurre"?

With the simplest and, doubtless, most inefficient equipment it takes one to one and one-third quarts of cream to make a pound of butter. Here one may pause and speculate as to what else the dairymen put into a pound of butter that retails at forty-five cents besides the butter-fat that stands them fifty odd cents a pound. There must be monkey business somewhere. My calculations cannot be that far wrong. Nor can I believe my butterchurning is that inefficient.

For a long time butter-making was my bêtenoire. Traditionally it is skittish and coy. Sometimes mine would churn in ten minutes; otherwhiles it took thirty-five or forty; occasionally it would not churn at all. I tried sweet cream, sour cream, and various mixtures of the two. I took 
a State College correspondence course in buttermaking. All of which worked not the slightest improvement. One day I took a leaf from the book of that one of my lives that knows me as a maker of cosmetic creams. I brought a thermometer home from the factory. As long as cream is at the proper temperature-sixty degrees Fahrenheit for oursit will churn like a breeze in seven to ten minutes into good butter that will wash clean and, unlike the farm butter of childhood's unhappy memory, stay sweet.

Summer, when the cows are on pasture, is the big butter season. Some farmers make it up in quantity and salt it down for winter use. There is a government pamphlet tells you how. But I have never done it. Such butter may be fine eating but for me it is as they say hereabouts of cold roast 'possum: it is supposed to be very good, but. nobody really knows because none is ever left over to eat cold.

Unlike the churning apparatus, the cream separator is a highly efficient piece of machinery. Here we generally use it once a day. It takes about five minutes to skim up to eight quarts. The skimmilk can then be taken right back to the pigs or chickens, the single quart of cream stowed in the refrigerator. The machine is something of a problem to strip, clean, and re-assemble until you are familiar with it; but it is far quicker and cleaner 
than fussing with rising pans and more efficient; it will soon pay for itself in the extra cream it extracts from a quart of milk compared to handskimming.

The quantities of food a cow can consume are almost terrifying. She is a bottomless pit. It is not hard to understand how an animal that does what she does should need lots of food; as Abe Potash said to his partner, "a feller what gets no exercise but sits in an office all day like you, he should eat plenty." But a cow's idea of plenty would make Abe gasp. She will yaffle off enough high-protein material to last a strong man a month, top.it with fifty pounds of hay-which is quite a pottle of hay -and tamp it down with a bushel or so of beets. If she is of the dairy temperament and feels up to her game she will do this twice a day. From time to time she will drink ten or twelve gallons of water. Have you ever seen a cow drink a threegallon bucket of water? It is something to make the unskillful laugh: one s-s-s-sip-and it is down the hatch.

Yet the aforementioned Hunterdon County research indicates even the less efficient animal will produce milk at a feed cost of $\$ .0286$ a quart. During the year just ended my own cows produced milk at a cost for store-boughten feed of $\$ .036$ a quart. This was using the best grade of mill feed bought at retail and not much else, for there was 
scarcely any carry-over of home crops into the new year. In the six months from June to November my feed cost was less than half a cent a quart; while in the four months from July to October there was no cost at all: the cows subsisted wholly on pasture grass. The price I got for one milch cow with calf paid all but $\$ 12.20$ of the mill feed bill. Meantime, excluding the time they were on pasture, the cows produced not less than twentyfive tons of manure.

In reckoning milk feed costs I exclude feed bought for calves, as well as the farm labor and expense for home hay and grain crops. As I said before it is impracticable to allocate the latter in accurate proportion to the different kinds of livestock. Calf feed is really capital investment: it is a good plan to have young cows coming along; if they are not needed at home the investment can always be quickly liquidated. In 1937 I sold two cows and a bred heifer for three hundred and eighty-five dollars, which more than covered the milk feed, calf feed, and farm crop costs.

The one thing we went short on in 1937 was veal. Of four calves dropped on the farm in twelve months only one was a bull. (It is of record that the mother of one of my cows-related to all the herd-never dropped a bull calf in her life.) It would suit both my purpose and my taste better if the proportion were reversed. Until I had eaten 
the home-grown variety I had no idea how good milk-fed veal could be. Chances are I never tasted it. The same goes for home-grown beef. I was doubtful about raising dairy bulls for beef although the veterinary assured me it would pan out all right: the feed a dairy critter gets makes much better beef than you can buy in stores. The only obvious difference between dairy- and beefbreed meat is that the fat of dairy beef is yellow instead of white.

I have no idea how much it costs to produce beef at home since the steers, like the sheep, must be fed from the same supplies as the milch cows. Like the illicit items in the swindle sheets of the vanished New Era, our veal, beef, and mutton are in the milk bill, but you can not see them. Which reminds me to conclude these rambling remarks on meat and milk with the story of a statistic.

While the spread between production cost and consumer price vitally concerns us all, you have no conception how tiresome discussion of it can become unless you are a practicing perfumer. In the midst of an especially virulent siege of ennui I worked out an elaborate comparative computation of the difference in spread between the price a Bulgarian peasant gets for the rose leaves that go to make up a simple rose extract, and the price they fetch when sold as such here in America; and that 
between the current farm price for hay used to. fatten beef cattle, and the final restaurant price for filet mignon. Necessarily the calculation is not accurate. But Hell's delight! It need not be. Whereas thirty-six dollars will buy, complete with bottles, caps, labels, and so forth, the perfume made from roses for which the Bulgarian received the local equivalent of one dollar, it takes about two thousand five hundred dollars to buy a dollar's worth of hay converted into filet mignon.

There's the respect that should give us pause. 


\section{Poultry: A Success Story}

LET us consider the egg. First, as food. To most people an egg is simply an egg. It is either fresh, or bad-without graduation of quality. A few distinguish between white and brown eggs, between "strictly fresh" and "cold storage." A very, very few, who go in for the more esoteric technicalities, describe further classifications: "large" or "small." Of those who have heard of "candling" probably as many suspect it is a way of propping up inferior eggs for market as understand its real purpose.

The United States Department of Agriculture has defined various grades of eggs. In its bright lexicon are no such terms as "strictly fresh," "day old," or even "fresh," although there is one classification to gladden the phrasemaker's heart: "standard dirty." Such fanciful names or descriptions as are applied to eggs-as to banks-implying honesty, sincerity, thrift, stability and solid worth are, of course, wholly outside government's pale. Take the phrase "day old": it is a good catch line, "fine for a flash," as we say in trade. But it means 
nothing. An egg can be literally less than twentyfour hours old and still be far from fresh, or first quality. Time, study, and the exhortations of the feed mills, that do a first-rate job of telling their customers how to trade-up, have taught me to judge an egg's quality and how to produce the best. "Let me now from the bonded warehouse of my knowledge" pass along the lowdown.

Every housewife knows the supreme test of egg quality is the poaching pan. An eggwhite that spreads, breaks, and scatters when dropped in scalding water is certainly inferior and probably stale. If the yolk breaks it may be too bad for human food. Egg quality can be tested, checked, practically insured, without putting all one's eggs in the poaching pan. Break one into a flat dish and hold it up to the level of your eye. A good egg will not spread out all over the dish. There will be cohesion in the white: it will rally 'round the yolk, holding it in suspension with a good layer of white overlaying it. If it is the kind of super-special egg laid on Medlock Farm you can lift it in the tips of your fingers a foot or so above the dish, let it slip back again-and the yolk will not break. Needless to say it will contain no blood spots or other imperfections that can be detected and culled out by candling.

You have heard the comparison: "as full of soand-so as an egg is full of meat." How full of meat 
is an egg? Never chock full. It is born with an air cell in one end. Time and deterioration increase the size of this air cell: the fresher the egg, the smaller it is. Its outline is visible to the candler. $\mathrm{He}$ can, therefore, grade according to cracks or checks, spots, and air pockets. But gazing through an egg held against a strong light, everything is light and shadow-black and white. It is impossible to candle eggs for yolk color, which is important to palatability in an egg just as is the color of the coffee to which you add cream. Color also bears a traceable relation to actual food value: the yellow vegetable pigment in the feed which determines the shade of the egg yolk is a vitamin medium.

Although eggs are usually sold the consumer by count only, they are nearly always bought by those who trade in them according to weight. Disregarding the subnormal and abnormal, eggweight ranges from eighteen to thirty-two ounces to the dozen; most egg scales are dialled from nineteen to thirty. This is a huge variation: from one and one-half to two and one-half ounces per egg. It is quite enough to account for inexplicable failures at cooking with otherwise meticulously accurate recipes which indicate eggs numerically. "One egg?" What, an eighteen-ounce egg or a thirty-ouncer? 
In grading eggs for weight, Hurd ${ }^{1}$ says "fancy weight should be two and one-quarter to two and one-half ounces, or more, each, twenty-seven ounces to the dozen. ... The 'standard' size of first quality eggs in nearly every market in the United States varies between one and fifteen-sixteenths and two and one-quarter ounces for each egg, twenty-four ounces to the dozen." But there are few "markets in the United States" where there is any compulsion to brand standard weight "standard" rather than "fancy," or where it is not esteemed legitimate to include all weights in a single dozen as long as the total weight of the dozen is as it should be. To be sure, no farmer, grading a limited number of eggs, could otherwise hope to turn out uniform dozens.

To produce good quality eggs the first thing to do is to grow good quality hens, in which proper feeding and management play at least an equal part with proper selection of growing stock. Poultrymen still have something to learn from that dairy expert who told me you can not overfeed a good milch cow: their tendency still is to try to figure out minimum feeding programs, instead of feeding the birds all they will eat and then cashing in on selective breeding. From the time they start

1 Louis M. Hurd, Practical Poultry-Farming, New York, Macmillan, 1934 . 
to eat, twenty-four to thirty-six hours after they are hatched, I feed my growing stock all they will take of the best complete feed. It makes for good, husky hens that do not borrow from egg quality to supply bodily wants. Once they have reached laying age I limit the quantity of feed somewhat, although still giving more than current practice calls for. Any charge for overfeeding is well salvaged in the weight and quality of the meat, when a hen has finished her laying career and is ready to be eaten. Furthermore, whereas the average poultryman expects a big percentage of his hens to die of exhaustion at the end of the laying season, all but a negligible few of mine come through fat and sassy. In sections of the country where, as here near Philadelphia, chickens should be kept penned, the expense of fencing runs and yards is considerable. Adequate feeding eliminates much of that expense: a determined and ingenious hen can get out of almost anything if she is hungry; if she has plenty to eat she will not even try. Except for dustand sun-baths, my hens seldom leave the laying house, even though it is wide open.

Uniformity of feed makes uniform yolk color. I wish it were as easy to solve the problem of flavor. Feeding and management do a lot to regulate it, yet it still remains a matter of individuality; do what one may, some eggs still taste "eggier" than others. 
Fertile eggs start to germinate at seventy degrees or less. They may be chilled off and the embryo killed thereafter; but spoilage has started. A sterile egg deteriorates slowly, hence it is always preferable to keep roosters out of the laying flock and produce sterile eggs. Despite man's best efforts there are seasons when the hens lay faster than their goods can be consumed. At such times sterile eggs are stored in water glass-a silicate solution sold in drug stores-against a rainy day. They come out perfectly fresh after two to three months in this kind of storage.

Not even sterile eggs should be stored at too high or low a temperature. In most laying houses -mine, for instance-each nest must be used by four or five hens. Hence unless the eggs are gathered more than once or twice a day they will be subjected to wide fluctuations of temperature as the hens climb on and off the nests. Dependent on the weather we gather Medlock eggs three to six times daily. They are then stored in a moderate, humid atmosphere. They are never washed until time to use them. Egg shells are porous, but when the egg is laid it is coated with a mucilaginous liquid that dries into the shell, checking evaporation and producing the bloom or sheen that is the hallmark of a fresh egg (it can be imitated with lard or mineral oil). This coating is easily soluble in water; so once an egg is washed the pores of the 
shell are permanently wide open, and evaporation and deterioration are accelerated.

Thus an egg may be a literal twenty-four hours old and still be on the stale side. If it is the product of an undersize, underfed hen; if it is left in the nest as long as five or six hours; washed when collected, and then stored in a hot or arid atmosphere it will not be as fresh as a good egg, well cared for, that is a week to ten days old.

In no other branch of home-farming so much as in poultry production is one repaid for following two fundamental rules that apply throughout the curriculum. The first is to stick to the best obtainable stock. Some of my friendliest critics ask me if I never make mistakes on Medlock Farm. Plenty. One of them was my first venture into chicken-keeping. I was impatient to get going but disinclined to pay the safe price for speed. I bought a crate of live hens at auction, figuring we would start having eggs at once. These hens were scrubs, undernourished and exhausted. They sickened and died that first winter without producing a single egg. I lost ten dollars and some three to six months' progress on that end of the program.

But I had learned my lesson. I still did not feel like risking bigger money to get started right, and at once. So the following fall I bought a small, oilburning incubator and raised my own pure-bred New Hampshire Reds, a breed later admitted to 
the American Standard of Perfection as Hampshires. This is one of the best of the "all purpose" breeds. The birds have tremendous resistance to disease and cold: my laying hens live in what was once the cowbarn, with no artificial heat, and with doors and windows open to the weather the year around. They are quick-maturing, relatively heavy producers of splendid brown eggs; and at all stages and ages they are elegant eating. Of course if one is handling chickens commercially it may be better to specialize in.either an egg- or meat-breed: Leghorns or Brahmas, for example. But in that case one must be content with poor eating on the one hand or poor laying on the other. For home use the all-purpose breeds, which combine comparatively good laying with excellent eating, if lesser gross weights, are best.

The second good rule with poultry is to start small. The investment is heavy in proportion to returns. Even though I built no housing but utilized part of the barn I still have a hundred dollars or so in plant and equipment, with a laying flock averaging only a hundred birds that are themselves no inconsiderable investment. It is dead easy to become over-enthusiastic and sink thousands of dollars-if you have them to sink-in a poultry project. Then a trifling error or oversight can upset the applecart. One winter, in spite of all that is written to the contrary, I put too much artificial 
light on my maturing pullets: instead of starting to lay they started to molt. I missed the high-priced egg season a mile, and landed in the red with a dull, grinding jar. But having only a small farm flock I was not utterly undone.

The hatching of day-old chicks is a big business in itself, and like many another big business it is founded on the sands of the fallacy that it is cheaper to buy it than to make it yourself. Household and home-farm methods never attain factory efficiency. Yet with boughten hatching eggs that must certainly be sold at something more than production cost, since I buy them from a middleman, I can hatch chicks cheaper than I can buy them in my kind of quantities, and then run way ahead in the saving on casualties incident to transferring the birds from the incubator to the brooder: a job that must most often be done in freezing weather.

When I was a child we hoped-it is an exaggeration to say we expected-to raise one-half to onethird of all the chicks hatched, whether brooded artificially or under hens. Chicken fanciers knew their greatest scourge was the disease called "white diarrhoea" but they had not learned how to combat it. It is transmitted by the carrier hen through her egg to her chick, and once developed spreads through the infant flock by way of the droppings. Today all first-class breeding flocks are blood-tested 
for the disease. Infected hens are culled out and only disease-free chicks are hatched. They are brooded on wire grating, an obvious precaution that just had not been thought of thirty or forty years ago, so that it is impossible for them to pick at the droppings. By such means, and by using electrically lit and heated brooders built of galvanized iron wherein rats cannot creep nor lice breed and corrupt, chick casualties can be cut to a trifle. The difference between right and wrong brooding is clearly evident in the statistics of my own flocks: of birds brooded on wire in galvanized iron brooders, eighty-eight per cent are raised to egg laying maturity or to the frying pan; of those put out on open ground at eight weeks, in midsummer, eighteen to thirty per cent were casualties.

I have two baby-chick brooders, each of which houses a normal hatching from my eighty-egg electric incubator up to the time the chicks are six weeks old. Thus the incubator can be kept working full time (in commercial poultry-husbandry idle plant is a big factor in expense). It still takes three weeks to hatch an egg; that is one direction in which art has not yet improved on nature although there is talk of it. When, with both brooders full, the third setting is hatched, the first hatch is six weeks old, ready to move out of the baby brooder and make room for hatch three.

At six weeks the birds go into a "finishing bat- 
tery": a four-story, eight-room, unheated and unlit affair that houses a hundred or so birds up to twelve weeks or more. Within ten weeks from hatching we start taking broiling and frying roosters of two and one-half to three and one-half pounds out of this machine. My records show that the revenue-either real or cash-from meat birds covers the whole cost of raising the hatch: that is, I have my pullets free.

With the exception of the incubator, which is in my study where it can be under constant observation, the bird-raising plant is all in the cellar. This sounds insanitary. Actually it is perfectly hygienic and healthy for both birds and humans: the very proximity of the chickens is a constant incentive to their proper care. The humidity of the cellar is just about right for growing stock, and the temperature is steady. With proper feed, which includes plenty of good cod-liver oil, chickens thrive and grow as well under artificial light as in the sun.

The poultry department is the biggest user of electric light and power on the farm. Six months of the year there are two sixty-watt lamps burning all night in the laying house. (Contrary to general belief artificial light does not increase a hen's total egg production: it levels up the production curve by stimulating laying in what nature designed to be an off season.) Three more sixty-watt lamps 
light the brooder batteries; and there are three heating units in the incubator and baby brooders. After prayerful consideration I adopted an arbitrary way of reckoning the poultry's cost in electricity: taking 1932-when no juice was burned for birds-as a base, I charge all increases in the electricity bills against poultry. During 1935 and 1936, with five hatches a year, the total increase over this basic bill was $\$ 23.65$-less than a dollar a month. True, between 1932 and 1937 we had two rate reductions. On the other hand, with a third reduction-our rate now drops to two cents on the 101 st kilowatt hour-and a restricted hatching program, in 1937 the electric bill actually landed in the credit side of the poultry ledger. According to the representations of the mail-order catalog, I reckon it costs me about as much to operate an eighty-egg incubator by electricity as it did to run a fifty-egg machine by oil, with none of the bother, far less fire risk, and much greater accuracy.

My father's unfulfilled ambition was to breed a hen that would lay two hundred eggs per year. Now, after thirty-five years' improvement by breeding and culling, such records are the rule rather than the exception. In her native state, one step or so removed from her ancestral pheasant stock, the hen laid a dozen or so eggs every spring and called it a job. She has just so many eggs to lay and seldom lays them all, even though she lives eight 
or nine years. The big pay-off in productivity is in her first three years. Hence, and also because in their first year pullets will start to lay at five or six months regardless of the season, one keeps a steady line of replacement pullets coming along, with hatchings timed to bring them into production in the fall and early winter peak-price seasons.

In summer some hens go into a "vacation molt," then molt again in the fall. Such birds never pay their own freight, for only the exceptional hen will lay through a molt. The only remedy is to band all the hens with numbered bands, provide trap nests, keep records of individual performance and cut the deadheads' tails off behind their ears. From thirty to sixty per cent of every flock will take this way to the everlasting bonfire. But trap-nesting is a tedious, exacting chore: it means visiting the laying house every hour or two, every day, for months. I have done it. But I decided two years ago to drop it, to postpone the higher efficiency until I can install laying batteries. These provide a private cage for every hen. Record tags are hung on the cages, and the minute a hen falls below an established minimum monthly production off comes her head. Meantime, pursuing a non-trapping policy I still find it possible to make the farm flock pay out, and on relatively expensive mill feed.

All the world is divided into two embattled 
groups of opinion on poultry business (commercial poultry-keeping is business; it is not agriculture or farming): that which esteems it a gold mine, and that which knows it is a delusion and a snare. Truly it is no business to tackle on a shoestring: for a plant of the slightest commercial importance, both capital investment and operating expense are heavy. Gross-profit margins are close in all departments; some of the best plants never yield more than a "labor profit": that is, the profit balance at the end of the year is the salary the proprietor has paid himself. But with modern improvements in technique and their attendant reduction of risks, along with the premium prices the best quality products always easily obtain, poultry is one of the most attractive businesses in a world wherein most business is in disrepute and decay.

Some day, when I can find the time, I am going into it. 


\section{Where Pigs Is Profits}

NO one who contemplates life on the land can ignore the pig: he is one of the easiest and cheapest animals to raise, and he produces a wide variety of products, many of which lend themselves to storing. My notes of the fall of 1933 and winter of 1934 reveal the following prices for pork products, taken from contemporary chain-store advertising just when we were "working up" our first two pigs:

fresh loin... .14 cents a pound (olaf hasholem!)

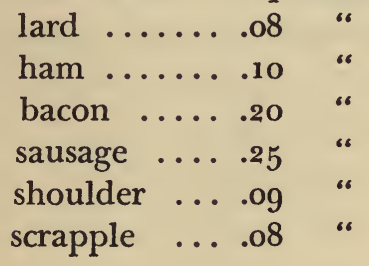

Food costs were all probably at bottom for my generation. Farm prices were correspondingly low: for a pig that would dress two hundred pounds the farmer would be lucky to get three dollars on the hoof. This would not pay the then low cost of 
production by mill feed. I well remember the indignation of one publicist who quoted an Iowa hog farmer as telling a shop keeper that before he would pay ten cents a pound for ham he would b'gosh go home and make ham off one of his own pigs-an unorthodox declaration of hideous rashness.

These same records of mine show that a pig which would not fetch three dollars on the hoof and the farm was worth to us when all dressed up for the table, at home and at the above retail prices, twenty-seven dollars and eighty cents. Our profit over all production costs was between four and five hundred per cent. The spread was so large as to make the typical industrialist's dream of the millennium look silly. Yet in the winter of $1935^{-36}$ an identical pig, with but insignificant productioncost increase, assayed nearly eighty dollars. Even now that happy days are here again and gone the gross value of such a pig, for home consumption, is nearer eighty than twenty-seven dollars.

Before I could start raising pigs I had to know what local regulations there might be against it. Many communities, especially in the neighborhood of large cities, have such. They are usually, as they are here, aimed against commercial piggeries, exempting the farmer who raises a small herd for home use. One of the pleasantest, most heart-warming by-products of part-time farming, 
by the way, has been to find myself projected from less than the dust wherein dwell manufacturers into the lofty realms of those most-favored citizens in deference to whose slightest whim all the manifold laws and regulations that limit the freedom, hamstring the initiative, and handicap the activity of lesser minorities are relaxed, amplified, or amended. There is hardly such a thing as a political thought, let alone a reality of legislation, that is not modified insofar as or insuchpart as applies to farmers.

The urban objection to pigs is that, like Huck Finn's King and Duke, "Dey do smell so." It is a thought to influence the location of the pig pen. And yet not so; there is no need for pigs to smell. There is no inherently cleaner animal. Under conditions that would stagger the best-intentioned human housewife the babies of a good brood sow will be miracles of cleanliness. The wonder is that pigs survive the sort of filthy treatment usually meted out to them. Given a good stout pen, clean troughs, frequent changes of bedding, and your pigs will smell as sweet as the cow barn.

Since his skin has no pores and he can not perspire the pig suffers intensely in summer heat. That is why he wallows in the mud-unless shade is provided for him. Their short nasal passages render pigs vulnerable to pulmonary diseases: colds, bronchitis, and such. Since their fat enables 
them to withstand almost any degree of cold they are therefore healthier if kept outdoors rather than in dark, ill-ventilated houses. Cholera, the scourge of large piggeries, is best controlled by inoculation and proper attention to sanitation.

There are two kinds of pigs: the lard type and the bacon type. Since there is plenty of lard on the leanest pig for the home-use farmer the bacon type, with its extra length from shoulder to rump, and its ability to put on lean meat rather than fat in the final stages of fattening, is best. I have heard it said and seen it written that all pigs tend to revert to the lard or "chuffy" type if too closely bred, but I can not contribute anything from my own experience on this point, beyond that our pigs have always been cross-bred and have always adhered to type.

The pig is the farm salvage plant par excellence. He will convert kitchen garbage, garden, and orchard waste into good meat. But the backbone of his diet is middlings. Pigs will thrive on corn, which we use in the finishing stages of the feeding program. But unless corn is balanced with plenty of skim-milk it will run too much to fat and to such undesirable results as soft bacon. Middlings make good hard lean meat; they are especially fine for brood sows and young pigs. After one rather costly experience we learned to be cautious about feeding garbage other than our own. 
The pig is tough, and he is a good sport: he will try anything once. But he can not digest powerful cleansing agents, broken glass, tin cans, bottle tops, or match sticks. About the only thing my pigs will not eat is a raw potato. Whether no pigs will, or whether it is a peculiarity of Medlock pigs, I do not know.

A pig farrowed in March is ready to butcher in December. It should neither be too large, for in that case it will run too much to fat, nor too small, when an undue proportion of its weight will be bone. One hundred and seventy-five to two hundred pounds is the ideal weight for home use. We always aim to pick a cold spell for pork butchering: there is more meat on a pig than an ordinary refrigerator will hold, and a lot of it has to be stored in a rat-proofed cage in the cool-cellar. I say we aim at cold weather. Usually the weather breaks and an unprecedented thaw sets in on the day we butcher. I have found the remedy in such cases to lie in a strict attention to Napoleon's rule of "previous preparation." If everything, from the tools to the pickle tub, is ready and in order a two-hundred-pound pig can be worked up and stowed away without any spoilage.

Of tools one needs two or three sharp butcher's knives, with a stone and a steel to keep them edged. We use a light block and tackle designed for meat on one heel, the hay rope on the other, 
to hoist and spread the carcass for splitting. It can all be done on one rig, if one uses a gambrel to spread the hind legs. A pig is never skinned when it is butchered; removing its fell of hair is one of the toughest jobs on the farm. It is done with hot water and a thing that looks like a candle stick, called a hog scraper. The water must not be too hot, lest it cook the hide and set the hair in it for keeps. Yet unless it is hot enough at the start it will cool so quickly in the winter air that it will not loosen the hair at all. For a long time we worried along with gunny sacks, making a shift to soak them in scalding water, steam and scrape one side of the carcass, then turn it over and hot-towel the other. Finally one of my neighbors loaned me a scalding tank. That was a couple of years ago. As so often happens with farm tools that are loaned around-it is still here.

Since we are talking of butchering, this is perhaps the best place to step aside and mention something that has been on my mind since I wrote the first word about home-grown meat in this book. The natural tendency of all normal people is to make pets of farm animals. Especially must the person who cares for them get to know them and like them. One particularly matter-of-fact and scientific poultryman has written that the biggest factor in poultry success is love. It is true: the hens will lay more eggs, the cows give more milk, even 
the pigs will fatten quicker and better if cared for with loving kindness. But there must be a limit to this and a rational view of it. As far as is humanly possible we avoid making pets of the animals, especially of those grown for eating. When the limit is reached we remind ourselves that the animal is fulfilling its destiny with a certainty denied us mortals; that all flesh is grass; and that in the course of time our positions, with respect to the children's children of those we eat now, will be reversed. Perhaps this is a little morbid, but it is the best that can be done.

The butchering of one animal differs only slightly from that of any other. The pig's distinction is this matter of hairing. After it is done and the carcass has hung overnight to cool we take it to a long table in the cellar and cut it up. Everything is used: the lard is cut away from the outer skin, and the skin set aside, along with the top of the head and boney scraps, for scrapple; and bits of lean meat for sausage. Every man to his taste: in sausage mine is for all-pork, rather than porkand-beef; and, with good fresh meat, not too much seasoning. None of us had ever cut up a pig back in December, 1933. However, a little common sense and careful attention to the directions in the State College course and in Farmers' Bulletin No. 1186 brought us through in triumph. As we grow in expertness the sausage meat pile shrinks; lat- 
terly we have had to augment it by cutting up a shoulder, which otherwise makes a good roasteither fresh or pickled-or steaks. There is usually as much fresh meat as we can handle in the loin.

After sausage meat has been ground and seasoned it can be eaten, as is, in cakes; but it will keep longer uncooked and handle better if run into links. I have never made my own casing because my mother tells me it is a long, hard job to get it perfectly clean, and because salted casing, enough of it to do three pigs, can be bought at the local butcher shop for two bits. The casing is soaked in water, then run on the nozzle of a little machine called a sausage stuffer, and the meat forced into it. Of all parts of the pig fresh sausage spoils quickest, so beyond a week's supply we cook it and pack it down in a stone crock and cover it with lard. That way it will keep all winter. Hereabouts a good many people pickle it and smoke it -very good, too-but I have never done this.

Lard is made by trying out the fat over a slow fire. This takes time and, at the start, a good deal of care to prevent burning. When the crackling begins to disintegrate, which is some time after it will actually crackle when squeezed against the container wall with a spoon, the lard is done. It is strained through cheesecloth into a large, frictiontop tin and stowed away in a cool cellar. It will keep through summer heat if it has been made 
right-that is, if all the water has been extracted from it, and if it is not exposed to the light. While the difference between home-made and storeboughten foods is always notable, it is nowhere so remarkable as in lard. Until I made my own I did not realize lard had any flavor at all-or color.

Now we turn to scrapple, the Pennsylvania gourmets' bone of contention. One school insists that scrapple is not scrapple but panhas masquerading under an anglicized name given it by our Welsh settlers. Have no truck with such unbelievers. Scrapple is scrapple and panhas is panhas. Both are of the gastronomic nobility in their own right; but they are not nor ever can be the same. Panhas is made by taking the broth left over after making liver puddin' and lacing with cornmeal and buckwheat flour. It contains no meat. It is cooled and hardened in pans, then sliced and fried like mush. Outside the true scrapple belt, eastern Pennsylvania, it is frequently fobbed off on the innocents as scrapple.

Every scrapple fancier likes his own recipe best. Here is mine, again all-pork: into a large vessel toss the head (not the jowl), the kidneys, the liver (unless you like it fried, when it equals calves' liver, or made into pudding), all the bits of skin and of boney meat that can serve no other purpose, and the cracklings that were strained out of the lard. Cover with water and cook until the meat 
falls off the bone. Strain off the liquor, remove the bones, and run the meat through the grinder. Return the ground meat to the liquor and bring to a boil. Now season to taste and then some, because after the seasoning is done there is a large volume of cornmeal and buckwheat flour to be added. It is the seasoning that makes or breaks a batch of scrapple. Some like it high, some like it low. With clean, fresh meat and home-ground meal it has enough distinction of its own to bear with mild seasoning. Mine is done with salt, black pepper, thyme and sage. When commercial meal is used undoubtedly some sugar should be added. When the seasoning is done boil up the mixture and add the meal. Two people are needed to do this: one to stir constantly, the other to sprinkle the meal in slowly and thinly by hand; if added in large gobs it will cook in a lump. The proportion is about three parts buckwheat to one of corn. Keep on adding meal until main strength can stir the mass no more. Then ladle it out into pans to cool and set. Fill the pans within a half inch of the rim; then if enough lard doesn't float to the top in cooling, more can be added to make a tight seal that will keep the scrapple fresh for three or four weeks. Dust thin slices in flour and fry in a little hot fat. Just before serving drop a poached egg on it. There's the stuff to grow hair on your chest.

The pigs legs are cut into two lengths; the 
knuckle end, with the tail, is best eaten fresh, boiled with sauerkraut. The feet are cooked down, the bones removed, vinegar, whole clove, and bay leaf-other spices to taste-are added, and a delicious aspic-"souse"-is the result.

So much for the fresh goods. Almost any part of the pig can be pickled and smoked. At Medlock Farm we confine ourselves to the hams, bacons, shoulders, jowl, and spare ribs. All these are packed in an oak barrel and covered with a brine made of salt, brown sugar, and saltpeter. Like the smoking, and contrary to general belief, the saltpeter has no curative value whatever: it is put in to give the meat its typical red color. The meat is weighted down with a bit of board and a stone, so it will all be covered with brine. It is left there three days per pound. A twenty-pound ham, for instance, will be in pickle sixty days. When removed, the bacons are soaked thirty minutes, the hams an hour, in fresh water. They are then ready for smoking.

The intrastate controversy over scrapple is nothing to the deathless war that rages back and forth across the Mason-Dixon line over the proper way to smoke hams. North of the line only a few dastardly renegades use hickory; all us patriots smoke with apple wood. However, as one expert points out dispassionately, any non-resinous wood will make a good smoke. When we began making our own ham and bacon we smoked it in the din- 
ing room fireplace, which would have been all right if the damper had been high enough to permit hanging the meat well up the chimney. As it was we had to use so low a fire the chimney never warmed up properly, and the back draft kept the dining room full of smoke. Then for a season we took our meat to a small near-by packing plant (Pennsylvania is thickly studded with little, independent packers) and got it custom smoked. The pure food sleuths ruled that out after one short year. Now we smoke in a hogshead that has the end knocked out of it. The fire is built outside, the smoke led into the barrel through a short covered trench, and the draft checked by a covering of wet gunny sacks.

Occasionally instead of smoking a ham we bone it and simmer it twenty minutes to the pound at one hundred and seventy degrees. Sliced down, this sort of ham usually retails at from fifty cents to a dollar a pound. It is fine to-as they say hereabouts -"eat along": meaning to sustain life between meals or late at night.

The experts make considerable pother about the proper way to preserve hams, after they have been salted and smoked. My own observation is that they-and all the other pork products-are a good deal like what I said a while ago about cold 'possum meat. We have never yet butchered enough pork to last over into the next season. But we have 
kept both ham and bacon through hot weather. Over the north wing of Tavern House is an attic open at the eaves. It gets fearfully hot but apparently this does not matter much: the important thing is the circulation of fresh air. In damp weather the meat gets mouldy on the outside, which does no damage if it is scraped and washed off before cooking. There is even one school of hamologists says a ham is not ready to eat until after it has grown its first coat of mould.

I started my piggery with two young animals, just weaned-a sow and a barrow. A barrow, to borrow Mr. Charles Browne's definition of a capon, is a boar that has given up hope. They came on the place in the spring of 1933. That fall we bred the gilt (young female pig), and we have been growing our own ever since. So far my investment in pens is nothing but time: they have been built of the scrap lumber that mysteriously and constantly accumulates on the farm, but I foresee a day when something different must be done. For at the present writing we have, in addition to the brood sow, five adult pigs-including one that belongs to my man-and eight sucklings. Two of the adults will be sold off, on the hoof, and the other three will be worked up, before the winter is out. Nevertheless the herd seems to grow steadily.

The explanation is that we have a good brood 
sow and pursue the Medlock policy of adequate feeding. During the gestative period, in addition to plenty of good feed, the sow gets a daily tonic: a tablespoonful of a $1 / 128$ solution of potassium iodide. This grows hair on the young, so that when they arrive they are well armored against. the weather.

If you, by chance, should contemplate growing your own pork, let me conclude these notes thereon with a caution: keep hands-especially little children's hands-away; a pig has powerful jaws and the hardest teeth in the animal kingdom. It is not a vicious animal, only heedless. And a brood sow is querulous and flighty. Let her be tended by the same person all the time; if she needs help at farrowing-pigs frequently have great pain and difficulty at birth-let that person be the one to nurse her. For a week or so after farrowing let no one go near her pen "just to look" at the young. After a sow has had six or eight litters-she may be bred twice a year-it is time to sell her to the pork butcher and start breeding from a young animal. 


\section{The Garden and Orchard}

IT was Lord Verulam who pointed out that "God Almighty first planted a garden." It is not a matter of record but a safe bet that He no sooner did so than $\mathrm{He}$ began to look about and mutter to Himself:

"Next year I am going to do this differently. ... Instead of putting man in the Neander valley or on the Pilt down I am going to put him along the Euphrates, there by the apple orchard.... And I am going to try a new variety: Neander does not flourish here. ..."

That has been the way of all gardeners since creation. For the perfectly satisfactory garden has not yet been planted and grown. Indeed the plain lesson of the Book of Genesis is that it is a task beyond even infinite power. This year's garden is no sooner started than you begin to plan improvements on it-next year.

It is impossible to make two gardens precisely alike. Even in the same soil, side by side and in the same year, they will vary. No matter too how carefully one plans and works his garden it never 
turns out exactly as anticipated. Not invariably, but with sufficient frequency to reduce the phenomenon to the level of commonplace, the crops most counted on turn out failures; whilst those of which no more than a side dish is expected burgeon and bear with a vigor and fecundity that nearly crowd one off the land.

Take squash. I mean, you take squash; I am fed to the teeth with it. Squash reminds me of the story about my great-grandmother and the tea. When the Tetlows came to America they settled in South Jersey. My great-grandfather who was, doubtless, as my mother says of all the Tetlows, "a little crazy," had the misbegotten notion he could make money farming in the pine barrens. The drinking-water supply for the new homestead came from a spring near the house. Upon occasion greatgrandfather complained that the tea was too strong. Next day his wife made it weaker, but it was still too strong. So the next day she made it still weaker, with no better result. This kept on day after day until finally came the day when she put no tea at all in the pot. Great-grandfather made a terrific row: the tea was still too strong. It turned out the spring water came from a patch of swamp cedars, and was itself the color of strong tea.

Squash is like that. Starting ten years ago I planted less and less of it year after year, and each year harvested more and more squash. It is a vege- 
table of which a little goes a long way at home, and for which there is but a limited market abroad. There came a summer, two or three seasons back, when having planted what I esteemed the absolute minimum we were inundated, deluged with squash, until even the pigs wearied of them, grown from the seed of the last year's fruit that had been left on the vine to rot. This despite the facts that squash is little more than a subtropical vegetable, and the previous winter was the most severe in the Weather Bureau's records. Sometime I shall take a leaf from great-grandmother's book and plant no squash at all.

The first and most important job in any garden is laying it out on paper, marking in each row the succession of plantings, calculating the amounts of seeds needed, and writing up the seed order. To do this the records of the last year's crops and plantings, as well as the copy of the last seed order, are extremely helpful. The order shows not only the quantity but the variety of each kind of seed bought. There are few garden vegetables of which the number of varieties is not legion. Not all varieties thrive as well on the same land. When we strike a good one we stick to it. If unsatisfactory we check the list and try a new one. Sometimes we try two or three new varieties in one year; I had to do that with melons and lima beans 
for years before we struck the right ones for Medlock Farm.

A vegetable garden is really three separate gardens: one for immediate use, one for canning, and one for winter keepers. It is hard to say which one is most important, but certainly the winter garden presents the most serious problem: such things as turnips, beets, cabbages and carrots are easy to raise and to keep, but green winter vegetables are something else again. Celery is hard to raise properly, still harder to blanch and store. So are leeks-a delicacy much neglected in this country. Endive, when it will grow at all-a thing I have not been able to make it do these last three years-is not quite so difficult. All these crops are slow in maturing, requiring long seasons and constant cultivation. On the other hand the raw green vegetables are of major importance in the winter diet; and they are expensive to buy: they are worth the struggle.

The canning garden is closely allied to the one for immediate use. Scarcely anything grows that cannot be put in a mason jar and kept indefinitely. We have tried nearly everything once: we have even canned squash. But a steady annual improvement in the winter garden and in fall-cropping the spot-use garden has gradually limited the variety of stuff we need to can until, this last season, 
we were down to two products: tomatoes and peaches. We still find it good policy to can as large a quantity as possible. You never know what may happen. One year a shortage of water, not enough to affect the crops, was yet sufficient to put a bad dent in the canning program. But we had a big carry-over from the year before that carried us well through the following winter.

Year in and year out tomatoes are the backbone of the canned-food supply. Their food value is equal that of the raw fruit; their flavor, in my opinion, superior. The crop is prolific, and of all the garden truck tomatoes are quickest and easiest to put up. As an instance of just how well it can pay you to grow your own food, last year, after two comparatively lean tomato years, I plunged on tomato seed. Instead of the usual ten-cent packet I bought three-of three varieties-for the staggering total of thirty-five cents. We sold some of the young plants-more than enough to pay for the seed. Of what were left we set out four rows totaling eight hundred feet. Once the vines reach a certain size they need practically no attention; within the memory of men now living they were esteemed but a weed; they still grow that way. Including harvesting time we did not dedicate, all together, eight hours' work to last summer's tomato crop. Yet we harvested, as nearly as I can calculate, something more than three-quarters of a ton. 
At the height of the local season tomatoes did not go below five cents a pound in the Philadelphia stores.

In the immediate-use garden the thing most often overlooked and neglected is the late summer planting for fall use. All those vegetables that require cool weather-lettuce, radishes, spinach, peas, and so forth-will flourish in the cool of fall quite as well as in the cool spring. Hereabouts our first frost comes in September, but the real severe freeze is usually deferred until Thanksgiving or later. Lettuce, Chinese cabbage, spinach, and such like will keep well into the winter if protected with leaves or litter. Which reminds me that a valuable adjunct to the early and late raw-greens crops is the water cress.

Midway of the fields at Medlock Farm is a shallow spring. In the summer of 1921 I planted five cents' worth of water cress seed along it. I do not think there has been a year since that we have not had at least five dollars' worth of cress from the bed; while the stream that flows from the spring has seeded water cress on our neighbors' farms from here to Norristown. And there is more than the mere monetary or physiological profit in that bed: there is the high aesthetic satisfaction that comes of walking through the fields of a cold March evening, when snow still lingers under banks and fence lines but the bark of the maples 
is reddening, to peer down into the hollow where the spring rises at a solid green carpet of cress floating in the icy water. There are 'coon tracks at the brink; perhaps you surprise a muskrat, or a bachelor quail bob-whiting his complaint that this early in the season his gal has shook him for another. If you stand perfectly still long enough in the dusk you may glimpse one of the timid deer that have lived on Medlock Farm since the drought of 1931 drove them down from the northern counties. Then to get back into the warm house, thaw your frozen hands, and return-Altheus-to the study of seed catalogs, those last baroque flowerings of that Elizabethan prodigality which is our speech's pride.

In the home-use garden most crops stay in the ground until they are used or grown too old for human food. Large areas of any kitchen garden are always thus occupied. The resultant superficial impression is that garden truck returns a very low yield per acre. On the contrary there is no more profitable use to which land can be put. The difference here between home-use and market gardening lies in the method of harvesting. The market garden, instead of-say-one row of lettuce in spring will be all lettuce. True enough, not every head will mature at the same time. But it will sell off as fast as it matures, and will all be gone in a week or-at the outside-ten days. That 
ground is immediately planted to another crop which in turn will all be harvested at one fell swoop, and so on throughout the growing season. Intercropping-planting between rows-is not practical in the home-use garden, where both rows may be left partly standing for weeks, and essential cultivation is impeded; in market gardening, when each crop is snatched from the ground the minute it matures, it is perfectly feasible. Thus not only multiple crops can be raised on the same ground at the same time, but where a home-use garden of high efficiency produces not more than two crops a year, the market garden will grow four or five.

With the increasing efficiency of our fall and winter gardens we have been able to can less and, consequently, sell more and more. A benign circle has been created: the more we raise for winter, the more we can sell in summer; the more we can sell, the more we can grow without taking more acreage into the truck patch-a consummation to be avoided: the eternal temptation of the vegetable garden is to plan and plant more than you can care for.

As with everything else on the farm there is no comparing store-boughten vegetables with fresh ones. Many perishable fruits and vegetables cannot possibly get to town in prime condition since they must be picked before they are ripe if they 
are to stand up on the haul to market. Of others that may be ripened it can be said the processes of chemical change and decay start the minute they are plucked or uprooted. Of these the most spectacular is sweet corn. They tell me that two hours after it is picked ninety per cent of its sugar has turned to starch.

I wish I could speak of the miracles we have wrought in hotbed and greenhouse but alas I can not. It is said land under glass is fifty times more productive of money crops than open ground. I can believe it. Glass is certainly the solution of the raw winter greens problem. For with no more than the two-sash hotbed in which we start tomato, pepper, and other seedlings, we can eke out the fall lettuce supply until after Christmas.

Closely allied to the garden is the orchard. There is indeed a twilight zone of vegetation not readily assignable to one or the other. What is rhubarb: a fruit or a vegetable? Or need we not debate such niceties? Strawberries, rhubarb, and such cane fruits as raspberries, blackberries, currants, and gooseberries are usually assigned space in the vegetable garden. Save when they are set out in rows and cultivated like vegetables, grapes usually occupy a somewhat snooty position in an arbor of their own, between garden and orchard. For the rest, here in the latitude of Philadelphia, 
when we say "orchard" we mean a collection of fruit-bearing trees.

Experience long ago showed me it is not necessary to lay out large sums for matured berry plants. The cane fruits can be multiplied rapidly like climbing roses, by turning down and re-rooting the canes. The new canes can then be cut loose from the parent stock and transplanted. Currants, gooseberries and grapes are propagated by taking cuttings six or eight inches long, from new wood, in the fall. These are heeled-in half their length and covered with litter. By spring roots have sprouted from the buds held underground. Strawberries multiply by throwing out runners, which can be detached from the parent plant and set out on their own.

Like most old farms mine contained its quota of run-down fruit trees. In some such cases the fruit of the older varieties is so inferior that rehabilitation does not pay. I can count four apple trees, three pear, and one pie-cherry that have responded well to treatment (one of the pear trees yielded nearly a thousand pounds of fruit year before last). But mainly we look to the new orchard -which should have been set out ten years earlier -for our fruit supply.

If the battle with insects and fungi in the garden is fierce, in the orchard it beggars description. Unless you spray, spray, spray all the time there 
is no chance of having good fruit. Spraying can be done with rented equipment and contract labor. Having tried it, I know that here is one place where it is better to own your own machinery than to hire the job. All spraying must be done at just the right time-especially that done after the leaves and blossoms form up. That time is of course practically the same for all fruit trees for miles around. But it will not be the same for all kinds of fruit. Hence on the one hand there is no certainty the sprayers will reach your farm on the right day, since their work is crowded into short seasons; on the other, if the job is to be done thoroughly, they must come back three or four times for each spraying, as buds, blossoms, and leaves unfold on various kinds of trees. Further, a change of weather may necessitate a spraying's being repeated within twenty-four hours if it is to be effective. Altogether, no nurseryman can give the kind of custom service a home-use orchard needs, at a price it can afford.

Not the least important place on the farm is the flower garden. Without flowers there would be small joy in the country. A priest once tried to explain to me the theological distinction between a miracle and a mystery, but I still stick to my story: the flowers are the greatest miracle on earth. Just why one seed should turn out a radish, the next a head of lettuce, is somehow not so remark- 
able; but that the third should grow into a snowy sweet pea, the fourth into a scarlet zinnia or bronzed snapdragon, beats me. Miracle or mystery, we try to have some flowers every month of the year. Next to children nothing livens up a house like flowers.

Without a greenhouse our winter flowers are limited to potted plants and bulbs. But seven months of the year we have the flowering trees and shrubs, the borders, the space-fillers around the house and out-buildings, and a not-so-awfullyformal garden,-a "look piece" as our Tudor ancestors may have called it-that, however modest its beginnings, we hope some day may approach the garden Francis Bacon so graphically describes. The permanent cadre of this formal garden is composed of the perennial root and bulb plantsiris, phlox, peonies, delphiniums, roses, and the like. It is backed by a grape arbor that, until the Japanese beetles were sent to plague us, afforded outdoor privacy in those months when it is better to live out of doors. On the north side of the garden is a grove of self-seeded pie-cherries. From time to time the ranks of the perennials are augmented with seedlings of annuals thinned from the number two flower garden. But its chief fault continues to be that implied by Ruth Draper in one of her monologues: everything in the garden will not bloom at the same time. When the peonies 
are in bud the iris are dying-and so on through the year.

Garden number two is planned and planted in rows like a vegetable garden. Its function is to supply cut flowers for the house. We have found it better, rather than try to have too great a variety, to make sure of having something in bloom each month from early spring until killing frost. A twenty-five-foot row each of tulips and jonquils, of sweet peas, corn flowers, baby's breath, love-ina-mist, scabiosa (who would willingly so dub the lovely "mourning bride"?), zinnias, gladioli, dahlias, cosmos, marigolds, and asters make a nursery and cutting bed that supply the formal garden with plants, the house-and customers-with cut flowers from May until October.

Here, too, rather than in the vegetable garden, we grow the herbs-parsley, dill, sage, summer savory, and tobacco-because of their aromatic habit. There is only one scent finer than that of the flower garden on a humid midsummer evening: that is the crisp, harsh odor of the celery and cabbage what time you start out after pheasant on a cold fall morning, with the sun blood-red in a dark southern horizon, the pink and yellow maple leaves falling silently through the pale light as they fall in the last act of Cyrano. That is a thing for a man to have seen and smelled in his time. 


\section{Planning Side-Line Produce}

WHEN we set out the new orchard we dedicated a space to sugar maples. They are set twenty feet each way, even though the productivity of a sugar tree is in direct ratio to the spread of its top hamper. Sugar maples are perhaps the world's slowest growing tree; by the time these are of productive size storm and disease will have thinned them out. By that time, too, we will be, if not pushing up the daisies, tottering along with one foot in the grave. One may therefore ask: Why plant them? Well ... of all human foodstuffs sugar is the hardest to produce in the temperate zone. Perhaps those who come after us may find it still harder. Meantime some thoughtful genius may devise a simple and practical contraption for home extraction of corn syrup. And while we wait, we yet have maple sugar.

Maple sugar is one of those things the truth of which is kept hidden in the forestry text books. Save the above-mentioned saplings there is not a sugar maple on Medlock Farm. That is no bar to having maple syrup and sugar, for the truth is 
that any maple tree produces good sugar sap. At the back of the house are half a dozen silver maples. Come February we nick them to see if the sap has started to run. If it has we drill holes breast high on the south side of the trees, insert the fourinch lengths of pipe supplied by the plumber, hang up the buckets-and off we go. The rest is easy.

Silver maples are actually bigger sap producers than sugar maples. The difference lies in the quantity and flavor-which is different, but not inferior to the sugar maple's-of the sugar content. For all I know, there may be countless trees outside the maple family that produce good sugar sap.

This thing of maple sugar is analogous to the hoorah over cane sugar thirty years ago. If you are old enough to remember the ballyhoo that preceded the passage of the Pure Food and Drug Act of 1906 you will recall that glucose was anathema; the very thought that manufacturers might use it to sweeten canned and preserved foods swept waves of horror and indignation across the country. Unless I am mistaken it is still unlawful to introduce it into manufactured foods unless you admit it on the label. Yet what is the truth about glucose? The truth is that before the human frame can assimilate cane sugar it has to convert it into glucose.

But to return to the trees. As soon as the truth about sugar maples was made known to me I 
stopped setting them out. Silver maples grow like weeds hereabouts and reach productive age in half the time it takes a sugar maple. And to my taste their syrup has far more character and individuality. There may be, as Huck remarked on a memorable occasion when he was a guest of the Grangerfords, no early breakfast like cold pork and greens, with corn bread, butter and buttermilk. Maybe. But of a cold mid-winter morning give me home-grown sausage, with whole-homeground corn batter cakes, home-made butter and home-made maple syrup.

So far we have concentrated most of our bucolic attention on food. That is as it should be because it is the most important thing the land produces. But it also yields a number of useful non-edible things. Up to now I have given small attention to them. The woodlot, for example, has not gotten beyond the firewood, fence post, and beanpole stage; there is a lot of lumber waiting to be worked up whenever we get the equipmentfrom the mail-order house-and feel the need. Year for year, the experts say trees pay out better than grain crops. The state stands ready to help all who wish to re-forest land; many of my neighbors have taken advantage of this with satisfactory results. So far I have limited forestry to the six-acre woodlot and a policy of never cutting down a tree until 
I am sure there are at least three more coming along to take its place. Never mind where they are; if in a fence row all the better. For it has been demonstrated that even though crops will not flourish close up under the trees in a fence row, nevertheless the adjacent measurable difference in moisture content and soil fertility more than justifies the trees.

There is a good deal of difference between a timber forest and an ideal farm woodlot. The latter must serve a variety of needs. The more different kinds of wood it contains, the better; and there should be trees of all sizes and ages, so that the production of available material for various uses will be steady. Our biggest single need is for firewood. Although we use four fireplaces pretty steadily from early fall into late spring we have seldom had to cut up a whole mature tree for fuel alone: weed trees, fallen trees, and the topwood of trees cut for posts or other purposes supply ninety per cent of it.

We also have a small but steady by-product of hides, which are at present going to waste. Kephart has directions for home tanning with natural materials. There is a government pamphlet on how to do it with chemicals. But my few attempts have been abortive; tanning, in my opinion, is one of those things that a smart, up-to-date chemist could give his attention to with benefit to the home- 
farmer. Custom tanning will produce fine leather but is too costly to be of practical use.

Where there are hides there also are hair and wool. Most freshly transplanted urbanites, or countrymen of the nuts-and-berries school, are intrigued by the textile side of home farming. I have a spinning machine, and I have wool. I have tried washing, carding, and spinning. Without proper equipment the time that can be expended on the first two operations is out of all proportion to the possible return-in-kind. I was once offered a dollar a pound for home-grown, washed, and carded wool. It sounded like a lot of money. With zeal and a considerable quantity of spare time to consume, I set to work. At the end of an afternoon and a long evening my study was two to three feet deep in the little cigar-shaped rolls of wool that come off the carding bats. Perhaps it would be a good idea to weigh it up-no use doing more right then than the customer would take. I packed all that wool in a tailor's box and put it on the scales. There were four ounces of wool in it. My time was being repaid at something less than a nickel an hour.

Spinning time-and weaving time-might pay if done with home-grown materials, providing some efficient means of preparing these were devised. We can grow flax as well as wool here. But from what I read of its preparation for the loom 
the labor content of linen would be as high as or higher than that of wool. Dyeing would not be so bad: the woods and fields are full of good natural dyestuffs. Spinning, or weaving, from boughten raw materials I cannot see as a paying proposition. One enthusiast for the loom tells of a home-woven suit: “The yarn cost $\$ 4.50$, the tailoring \$30. I had it appraised by various socalled experts at the time, and they valued it all the way from $\$ 60$ to $\$ 90 . "$ Fine-if you are accustomed to buying sixty- or ninety-dollar suits. But "at the time" I read that my ready-made suits were costing something nearer thirty-four; and I was not buying them in dozen lots. Clothing-even in a seventy-five per cent feminine household-is relatively so small a part of the total essential budget that it seems to me time spent on it is almost as ill-advised a reversion as it would be to take out the gas furnace and try to heat and cook by open fires.

On the other hand there would be both rhyme and reason in the production of soap. The farm uses a lot of it. I have kept book on kitchen soap and find the general average, which rises in a sharp peak during pork butchering, is a pound and one-half to two pounds a week. This is almost all bought as boxed flakes or chips that cost about sixteen cents a pound, retail. With lard, beef-, or mutton-tallow and a can of commercial lye you 
can make good soap for a cent a pound or less for boughten material. Or you can save and slake wood ashes and make it without any money outlay. If fresh animal fat should be lacking, a grease trap on the sewage system would salvage more than enough that could be reclaimed and used for soap -to the benefit of the disposal plant.

Tobacco is another non-edible product (in most parts of the country) that promises to pay out in a big way, though I am not yet prepared to speak dogmatically. The proper way to bring tobacco from the stalk up to good smoking condition is one of those things about which directions are hard to find. After the leaves have been stripped from the plant and air dried in the barn or attic they have to be packed away in a keg or crock and fermented. In the spring they ferment again, like wine. Thereafter as near as I can learn, they are ready to use. I fetched my first crop up through the second fermentation-then accidentally lost it. Meantime a season had come and gone without my planting a second crop. This year's planting, however, promises well. I reckon there should be enough finished goods to keep my pipes hot a twelvemonth-all from ten cents worth of seed. With just a little more care in setting out and tending the plants there would have been twice as much.

There are still a lot of things in the realm of 
foodstuffs we have not yet given our attention. During Prohibition we made sporadic attempts at wine, never with any real success. Wine making is not easy. It evidently requires a combination of good direction and a flair. Of late years the Japanese beetles have so depleted the grape vines that what little crop we get is dedicated to unfermented grapejuice, and jam. Cider, perry, and vinegar are all usable by-products. However, we have seldom -as yet-enough apples or pears to spare from canning, jelly, or apple butter.

Save for corn, we do not yet grow our own cereals. In view of our wide and varied diet very little wheat flour would be needed to supply our household: according to the findings of the Bureau of Home Economics about one hundred and fifty to seventy-five pounds a year. Therein probably lies the main reason why we have not grown our own. Since it is not a big factor in the diet, it would hardly pay to hire a reaper-and-binder and a threshing machine for our small needs. Of course it could be done with a cradle and hand-flail, but that looks like a lot of hard work for flour at five or six cents a pound. The sensible solution would be a planting big enough to justify the contract labor, with part of the grain crop, and the straw, used on the livestock. But that will have to wait upon adequate rat-proof storage for the grain.

Bees, and honey, are another incidental I look 
forward to with the keenest pleasure: bees do not have to be fed.

There is still lots of room for expansion in the poultry department. We have kept a few ducks for years, and since the earliest times a flock of scrub pigeons has condescended to live in the barn. They make it up to us by contributing an occasional pair of squabs. Ducks are very satisfactory meat critters; they are prolific and quick-growing. Like chicks, the young flourish on wire better than in the open. They do not require open water; in fact, the meat is better quality if they are kept away from it, although they do say a breeding flock is the better for it. I have never raised either geese or guinea fowl, but suspect if turkeys, ducks, and-as per the performance of the state game farms-pheasant and quail are amenable to modern mechanized hatching and brooding they would respond equally well. I have incubated and brooded turkeys in my cellar factory with excellent results. Turkeys are generally esteemed the world's stupidest fowl: they literally do not know enough to come in out of the rain. Pre-maturity casualties under natural conditions are appalling. Under mechanization they drop to the same level as chickens. Another source of turkey casualties but lately revealed by research is a disease called the blackheaded worm. It is deadly to turkeys; but chickens have an immunity to it and are carriers of it. 
Proper housing, segregation from the chickens, and sanitation are ample protection against this whilom scourge.

The most neglected meat animal in North America is the rabbit, or is it the hare? It is an extremely efficient meat producer: confined rabbits reach maturity, for the table, in something less than half the time of wild ones. The meat of the domestic rabbit is all white and tastes like a cross of spring chicken on frogs' legs. I have raised rabbits but closed them out against the day I could do it right: they require a somewhat special set-up for the most efficient production. The bucks fight to the death when housed together. Yet a mated buck cannot be left with the doe, or he will kill the young out of jealousy. Altogether a pretty difficult fellow. Another thing rabbits need is absolute rat-proofing: rats will gang up on the doe, just as they will on a mother duck, and kidnap her young.

Wild life, both animal and vegetable, is no small contributor to the family board. An intelligent conservation and protection policy has enormously increased the game supply in Pennsylvania in the last twenty or thirty years; it is said there is more game in the state now than there was when the Swedes landed. Thirteen weeks of the year there is some sort of gunning. A little more attention to it than I give would provide not only 
plenty of rabbit, pheasant, quail, 'possum, and 'coon for fresh eating, but also a sufficiency of deer and bear to salt and smoke. Outside the game seasons such animals as the woodchuck, rated no higher than vermin yet one of nature's finest delicacies, bolsters the fresh meat supply. Not much progress has been made in the state against the entrenched industrial interests that convert our streams and rivers into open sewers. Nevertheless there are still some fish to be had; in spring the near-by Delaware offers shad and herring in quantities and at local prices that make salting worthwhile.

Of edible wild fruits and vegetables there is almost no end. If you are particularly interested in this subject I commend you to Kephart's ${ }^{1}$ chapter on it, which I shall not spoil for you here. Sometimes it seems to me we neglect this side of the food supply; yet a tabulation of the wild stuff we regularly and habitually use presents a rather astonishing total. In the spring there is the dandelion, much in favor as a salad with a hot baconfat dressing; and the most successful of our assays in the field of beverage alcohols. Dandelion wine is not the sort of thing one could or would drink by tumblerfuls. It resembles a pale, sweet sherry, and makes an acceptable "cake-and-wine" drink;

1 Horace Kephart, Camping and Woodcraft, New York, Macmillan, 1927 . 
while for cooking fresh, home-grown foods whose delicate flavors would be assassinated by a Spanish brew it is a splendid seasoning.

In the same season we eat poke sprouts. The poke is an annual bush that under favorable conditions attains a height and spread of eight or ten feet. It bears small purple berries that are held to be poisonous in this vicinity, although Kephart says it is not the berry but the root that is deadly. When the young plant sprouts are a foot high, or less, they are cut just above ground and cooked like asparagus, for which they are a substitute so satisfactory that the poke has been exported and domesticated in France.

Later in the year, usually in early August, we enjoy prime blackberries in such profusion that we never domesticate them; and of course before them there are wild strawberries for anyone who has a solid working day to devote to picking a teacup full. With the first hint of cool weather the mushrooms make their appearance; given the right weather they will be with us until close to Thanksgiving. No one who has once tasted a wild mushroom will willingly go back to the cultivated kind; the flavor of the wild variety is such as to create an illusion that the domestic has no taste at all.

It is said that only a scant few of the fungi are deadly poison. When I was in college I ate some pretty fearful looking things that my room-mate's 
mother used to pick in the woods behind St. Remy. But she knew her fungi. Without such expert help my policy is to let severely alone not only the unknown but also those of which there may be any doubt whatsoever.

After the first two or three hard freezes there is a battle of wits 'twixt us and the 'possums to see who will get the persimmons. It is "only very seldom" we win; the 'possums take a mean advantage of us by camping right at the trees. From time to time we balance the score by getting the 'possums. 


\section{The Household Chores}

LET us now, after a brief but comprehensive glance at the farm, see how it affects the household. For it is in the house that all the work and all the planning on the farm culminate in a grand final crescendo.

Except for the business of caring for milk and cleaning the dairy utensils, the only household work that is distinctly traceable to the farm is the care and preserving of foodstuffs. When I say "household work" I mean the kind of task generally presumed to be woman's special province. And I make that statement after long and earnest communion not only with myself but with the other three-quarters of my household. If we abolished the farm as a productive enterprise tomorrow, canning, pickling, preserving, dehydrating, and the like are the only definitely farm chores of which the household would be relieved.

There is no peak season for the preservative function; it goes on all the time. For the sake of chronological clarity let us start in the spring. As soon as surpluses of vegetables or fruits begin to 
appear canning and preserving start. At one time we began with asparagus, which is harvested while the rest of the land is still bare. Since our finesse with winter keepers has improved, the strawberry is more likely to command what the exponents of business English call "our early attention." You can say or think what you like about the strawberry; in my opinion as a fresh, raw fruit it is a delusion and a snare unless "sugared down" overnight-and then it is no longer strictly fresh. In common with almost everything else in gastronomic nature, it takes a little sugar to bring out the best that is in it. There is not only the nostalgic characteristic that obtains for all sugar-preserved fruits and vegetables, to give strawberry jam its distinctive flavor; there is in it the accurate concentration of the true essence of strawberry. So we start making jam as soon as strawberries are ripe, and from then until frost cuts down the vegetation in the fall we are intent on canning and preserving.

Almost everything in the vegetable kingdom is preservable. For a safe, successful, and lasting job most things must be cooked at higher than boiling temperature or else conserved in sugar or salt. Canning-that is, preservation without condiments -is therefore best done in a pressure-cooker. This is a heavy aluminum kettle that will hold a number of mason jars or an even larger number of 
tin cans (it is perfectly feasible to can in tin at home: vide the mail-order catalogs). A quarter of an inch of water is put in the bottom of the kettle which is then loaded with jars. A heavy aluminum lid is bolted on securely with a strong collar. A petcock in the lid is turned wide open, the heat under the kettle set full blast. When all the air has been driven out and only steam remains in the kettle the petcock is closed. The rise of temperature within the kettle is thereafter indicated to the uninitiate by a thermometer, to those of us who belong to a vanishing civilization by a "pressure gauge." Once the cook-anywhere but on a farm it would have to be a licensed engineer-has brought the pressure inside the machine to the desired stress it must be kept there for varying lengths of time, according to what is being canned. When the cooking-i.e., sterilizing-is done the machine is allowed to cool down until it can be opened without scalding the operator; it is then opened and the jars are removed and sealed tight.

There are two other advantages in pressurecooking beside that it makes for better preservation. One is that with certain vegetables the total time for preparation and canning can be cut considerably below open-kettle canning. This applies especially to such things as corn that take hours of boiling by open-kettle, and then probably will not keep; it is not true of tomatoes, or fruits that 
are canned in sugar syrup. The other is that in kitchens employing some form of gas or other controlled heat, pressure-cooking permits a great saving in fuel. Once the desired temperature is reached inside the cooker the fire under it can be turned down and down almost to extinction; a saving not only in fuel but also in wear and tear on the human frame, since the temperature of a summer canning kitchen can be something ferocious.

A decided disadvantage of the pressure-cooker is that it needs watching. Those of us born in the age of steam still have a wholesome respect for boilers; the modern housewife may be able to go about her business and leave the cooker running, but not me. Even though the safety valve, pressure gauge, and thermometer are not apt to go out of action simultaneously, I still am taking no remotest chance of being blown to kingdom come by a piece of flying metal; I definitely gave all that up in November, 1918. And there is another good reason for keeping an eagle eye on the doings, whatever one's regard for life and limb: once the desired pressure has been reached it must be maintained evenly. Wide fluctuations spoil the batch. With the steadiest heat in the world this can only be done by keeping an eye on the gauge and a hand on the throttle. Hence, while the cooker is in operation the canner must either drop entirely 
or materially slow up the preparation of the next batch. And in any canning job preparation is three- or four-fifths of the work. When two or more people are working together, one person should be definitely assigned to watch the cooker.

To say we canned two hundred and fifty quarts of tomatoes, tomato juice, peaches, pears, and apple-sauce between the twenty-third of $\mathrm{Au}$ gust and the seventeenth of September sounds like a fairly big assignment. I do not mind saying we are glad when it is done. Not all of it has to be done at once. The crop does not mature that way. What we do is allow it to accumulate until an empty evening or week-end, then knock out a big installment; when you get production rolling it goes much faster than when you do a small lot at a time. Altogether we did canning on only eight days in that month.

Since it takes a lot of time whether you do it in large or small batches, the important question about canning is: Does it pay? In a previous chapter I mentioned a bumper crop of tomatoes in 1937. When we were canning it I made some cost records on it. Quart jars were four and one-half cents apiece, retail. Good glassware will last four or five thousand years; but allowing for breakage and replacement every nine years-and ignoring the fact that a lot of jars are used twice a year, in the summer for vegetables, the winter for meat- 
the write-off would be one-half cent per quart. Tops must be replaced oftener, say, every two years; rubber washers every time the can is refilled. Allowing for these, and adding one-third of a cent for fuel and water, the total cost per quart would be two cents. (Do not forget that the costs of planting, raising, and harvesting were more than covered by cash sales of fresh tomatoes, and that throughout the season we had all we could eat fresh ourselves.) At the close of the season when canned tomatoes are retailing at their low for the year, four number two cans were advertised by one of the local chains for twenty-five cents. This works out to seven cents a quart. The labor profit on canned tomatoes was therefore not less than ten dollars for two hundred quarts. Reckoned at the end-of-the-year store price for canned tomatoes it was sixteen dollars. On fruits it was, of course, much higher.

When all this is translated into hourly wages it is not impressive: somewhere from fifteen to thirty-five cents per hour. But to me it matters not so much how well it pays, since it does pay something for time not otherwise gainfully employed, as that it is not cheaper to buy canned tomatoes than it is to put them up.

It is not so easy to make accurate computations of jams, jellies, and preserves as it is of canned goods. The best I can tell you is that we do as 
much as we are able of every crop as it comes along; and that we use all sorts of odds and ends of glassware as containers. The total may range from one to two hundred glasses a year. The variety is infinite.

The canning and preserving season slacks down with the first frost. Thereafter until winter the important jobs are the storing of raw fruit and vegetables. Kraut must be cut and set to cure, cabbages and the root crops buried in outdoor pits, apples, pears, onions, and such semi-perishables as peppers and pimientos-that will keep, if rooted up plant and all and hung in a cool cellar, for several weeks-must be stowed away in the house. House plants that have been set in the garden beds to stretch their cramped limbs through the summer must be re-potted and brought indoors. Herbs are gathered and hung up to dry. All these are farm, as distinguished from domestic, chores. Unless a veal calf should unexpectedly intervene there is no more canning and preserving to be done until a week or so before Christmas, when the pork season opens.

Lest the reader receive a wrong impression let me here pause to say we are not always perfect in the execution of these household duties. It is not unusual to have a batch of fruit or vegetablesoccasionally even meat-spoil before we get around to preserving it. As I pointed out in the beginning 
of this work it is sometimes more fun to be not too efficient; especially if inefficiency can be condoned by the reassurance that spoilage is never all waste: what the household can not use, the pigs and chickens will.

All this talk about food has doubtless created the illusion Medlock farmers are prodigies of gluttony. It must be remembered we are, throughout this book, talking of food in terms of a year's supply. While we have healthy appetites, perhaps better than average for the whole United States, yet we do not pretend to approach even remotely the merest novice at such a board as, say, the hotel in Shartlesville-"up behine't Reading"-where the frailest will work through twenty or thirty different dishes at a "pick-up" supper. Two hundred pounds of pork, or two hundred quarts of tomatoes, sounds like a lot; spread out over a year it is not ten or twenty ounces a day.

An important point is how the wife and mother feels about all this. How does she like canning and preserving? How does she like having to create meals out of what happens to be around?

Mrs. Tetlow and I have discussed this aspect of farming for home use, backwards and forwards and up and down, not only with particular respect to ourselves but also as it might apply to others. Our first and major conviction is that if homefarming is to work for two, then two must work 
for it. There would be small incentive for one alone to keep the home-farm running if the other merely sat by and applauded or did only the pretty parts. As in any joint enterprise the spirit must be willing and right. On a camping trip, unless all hands show an equal willingness to pitch in and get the job done, unmindful of whose turn it is or what part of the total work each is doing, there will be friction and trouble. The fact is, I do a big part of the canning all by myself; and I help out with all the rest because, among other reasons, a man's wrists are stronger to close a mason jar top tight. Whatever heavy work crops up and intrudes on the household that is not done by the hired man falls to me.

The domestic aspect of our experiment has been complicated by the fact that during most of the time we have been working at it we have been without house servants; part of the time from necessity, but mostly because good ones are increasingly hard to get. There is much to justify the opinion of the do-gooders that house servants are underpaid and overworked. Yet there is the opportunity for intelligent people to earn good money at domestic service-the few good servants I have known were, I have noticed, always extremely well-paid both in money and in living-inkind-provided they have, along with the capacity, the patience and means to learn the job. Of all 
the skilled occupations it is the one for which least preparation is available, or expected.

A poor servant is worse than none. Repeated check-ups have convinced us that the total sum of wages and maintenance for such a one should at least be doubled to cover waste and breakage. To hold these to a minimum a poor servant must usually be watched like a cat: meaning that there is little actual liberation of time involved in employing one. A first-rate house servant, one that could get on with the work without constant instruction and supervision, would pay out at least as well as an extra outside hand. Mrs. Tetlow would have more time to devote to what for lack of a better name must be called "constructive" activities; the money spent on such a servant would re-appear in a better farm balance sheet. But try to find one ...! !

Of all servants the hardest to find is a good cook. Here again Mrs. Tetlow and I are in perfect accord: it is better to do without one altogether than to submit to the gastronomic indignities of a poor one. It is one of the most interesting sidelights on farming for home-use that it greatly simplifies the whole culinary problem; of the domestic servants that we could use, the best of cooks would contribute least. The simplification comes of the superior quality of home-grown food. Anyone who has ever gone fishing will understand 
this. It is not necessary to anoint a good, fresh fish with sauce meunière or marguery; it is not even desirable. For your truly fresh fish has a delicate flavor all his own that will be smothered in such concoctions. Thus, too, on the home-use farm the simplest recipes are the best.

The most serious mistake we have made at Medlock Farm-so far-has a bearing on this whole matter of domesticity. We made it before we began farming for home-use, but that does not right it. When we first moved here we found the kitchen in what is now my study. The north wing, in which the colonial kitchen had been situated, was destroyed by fire at some unrecorded time; when it was rebuilt in makeshift fashion the kitchen was moved into the main body of the house. Back of this room ran an open gallery. When we restored the north wing we put the kitchen in it. As a study, the room I now occupy is not large; as a kitchen it was enormous. It involved hours of waste labor and miles of useless walking. The new kitchen goes to the other extreme. As a room dedicated solely to the preparation of meals it is ideal; but as the manufacturing center of a home-use farm it is a washout.

To correct the error it would be wrong to enlarge the present kitchen. What we shall do some day is build something that every home-use farm should have: a separate building, housing on the 
ground floor a proper milk house, built according to specifications of the state law, and a room equipped for canning, butchering, pickling, and the like. The second floor-entirely isolated from the first-will be designed for the occupation of incubators and brooders. Such a house will save a lot of the waste motion currently involved in clearing the kitchen for a job of farm work and then clearing up the farm work to make way for cooking. 


\section{A' Babbled of Green Fields}

WE moved to the country originally because I was able to convince my wife it is the place to bring up children. When I say "country" I mean country-not suburb. When we came here Tavern House stood on an unimproved road; when a wagon or a car went by it was an event. The nearest railroad station is two miles away. One reason we were able to buy the place cheap was that the public did not yet fully realize the automobile had freed commuters from enslavement to the common carriers. As recently as 1920 suburban real estate advertisements always carried some such line as "two minutes' walk to the station" instead of "two-car garage." It is none of our business, yet amusing to recall how zealously the railroads cooperated with the automobile to help it take the cream of their business; only in the last seven or eight years has the line on which I do most of my riding permitted commuters to park their cars in station yards along the right of way. Although two of us can drive in much less than three hours from Tavern House to the Canal Street end of Holland 
Tunnel for a total cost including tolls, insurance, and depreciation on the car of a dollar and eightyfive cents apiece; and although the railroads have been able to make the New York-Philadelphia run in much less than two hours any time these last twenty years, it is only in the last three or four that they have scheduled faster trains, and little more than a year since with the greatest reluctance they reduced their fares.

For a long time the country remained a strange and fearsome place to my poor wife, who was brought up in the city. I taught her how to use a pistol, and in later years she has confessed she often carried it with her from room to room as she went about her household duties. No doubt to anyone accustomed to neighbors at arm's length there is an eeriness about the country. But it is a sensation that soon wears off. Today her attitude toward the country is accurately expressed by the fact that, returning from one of her brief, infrequent visits to the city, she flung herself down exhausted and exclaimed:

"I declare the city is a madhouse. I do not know how anyone can stand it."

As I said in the last chapter, a home-use farm will not work unless everyone works at it. Inevitably my wife does a lot of what are strictly farm jobs. She takes care of the milk and the dairy utensils, which is the thing to do if you want to be sure 
beyond peradventure they are clean. She feeds and waters the chickens and gathers the eggs at least once, sometimes twice, a day. She grades eggs, or picks fruit, or makes jelly, or cleans a chicken or duck, or helps at scrapple- and sausage-making. I could not list all the things she turns a hand to, from selling surpluses to dosing a sick pig.

It makes for full and strenuous days. But neither so full and strenuous as, on the one hand, to preclude a normal amount of recreation and diversion, nor, on the other, to sink to the dead level of drudgery. We both believe-we may be wrong-that the average inexperienced woman thinks farm life compounded of drudgery, monotony, and loneliness. We are equally sure that at least an equal number of women, here in the United States, hope to get through life without ever doing an honest day's work. Of them let no man speak. Comparisons should be made rather with the conscientious city housewife or the business woman.

The feminine bogies of drudgery and loneliness are a lot of tingle-tangle-certainly as far as this part of the country is concerned. True, our nearest neighbor is all of a hundred yards away, instead of being fenced out by a party wall. In the east it is pretty hard to get further away from a big town than we are unless one goes into the woods and prepares to make farming a profes- 
sion rather than the avocation that is my thesis. Any woman who drives a car is as centrally located in the country as, for the most part, she can be in town. Indeed, there are parts of any big city less accessible than the neighboring country; I can show you sections of Philadelphia from which you need more time to reach the corner of Broad and Chestnut streets than you do from Medlock Farm-especially in winter.

We have been snowed in once: the first winter we lived here. In those days Skippack Pike was still a county lane. Since then it has become a state road. Snow is cleared off or broken through as fast as it falls. The country roads are always cleared and navigable, while save for a restricted section in the center of the city, and in the car tracks, Philadelphia may be-often is-impassable for days.

We soon learned it is poor economy as well as inconvenient to operate only one car. We did it for over a year. One car, even though some of its trips may be shorter-as when it hauls the mister to a commuting station instead of all the way to work-must double up on so many runs that its total mileage will be greater than that of two cars combined. It wastes valuable time and it puts three members of the family at the mercy of the fourth. Now that both our daughters are old enough to drive we could do with three or four cars, if convenience were the only consideration. But before 
we take on more than two we will see about a trailer for farm hauling. The mail-order houses sell knock-down metal parts for trailers that are easily and cheaply assembled. There is a lot of incidental hauling on the farm that is not heavy enough for hiring outside help yet is sufficient to be hard on passenger cars. A trailer beats a truck on taxes and liability insurance.

Farm drudgery is one of those things we have all heard tell of. Except in isolated communities or on professional farms operated with limited capital, there is no reason for it. It is a legend, fostered by those with the wit and will to escape it. Like the thesis no woman should work if she can be spared, or the illusion that Education Conquers All, it is a hangover from pioneer times. Those of our forefathers who still harbored race memories of illiteracy sheltered in log huts and dug-outs might understandably promulgate such mistaken notions as "I never want any child of mine to work as hard as I had to work." But to suppose, because they fled to the city to escape drudgery or seek education, that therefore backbreaking toil and illiteracy are still the rural lot, is to suppose what is not so.

A lot of housework is drudgery. But there is not a single city device for its mitigation that the country wife cannot enjoy. Most such mechanical aids depend on electricity for power. Where elec- 
tric lines have not penetrated it is possible to generate your own power with internal combustion engines. Electric light, hot and cold running water, "in-door" plumbing, vacuum cleaners, mechanical refrigerators, gas or electric stoves, dish washers, and washing machines will run as well in the country as the city. Mind you! I do not say professional farming can be made to pay for all such luxuries. I should say it is extremely doubtful that it can. But the luxuries are available for any rural family that is for the most part supported by some sort of urban occupation.

In the countryside surrounding a city the size of Philadelphia-and doubtless elsewhere-all the city services reach to the farmhouse door. Four milk, three bakery, two ice, and two paper routes pass by Tavern House, all ready and anxious to serve us at instant notice. We have the further advantage of services unknown to the city: two butchers regularly use Skippack Pike, cutting and delivering meat from the back of the truck; the itinerant sheep-shearers and feed-millers reappear at stated intervals. The nearest general stores are half a mile in one direction, a mile in the other. All Philadelphia department stores and the mailorder warehouses make door deliveries miles out beyond us. A telephone call will bring a taxicab from the garage or a case of beer from the brewery post haste; while the nearest druggist is pre- 
pared to rush out an emergency prescription any time day or night, and at the drop of a hat. The countryside is dotted with competent physicians, lawyers, priests, preachers, and hex professors. The consolidated grade and high schools can be reached either by the school buses or ten minutes' walk.

I started this chapter by saying we came to the country because it is a better place to bring up children. In the way of formal education our country public schools are the equal of those in the city and, of course, far superior to private schools. However, from the educational standpoint, my contention of the country's superiority has little to do with formal education. On the strictly material side the city offers practically no chance to the child to learn how it lives. It will be a long time before I forget the day I took the nine-year-old daughter of some friends, who had driven out from the city of a Sunday afternoon to see how the Tetlows were getting along in their igloo, to see the dayold chicks. It was the first time the child had ever seen infant chickens. After she had admired and observed them a while she turned and pointed to a duck, fattening in a near-by cage.

"And is that their mother?" she asked.

Now, that episode is not funny. Here was a child, considerably above the average in intelligence, who did not know a duck from a chicken. It is a moral certainty she did not know beef comes 
from cattle or mutton from sheep. The more you contemplate that question, the more appalling its implications become. At her age my daughters not only knew a duck from a chicken; they knew which came first-the chicken or the egg-and how, and why, and what to do with the chick after it arrived. Yet this child with at least as good a mind but without opportunity to observe and learn not only did not know the difference between a hawk and a handsaw; she was not even conscious that a lot of such widely disparate things as hawks and handsaws existed. To her, food was something you eat off a table three times a day, water something that comes out of a spiggot when you turn the tap, and warmth a thing that circulates in radiators.

They tell me that in embryo a human being moves up through all the evolutionary stages from the primordial ooze. Whether or not in this process we acquire that part of our education variously called instinctive, involuntary, or unconscious, we might at least take a hint from it and, by "exposure" to country life teach the growing child how, so to say, its forebears contrived to get all the way from a Piltdown cave mouth to a revolving door on Park Avenue.

The country fosters self-confidence and self-reliance; it teaches children that if they are to be cared for, they must ultimately do it themselves; as well as how to do it. Probably because we live 
too close to the fact I find good, rural illustrations of this simple declarative hard to find. But I recall that several years ago we went away one weekend, leaving the children with their grandparents. They came back to the house Sunday afternoon to wash the milk buckets, strainer and separator. Incidentally, tearing down, cleaning, and re-assembling a cream-separator is an education in itself; it embodies most of the mechanical lessons that were denied me until I went off to the wars, and to the Infantry School of Arms at Fort Sill.

On this occasion the girls noticed a wet spot on the ceiling of the first-floor hall. They traced it to a broken-down piece of bathroom plumbing, and cut off the water at the basement valve. Since in so doing they restricted the whole household water supply, they called the plumber, and told him what needed fixing. Catastrophic damage was prevented. And by that I mean not only water damage to the house, but that unless checked such a leak might have run the well dry. Certainly not spectacular; yet what could the apartment-bred child do, faced with the same situation? Call the janitor. Which would be swell if we could invariably call the janitor. Or, as my cousin used to say when as children we debated what we should do when the earth got as cold as the moon: "Live on canned goods." Life abounds with situations in which neither janitors nor canned goods are on 


\section{A' BABBLED OF GREEN FIELDS}

call. The utter helplessness of the city-bred, specialized for success only within the narrowest groove, is not the least disturbing or distressing manifestation of modern unemployment.

Undoubtedly country living has an important bearing on health; yet just what, or how much, is difficult to say. If we were to believe statistics, which show lower death rates in cities than in the country, we should perforce esteem the country a poor place to live. But these vital statistics take no account of the fact that the drift of population is steadily from the country to the cities; or that in this drift it is typically the young and strong who leave the country. Of much more significance than the vital statistics it seems to me are the findings predicated on the government's dietary researches: namely, that so far this country never has produced enough foodstuffs to give every citizen the optimum diet recommended by the Department of Agriculture. To do so would require a total increase of forty odd million acres in food crops. Slight reductions could be made in wheat acreage, and in barley, rye, rice, and buckwheat. But cattle, hogs, poultry, dairy, fruit, and vegetable farming would all have to be enormously expanded.

In a broad way we have no idea how much benefit may derive from country living, for we have no idea what the effect on national health would 
be of each citizen's having enough to eat. To descend again to the particular, it is hard to say what the effect of farm living has been on the health of my own family because I can not say what it might have been if we had lived in town. We seem to be pretty healthy, perhaps healthier than the average for our economic level. Our resistance to the common ills of the flesh appears to be strong. We have energy to do rather more than average for our respective ages. Our doctor bills, year in, year out, are trifling. But whether this is the result more of the life we lead than of inheritance, who shall say?

If there is one impression I should be distressed to convey, it is that life on a home-use farm is all work and no play. Far, far from it. There is something going on all the time. And while all the synthetic distractions of the town are equally available to the country dweller, yet there is that in the life makes your own home-made amusements preferable to those ready put up at the store. With plenty of house room, food, and-if you like-home-made drink, one can entertain without much regard to cost. We often have one to a dozen house or dinner guests six days out of seven. On one occasion we provided for fifteen unexpected visitors at a Sunday night supper.

For those who like to sing in chorus, or dance to the radio, or play the noisier sorts of parlor 
games, the country offers the inestimable advantage that you can keep it up as long and as loud as you please with no fear of disturbing the neighbors. Much of the farm work itself is, as I have said, a more than satisfactory substitute for adult outdoor games.

Dining out of doors and picnicking are amongst our favortie recreations. Picnic food may be either hot or cold, though my own preference is for hot vittles any time. With a little experience cooking outdoors is about as easy as cooking in a kitchen. Most people consider picnicking as exclusively mild-weather diversion, yet winter picnics are as good fun as any other. A day spent outdoors, with adequate food and clothes, is a splendid refresher. And there is this to be said of winter picnics: if you are tired of your own place and crave a change of scene, good camp sites are not nearly as hard to find in winter as in summer. There are so few other people out looking for them. 


\section{Selling the By-Product}

NO study of home-use farming would be complete without a glance at the selling end of the business. For while the money crop remains a byproduct it is nevertheless an important one; without it a living-in-kind from the farm would cost as much as any other living.

We were well into our second year of homeuse farming before we began to have surpluses for sale. Surplus has increased steadily, yet we have never had any trouble disposing of it. The difficulty, if any, in selling the produce of a homefarm is that the quantity of any commodity for sale is necessarily limited (it is one of the few fixed rules that the household must never go short to make a sale) so that no sooner is a customer started than we may have to say "Sorry, but no more of that." Yet this may be the very thing makes selling easy: regular customers accept the inconvenience of irregular supply because they can be sure there is no hocus-pocus about it, no buying of storage eggs or discouraged vegetables in Dock 
Street commission houses to palm off as fresh, home-grown food.

Although we make sales en gros, as when we sell a cow or a couple of pigs, a lot of the business has always been direct to the consumer. It is a business dealing in a large number of small things, which is a diametric opposite of standard farm practice. Unless you are familiar with that type of business you will be skeptical-like the average farmer-of the way the volume rolls up. Take eggs for example. During the year just ending my hens produced a little over eight hundred dozen. Yet the fact that the eggs do not appear by the great gross but a dozen or two-at most three or fourper day, makes egg production look insignificant. Nevertheless we sold nearly six hundred dozenall a dozen or two, which is to say a few cents, at a time.

All together, in five years we have not had over thirty-six different customers, and of these not six could be described as regular. Yet they have been enough to make a difference in the net cost of living. Neither deliveries nor collections present any problem: most of the business is cash; either the customers come and take their goods away or delivery is incidental to some other errand. The occasions when a special trip must be made to fill an order are rare. The total of bad debts in five years has not been five dollars. 
There is not only no doubt, but there is every indication that with a little better, more systematic attention to this phase of home-farming we could make what is called "a good thing" of it. Last summer my daughters found themselves short of money for their vacation. I offered them all the receipts from all the sales they could make to new customers, with the proviso that these were not to be served at the expense of regular trade. It is true that in some departments of the truck garden they created critical shortages; on the other hand they got rid of a lot of stuff that would otherwise have been but pork and poultry salvage. And in less than two weeks, having dug up five new customers, they did over twenty dollars' worth of business.

Conversely, on another occasion when we were all otherwise too preoccupied to pay any attention to sales, they fell off alarmingly. Like everything else-you have to work at it. An intimate, up-to-theminute knowledge of what is growing on the farm is absolutely necessary. And one must tell the customers not only what is ready, but what to anticipate. Otherwise, for example, they are apt to indulge in an orgy of store-boughten broccoli the very week before ours is ripe, and then never want to see it again.

There was a time when farming was a race to get to market first with seasonal products and col- 
lect the premium prices they commanded. Maybe the race still goes on. If it does there is no point in the home-farmer's competing in it. Today fresh fruit and vegetables are market commonplaces the year around. Early maturity is usually attained only at some sacrifice of quality. And regardless of season there is always a premium market for top quality. We found that out. In the beginning we sold all our stuff at the prices advertised by Philadelphia's chain stores. It took me some time (in commercial matters I am frequently obtuse) to realize this was the wrong tack. Why sell stuff, admittedly superior to anything that can be bought in stores, at store prices? Eggs again furnish an illuminating illustration. The week these lines are written, the best grade offered by the local chain stores is at thirty-eight cents a dozen. Simultaneously at the nearest egg auction, three miles up the pike, farmers got forty-one and one-half cents a dozen for the same size eggs. Obviously no near-by farmer is selling the chain stores eggs they can retail at thirty-eight cents when he himself can get three and one-half cents more, wholesale. Today I mark my eggs up on a scale of which the auction price is the base. In this instance my price for the same weight is forty-seven cents.

I have often been tempted to start a roadside stand. Even though they are almost without exception hideously ugly there is no reason why one 
should not be an adornment to the landscape. And there are certain advantages to roadside selling. In the first place, an indifferent stand would be big business in comparison to what we do. It eliminates delivery, offers an opportunity for the display of goods, can be operated seven days a week, and catches transient as well as steady trade. Yet the objections to roadside marketing are serious enough to make me hesitate. Business is pretty much at the mercy of the weather and the seasons: a rainy week-end can put the kibosh on the week's gross. Hereabouts roadside selling is practically at a standstill from December to April, not because it is impossible to carry on in cold weather but because the city people who compose the bulk of the trade hesitate to venture out into the country in winter. It is vulnerable to the attacks of competition; one successful stand is an invitation to all the neighbors to go into business. Either a roadside market must involve a considerable capital investment or it must be almost an integral part of the home. The thought of this invasion of one's privacy is repugnant, and in the country, where we must do most of our own policing, it is not safe. Whether right in the home or segregated from it, if a roadside market is to succeed there must be one or more persons in constant attendance. The number of things I myself have not stopped to buy simply because I could see no one around to wait on 
me is legion. What the total loss to the nation's roadside business directly chargeable to poor and indifferent service may be is incalculable, but it must run into billions.

The greatest objection to a roadside market to me, however, is that at present Medlock Farm could not possibly keep such a stand in stock. The result would be either a loss of steady trade on one hand, or the temptation to do a phoney business (buy wholesale produce and sell it as home-grown) on the other.

Since we have left the straight and narrow path traced by personal experience and have branched out, as Mark Twain somewhere says, into the "glad, free realms of things we do not know anything about," it may not be inappropriate to set down some of my thoughts on ways to supplement the part-time farm's money crop. The whole field of cottage industry lies open before us, for once the farm is organized and running it does not preempt all one's spare time and attention. Clothing and textile manufacturing, while of secondary importance to the maintenance of the home and the success of a home-use farm, nevertheless merit a place there. Any social cataclysm that threw one back to complete dependence on the land for sub- . sistence (and it must not be forgotten it was the prospect of just such a possibility set me off on my original experiment) would leave one distinctly 
out on a limb unless prepared to clothe as well as feed and shelter the family. Meanwhile textiles as a by-product would swell the dollar income.

As a source of income if not as a maintenance necessity I should rate pottery well up alongside textile production. It was my privilege to know one of the last of the great Pennsylvania German potters, Mr. Jacob Medinger. He came nearer to having the world by the tail than any man I ever knew. His shop and kiln adjoined his house, on a small farm a dozen miles north of Medlock Farm. Everything he made was sold before it was fired. He loaded up the kiln two or three times a year with a large assortment of plates, cups, saucers, platters, bowls, jugs, pitchers, and pots. If an article did not fire exactly as he wanted it the customer could not have it. He stuck to the traditional conventional Pennsylvania German styles and decorations, in which the tulip and the peacock predominate. He often hinted that his work sometimes found its way into collections of early American antiques. It might just as well; it is as authentic, as true to type, as the work of his greatgrandfather. Because it was first-class, the world of trade beat a path to his door; he had no overhead expense, no payroll to meet, no merchandising or selling costs, no delivery charges, no exchanges or returns. He got cash in advance or on delivery. In season he varied pottery with a bit of home-use 
farming and the manufacture of cider and apple vinegar, for which, too, the trade was always lined up waiting.

Like all good artists and craftsmen Mr. Medinger delighted to exhibit his skill. I remember one time asking him to make a jug for me.

"One quart, or two quart?"

I said two quart. Without recourse to any plans or calculations; with no tools but the wheel and his bare hand he "threw" the jug in less than ten minutes. It stands on my mantel now, with the inscription burned in it:

"June 151931 Made by Jacob Medinger for Henry Tetlow while here at Limerick Pottery."

It holds exactly two quarts.

China clay is the prime raw material of pottery. There is a bed of it on Medlock Farm (it is found almost everywhere) big enough to keep a cottage kiln busy for years. It lies about six inches below the surface and can be worked with a spade.

Iron, like pottery, lends itself to cottage industry in that the necessary plant is cheap and compact. Although the probability of extracting the raw material from one's own land is remote, commercial supplies are neither expensive nor inaccessible. Hand-wrought iron products of all sorts are always in demand. There are several masters 
of the craft in this neighborhood who keep steadily busy making household hardware and implements, mainly in the traditional local patterns. The force of those traditions is, by the way, something to reckon with. When we were furnishing the rebuilt wing of Tavern House it struck me the conventional tulip design would make a nice wall bracket for electric lights. In iron work the tulip is seen in strap hinges, shaped thus:

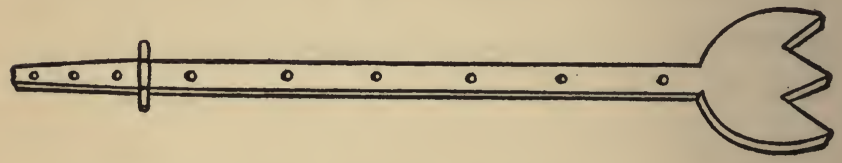

My idea was that a tulip light bracket should be shaped so:

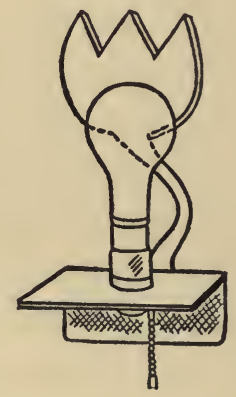

I drew a sketch and showed it to one of the local iron masters. He did not point-blank refuse to make the electroliers. But I could see he might. And I still have not got them. Why? There never 
has been, in wrought iron, a conventional tulip with a curved stem.

Other metals besides iron-pewter, aluminum, copper, brass, and silver-are all amenable to cottage industry. I have a neighbor who works in all of them. Leather is another by-product of the farm that, once a practical home method of tanning is devised, can be put to infinite uses. And, of course, before all these there is wood. It has this great attraction: all the modern power tools for woodworking have been cut down to household or home-farm size and price. With a minimum capital outlay at the mail-order house one can install a plant that will work up a raw log into finished cabinet-quality material.

Now that we are so far afield from home-use farming let us take a step further and glance at commercial farming. For while cottage industry is nice for the long winter evenings, commercial farming is the obvious next logical step after farming for home-use. Before telling why I shall probably never take it, let me first say it is a mystery to me why the belief persists that commercial farming cannot or will not pay. To be sure, it would be hard to succeed in any business in which, as on the farm, it is customary to buy at retail and sell at wholesale. Yet it is not this anomaly that causes most farm failures: it is lack of capital. Farming takes a lot of it-more than any other 
business. The plant investment is large, the turnover is slow, and the gross-profit margin small. The risks are greater, since to normal business risks is added an almost complete dependence on the whims of weather.

The activities of our government have made most of us familiar with the plight of the wheat, corn, and cotton farmers; we know what causes it: specialization. Nevertheless successful farming is specialization. This does not mean specializing in a one-crop commodity like wheat, corn, or cotton that, no matter how high its quality, must be sold in a world market at world commodity prices. It means specializing in a high quality consumerproduct that will command a premium retail price. The farmer who is not geared to do that has no business in commercial farming; he should revert to home-use.

The best example of the successful specialty farmer I know was my grandfather. At the age of seventy-five, and with no previous practical experience, he bought two hundred acres just across the river from Valley Forge-a farm that had been a conspicuous failure at general cropping. $\mathrm{He}$ spent two or three years improving the fertility of the soil by unconventional methods he had figured out for himself. He used to storm and curse with tears in his eyes at the cost; I doubt if in those first years he got even a part of his bait back, but 
he went right on. When he had brought the land up to the proper pitch he bought out an entire nursery from a Maryland operator, set out all but a smidge of the two hundred acres in peaches and apples, and hired the ex-nurseryman as his head farmer.

It is noteworthy that southeastern Pennsylvania is not-or was not then-considered "peach country." All over the farm Grandfather drilled artesian wells as insurance against drought. He instituted a thorough and intensive régime of fertilizing, cultivating, pruning, and spraying: his best insurance against frost, as well as guarantee of bumper crops of what were probably the world's finest peaches. Thousands of people can, like myself, testify they never saw or ate better. In the middle of the season, when prices were at the bottom, his peaches used to retail in the best Boston, New York, and Philadelphia markets at a dollar apiece-and that was before the war. They were always sold under his own brand name. Buyers knew where to come to get them; selling was the least of his problems. He did not live to put his apple orchard through its paces, but when he died in 1919-ten years after he bought the farm-he had all his bait back and I reckon, although I never had his confidence, something around a quarter of a million besides.

This kind of farming demands big capital and 
expert management. But the expertness, while of a sort fairly common to industry, is practically unknown to agriculture. All that Grandfather knew about raising peaches you could put in your eyeexcept what he read in books. Armed with this knowledge he had the intelligence to figure out how to produce bumper crops of super-peaches. Thereafter the mechanics of production could safely be left to any experienced orchardman who could be depended on to follow instructions when they departed from the norm (probably the hardest thing in the world to persuade the average "dirt farmer" to do).

When the trees came in bearing, the capital account was still sufficiently unimpaired so that Grandfather instead of begging the commission men to hand him a little money for his produce, could afford to be snooty. He put the first bushel of peaches that ever came off the farm in a hamper in the back of the cut-under, put on his store clothes and his priceless Panama hat, and drove to Philadelphia. There he pulled up in front of the leading fruiterer, far from the prying eyes of all but a few hundred thousand citizens, and consented to trade with the fellow for a trifle less than the peaches' weight in gold. From that time on he sold his peaches only in carload lots, but always at premium prices. He was long on what most 
farmers conspicuously lack: merchandizing ability and showmanship.

This revelation of family history discloses the reasons why I shall not go into commercial farming. The mere fact I own forty acres of land and extract therefrom part of my living does not qualify me for the commercial category. To switch Medlock Farm over would require more capital than I could afford to risk in such a venture: three or four times what is in it now. But the greater deterrent is that to make a success of commercial farming I should have to devote all my time and attention to it for at least four or five years.

By the end of that time-who can tell?-there may be a law against commercial farming. 


\section{Some Conclusive Comparisons}

THROUGHOUT this book I have emphasized the profit and cost side of part-time farming, not because I believe it the only important advantage of country living, but because of all those it enjoys over the city this is the one of which I find people universally skeptical. They are hard to convince that a better living can be had for less expense in the country than in the city. They will agree about everything else; it is not even uncommon for women to concede country life need not be hard and dreary. But when it comes to showing them that the cost is less, even those most anxious to believe will hesitate. At the risk of tedium I am going to enlarge that side of the picture a little more. Whereas in the beginning I showed the costs of Medlock Farm, now I am going to show some comparisons.

The first is within the farm itself. There is a profound difference between. the record of performance and the potentialities of the place. I have said that this is a growing farm. With the same plant and equipment we will produce larger yields 
from year to year without appreciable increase in expense. We are now eating all we can hold; the only way to utilize increased production will be in increased sales. Up to a certain point, that is to say for several years to come, net cost of living will therefore continue to decline, whether the general cost of living goes up or down.

Now compare a neighboring farm which is used only as a suburban home. The family is the same size as mine. The farm is less than a third the area of mine, yet there is room on it to do nearly everything we do here. No attempt is made to produce anything from it but a summer vegetable garden. I have said the difference between merely keeping property from going to rack and ruin, and putting it to productive use, is insignificant. This case history exemplifies the contention beautifully, for there is a weekly labor bill as big as mine-excepting heavy, contract labor-and an annual overhead expense-insurance, repairs, and so forth-usually as big, sometimes bigger than, mine. For lack of farm manure that part of the land in use has run down, so there is actually a depletion charge (which I do not have) which will only show up when and if the farm is sold. The combined cost for food and the farm in this case is more than forty dollars a week: more than double the net cost of living at Medlock Farm.

Now observe. If and when the general cost of 
living rises, the cost of living on this particular farm goes up too-with no compensatory return: either that family's living expenses must increase or, if they are maintained in statu quo there must be a less bountiful provision. Whereas it matters little on Medlock Farm whether the cost of living goes up or down-it is not so much the market price of a dozen ears of corn that concerns us as that we have our own corn on the cob. No matter how low it goes it will still be cheaper to grow it than to buy it. Yet if the cost of producing rises the increase will be more than offset by the increased price we will receive for what we sell: a rising market rather favors the home-use farm. For while farm prices are usually slowest to "improve" -as it is ironically called-retail food prices are the most sensitive in the whole economic structure.

It is interesting in this connection to trace the price fluctuations of pork at retail, compared to the price of middlings, the biggest factor in pork production. In the dark winter of 1933 the average retail price per pound of all the products we got from a pig was .118 cents. At the perihelion of planned production, the winter of $1936-37$, this average had risen to .322 cents per pound. Now in the winter of the New Deal's discontent-1937-38, the Medlock pork index has dropped to .221. Which goes to show there is something preposterous somewhere in the American system. For ob- 
serve the course of the price of middlings under the aegis of the Brain Trust. Starting at $\$ 1.50$ a hundred in 1933 they rose to a peak of $\$ 2.60$ a hundred in the late spring of 1937 . Not long thereafter-although it was probably inaudible in the roar and clamor of the capital-the recessional sounded off. The last bag of middlings bought in 1937 was billed at $\$ 1.65$. These are all, let me repeat, retail prices. What relation they bear to wholesale price movements is of no interest to me. What does interest me is that the fluctuations in the consumer's price of pork are out of all proportion to those in the price of feed. Assuming it takes four hundred pounds of middlings to produce a hundred pounds of dressed pork, then:

100 pounds that cost the consumer $\$ 11.80$ in $1933 / 4$ cost the farmer $\$ 6.00$.

100 pounds that cost the consumer $\$ 32.20$ in $1936 / 7$ cost the farmer $\$ 10.40$.

100 pounds that cost the consumer $\$ 22.10$ in $1937 / 8$ cost the farmer $\$ 6.60$.

The farm cost is back where it started, while the consumer is still paying double. At the later high prices of pork the home-use producer is nearly three times better off than he was in the low-price era.

There is another comparison that illustrates the economic worth of the home-use farm. To 
make it clearer, as well as to conceal some of the facts of my life from too prying eyes, I have uttered what I call the Medlock Dollar. This base unit represents all my living expenses in the year 1932. Of the Medlock Dollar, thirty-one cents went in 1932 to the costs of food and the farm, sixtynine to all other expenses. That was in the last year before we began to produce seriously. It was also-need I repeat?-a particularly disastrous year in the business world. My income from all sources was, in terms of the Medlock Dollar: forty-six cents. My deficit was fifty-four cents, which was met out of the granaries of the seven fat years.

It took us four years to turn the corner (there ought to be a moral or at least a gag in that somewhere). In 1936 our total cost of living in terms of the Medlock Dollar had dropped to seventy cents. By hook and crook we had hammered down "other" expenses from a sixty-nine to a forty-sevencent share of the dollar. Farming and food costs had dropped from thirty-one to twenty-three cents. During the same time income had staged a nottoo-robust comeback; it had risen from forty-six to sixty-two cents. The mental calculator will see at a glance that this still left a deficit of eight cents in every dollar. The reason I say we turned the corner is that this deficit was supplied by cash income from the farm; the actual budget was in balance for the first time in four years. 
This, to me, is the crux, the climax, the essential raison d'être of the part-time experiment. My business is a small one. What I take from it as salary can be-nay is-in a lean year an important factor in the total cost of production. No matter how well buttressed any business may be, after it has operated in the red continuously for two or three years it feels the slightest strain. While it would be an exaggeration to say that without the help of the home farm it would have been impossible for me to pull my business through those lean years, yet the occasion when that could be true is not hard to imagine. It may happen yet.

To make the history of the Medlock Dollar a little clearer I have drawn up a table:

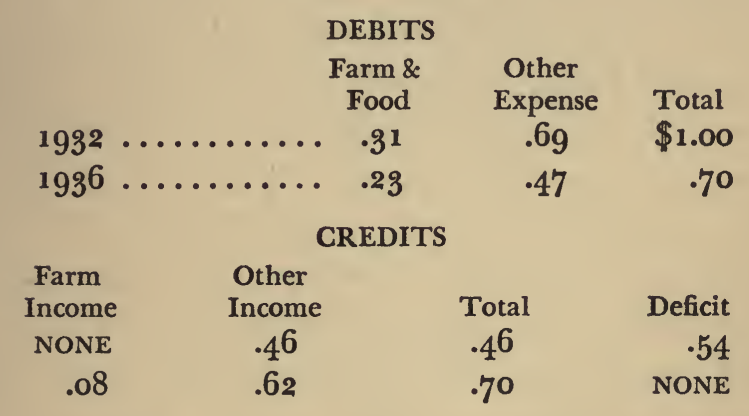

No "adjusting" has been done to these figures to allow for the rise in all costs-for the shrinkage in the value of the federal dollar, in those four years. If it had, then a corresponding adjustment would 
have to be made to indicate income-in-kind received from the farm, without which the total cash income of seventy cents as shown above would not be worth much more in real income than the fortysix cents of 1932; it might not be worth as much. The alternative to operating a part-time farm back there in 1932 was to discharge my man, and reduce all outside expenses to an absolute minimum. It would hardly be fair to say I might have sold the farm and moved into cheaper living quarters altogether; in that year it would have been almost impossible to sell it at any price, whereas it would be essential to the success of such a move to get a good part of my capital investment back out of the place. To pursue a policy of minimum expense and consequent neglect would have produced a further deterioration in the value of the property. Even, however, if it could have been maintained at something like the then level at, let us say, only one quarter the cost, the rise in food prices has been such that by 1936 the total expense for food and the farm would be, instead of thirtyone cents of the Medlock Dollar, something like forty or forty-five cents. Almost all the other savings we managed to make would have gone to naught. A large chunk of capital investment would have gone the primrose way of erosion down Stoney Creek; and a good man would possibly be looking for a job. 
As to him this may be said: on the one hand he is doing more work than he did prior to the late fall of 1932: measured in time, one-quarter to onethird. But up to the fall of 1932 he had taken no salary cut, and he has not yet: he is still enjoying the wage scale of the New Era. Compared to the people who work in my factory, and I suspect in a lot of other factories, his position is greatly improved on that score alone. When on top of that we put his share of income-in-kind deriving from the farm, we find that his real wages-"unadjusted"-show an increase of twenty-five to thirty per cent over 1932.

Let us return to my statement that potentially the farm is better off than the records show, and amplify it a bit. Consider the matter of milk supply versus stock feed, for example. In raising enough cows to insure a steady flow of milk into the house we have relatively to feed more; in consequence, growth of the herd has kept ahead of home feed production. It is only in the last year1937-that we have had any income from the sale of excess livestock. From now on, this will afford a steady source of cash income. At the same time the improved fertility of the farm from the accumulated manure will give us a chance to catch up on stockfeed production; the actual cost of maintaining our own milk supply will turn down.

The same thing is true in the poultry depart- 
ment. We have been building up a farm flock sufficient to care for our own needs. The expense of maintaining the flock has been disproportionately large. But now that we have a mature flock this disparity will disappear; the expense of growing stock will sink back to the normal level for replacement. There will be just as many surplus eggs to sell, with less cost to produce them. At the same time the incubating and brooding equipment will have its load lightened: it can be used for the production of other kinds of fowl, thus further contributing to the variety of diet, and helping to keep down the cost of store-bought food. Nature, in short, will begin to pay compound instead of simple interest. And how she can do it!

It is impossible to contemplate my individual experiment without speculating on the social and economic consequences implicit in the more general adoption of such a way of life. I would remind you that even before the government entered on a policy of destruction and restriction of crops one of its own departments determined that we do not produce enough of all foodstuffs to give every citizen what government itself recommended as an optimum diet, even if the citizen-or the tax-payer -had the money to pay for it. To do this we should have to put another forty-odd million acres in production. Our thirty-two million rural population now till an average nine acres per capita. Hence, 
with our present productive efficiency the land should support another four and one-half million population without producing a literal glut of foodstuffs-however much their activities might disrupt markets and dislocate government plans.

Let us suppose a million families averaging 4.5 persons per family should move out of our cities and take up part-time farming. In the fullness of time this million families would re-employ a good half million hired men (no scheme of re-employment has done that much yet), preferably family men, at steady work and good wages the year around. This would raise the total of repatriated citizens to nearly seven millions, which is a lot of people to move beyond the risk of sudden, catastrophic destitution; a risk all those who depend solely on money for their support must constantly face.

While we are pipe-dreaming we may as well make a good job of it. After those seven millions have bought their farms or rented their tenant housing they will be in the market for a lot of capital goods. Let us overlook the water-supply and heating systems, the bathroom fixtures, vacuum cleaners, refrigerators and other gadgets they will want-to say nothing of roofing, flooring, painting, and so on-to turn their farms into the type of luxurious residences to which as city dwellers they were sometimes accustomed, and concentrate on 
what we know they must have to start home-use farming. At today's prices it is about five hundred dollars' worth of livestock, nursery stock, and manufactured equipment. A two-and-one-quarter-billion-dollar order awaits the industries involved, any time they are smart enough (and it would not be much of a trick; at least one of the railways did very much the same thing, years ago) to organize the part-time farming movement and get it going. Two and one-quarter billions is enough to make even a politician perk up his ears, let alone a capital goods industry.

The social and hygienic implications of such a movement are too intricate to assess or forecast. That they would be profound is as certain as that the political result of moving three and one-half million votes out of large cities where they count for little into thinly populated counties where they count for much would be practically revolutionary. It would be a further step in the disintegration of the city, and to that extent would be all to the good. For the city as a sociological institution has already become in our time-though we still do not suspect it-almost obsolete.

But soft! Night thickens. Good things of day begin to droop and drowse. Come to look at the clock, they have been drooping and drowsing quite a while: it is after two. The chickens should have been fed six hours ago. They will enjoy it none 
the less for that. I leave my writing and step out the side door into a dense fog that hangs low and trembling on the bridal bush. The ground is like a sponge. I stand listening to the dripping moisture and the far-away, desolate call of a perplexed and hurrying locomotive. Somewhere a dog whines. I grope my way through the fog and mud to the barn, switch on the light and take a look around. It is the sort of scene you have applauded on a stage; yet all is but toys until you are vouchsafed the reality of your own barn, full to the guards with stuff to feed your livestock until another growing season.

The chickens have waked every creature in the barn with their complaint of the slow service. They are fed in a minute. Now for a look in the cow barn: cows do not mind being disturbedmuch. They condescend to rise in their byres and be rubbed and scratched behind the ears. Outdoors again it is raw cold. So once more through fog and mud and back in the bright house, shucking dirty shoes and casting sheep's eyes at the rum closet.

It's the life. 



\section{Bibliography}

A complete bibliography of home-use farming would stretch from here to the moon. The following are only books actually contained in my own library, and frequently consulted:

Your Meals and Your Money, by Gove Hambidge.

Whittlesey House, New York. 1934.

A Living from the Land, by William B. DuRYee.

Whittlesey House, New York. 1934.

The Farm Woodlot, by E. G. CheYney and J. P.

Wentuing. The Macmillan Company, New York. 1926.

Dairy Cattle Feeding and Management, by CARL W.

Larson and H. O. Henderson. John Wiley \&

Sons, Inc., New York. 1928.

Productive Swine Husbandry, by G. E. DAY. J. B.

Lippincott Company, Philadelphia. 1915.

Fertilizers and Crops, by Lucius L. Van Slyke.

Orange Judd Company, New York. 1920.

The Trees of Northeastern America, by CharLes S.

Newhall. G. P. Putnam's Sons, New York. 1890.

Camping and Woodcraft, by HoRACE KePHART. The

Macmillan Company, New York. 1927.

Productive Poultry Husbandry, by HARRY W. LewIS.

J. B. Lippincott Company, Philadelphia. 1914. 
Practical Poultry-Farming, by Lours M. HuRD. The Macmillan Company, New York. 1934. Biggle Orchard Book, by Jасов BiggLe. Wilmer Atkinson Co., Philadelphia. 1911. 


\section{Index}

Abortion, chronic, 77

Acres in cultivation, national, 163,188

Adjustment of the dollar, 185

Agriculture, correspondence courses in, 50

Animal Industry, Pennsylvania State Bureau of, 54

Animals as pets, 107

Apples, 148

Around the Year in the Gar. den, 72

Artificial light for chickens, 95, 98

Asparagus, 143

Autos, number needed, 157

Bacon, 102; type pig, 105

Bang's disease, 77

Beef, 31, 86, 87; production, course in, $5^{1}$

Bees, 186

Beetles, 37

Beets, 119

Biological balance, $6 \mathbf{5}$

Birds, 65

Blackberries, 124, 140

Black-headed worm, 187

Blood-testing, 77; of chickens, 96

Bookkeeping, 72; farm, course in, 51; see also Records

Borsodi, Ralph, Flight from the City, 57
Brahmas, 95

Breeding: of cows, 78, 80; of hens, 94; of pigs, 105, 115

Brooders, 97, 99

Brooding of chickens, 96

Budget, food, 8, 13, 184

Bulb plants, 127

Bulls, 79; see also Livestock

Bureau of Home Economics, $54,67,196$

Butchering, 41, 106, 108

Butter, 13, 32, 82; course in making, 51

By-products of part-time farming, 166; handicrafts, 171; roadside stand, 169; selling surplus, 166

Cabbage, 119; Chinese, 121

Calves, feed of, 85 ; see also Cows

Candling, 88

Canning, 41, 143, 150; of vegetables, 119,123

Capital, 24, 52, 175; see also Investment

Carrots, 119

Cats, 65

Cattle, 77, 85; see also Cows

Celery, 119

Cereals, 136

Channel Island cattle, 79

Chickens, 66, 68, 97, 137; breeds of, 94; feed of, 98; hatching, 
96; investment in, 95; see also Hens, Poultry

Child labor, 46

China clay, 173

Cholera, 105

Chores: farm, 40, 148; household, $142,15^{\circ}$

Chronic abortion, 77

Climate, variations of, 55

Clothing, making, 171

Cod liver oil, 98

Commercial farming, 52, 175; piggeries, 103; poultry-keeping, 97,101

Consumption: of food, 66,81 , 149, 163; of power, 98; of soap, 134

Contract labor, 40, 126

Corn, 60, 61, 136, 144; crop, 20; sweet, 124

Cost accounting, pitfalls of, 17

Costs, 18, 27, 180; adjustment of, 185 ; capital, 24; of butter, 32 ; of canning, 146; of food, $8,10,12,64,181,184$; of living, 181; of orchard, 26; of poultry, 20, 96, 98, 99; of soap, 134; of time, 32

Country life: and children, 154, 160 ; and health, 163; education in, 160; recreation in, 164

Courses, by correspondence, 50

Cows, 77, 79, 84, 187; breeding of, 78,80 ; feeding of, 54,84 ; labor time for, 41, 43; manure, $63,66,74,85$; milk, 75 . $78,80,84$; sales of, 167 ; testing of, 77 ; yields of, 81

Cream, 76,81 ; separator, 83

Credits, table of, 185

Crisis: of 1907, 57; of 1929, 7 , 57; of 1933, 3

Crops, 20, 23, 146, 148; national, 163
Currants, 124, 125

Dandelions, 139

Debits, table of, 185

Diary, 72

Dill-pickle preserving, 54

Diseases: of chickens, 96 ; of cows, 77; of pigs, 104; of turkeys, 137

Diversification in farming, 36 , 38

Drudgery, 40, $15^{8}$

Ducks, 15, 20, 137

Economic effects of part-time farming, 188

Education in the country, 160 Eggs, 88, 93, 100, 188; hatching, 96; price of, 13, 169; sales of, 167 ; storage of, 93; tests of, 89; weight of, go; yield of, $68,70,99,167$

Electric power, 98

Endive, 119

Equipment, 25, 59, 83, 190; bird-raising, 98; for spraying, 126

Expenditures for food, 8, 10, $12,64,181,184$

Farm: diary, 72; diet, 29; life, $35,47,15^{8}$

Farmer, Fannie, 54

Farmers Bulletin No. 1348, 54

Farming, 36, 38, 55, 166; chores of, 40, 148; commercial, 52, 103, 175; courses on, 51 ; planning, 48, 50, 61; see also Home-use farming

Feed cost of cows, 84

Feed for livestock, 63

Feeding: of hens, 91, 98; of pigs, 115

Fertility of farm, 187

Fertilizers; commercial, 62; 
course in, 51; see also Ma. nure

Flour, 136

Flower gardens, 126, 128

Food: budget for, $8,13,184$; consumption of, $66,81,149$, 163; cost of, $8,10,12,64,181$, 184; habits, 30; national requirement of, 188; preservation of, 142; prices, 13, 102, 169,182 ; supply, 29, 68, 81, 85,136 ; wild, 138

Frosts, 37, 121

Fruits, 124; cane, 125; storing of, 148 ; wild, 139

Game, $13^{8}$

Gardening: course in, 51; labor time for, 44

Gardens, 116; flower, 126, 128; for immediate use, 122; kitchen, 122; planning of, 118; vegetable, 119, 124

Geographic variations, 55

Glucose, 190

Goats, 75

Gooseberries, 124, 125

Government publications, 52

Grades of eggs, 88, 91

Grapes, 124, 125

Greenhouses, 124

Guernsey cows, 79

Gun Club Cook Book, The, 82

Hall, Bolton, books by, 57

Ham, 102; preserving of, 113; smoking of, 112

Hambidge, Gove, Your Meals and Your Money, 59, 67

Hampshires, 95

Handicrafts, 133,171

Hand-wrought iron, 173

Hare, 138

Harvesting, 122; labor time for, 44
Hatching chicks, 96

Hay, 87

Haying, labor time for, 43

Health and country life, 163

Hens, 15; feeding of, 91; molting seasons, 100; productivity of, 93, 99; see also Chickens, Poultry

Herbs, 128, 148

Hides, 132

Hired man, 6, 13, 45, 186

Home-use farming, 149, 155, 166, 182; see also Production for use, Part-time farming

Horse manure, 74

Hotbeds, 124

Household work, 142, 150; la. bor time for, 43

Housewives, 33

Hurd, Louis M., quoted, 91

Immediate-use garden, 121

Increasing farm income, 171

Incubators, 97, 99

Inoculation of pigs, 105

Insects, 37, 65

Insurance, 18, 35

Intercropping, 123

Interest, 18, 21

Inventory value of Medlock Farm, 14, 27

Investment: capital, 24, 52, 175; in chickens, 26, 95; in livestock, 27; in pig pens, 114

Japanese beetle, 37

Junket, 81

Kephart, Clarence, Camping and Woodcraft, 59, 61, 66, 132, 139, 140

Kitchen: gardens, 122; on farm, 152

Labor, 40; and textiles, 133; child, 46 ; cost, 32 , 42; con- 
tract, 40, 126; time studies of, 43

Lard, 102, 109; type pig, 105

Lawn-mowing, labor time for, 43

Laying batteries, 100

Leather, 133

Leeks, 119

Leghorns, 95

Lettuce, 121, 124

Light, artificial, for chickens, 95, 98

Literature on farming, 50

Livestock, 15, 66, 69; feed for, 63; investment in, 27; sales of, 85,187

Living, cost of, 181

Machinery, 59; see also Equipment

Malta fever, 78

Manure, 62, 187; course in, 51; cow, 63, 66, 74, 85; horse, 74; pig, 74

Maple trees, 129

Meat, 12, 86, 108; dressing and curing, course in, 51

Medinger, Jacob, 172

Medlock Dollar, 184

Medlock Farm, 62, 121; before 1932, 5; debits and credits of, 185; inventory value of, 14 , 27; kitchen of, 152; life on, 154 ; location of, 4 ; operating costs of, 64; see also Homeuse farming

Metal-working, 175

Mexican bean beetle, 37

Milk, 13, 78, 187; cow's, 75, 78, 80,84 ; goat's, 75

Molting seasons, 100

Mushrooms, 140

National foodstuffs requirement, 188
New Hampshire Reds, 94

Nuts-and-berries school, 75, 133

Onions, 148

Operating costs, 64

Orchard, 26, 124; labor time for, 44

Panhas, 110

Part-time farming, 103, 171, 180, 188; see also Home-use farming, Production for use Pasteurization, 76

Peaches, 120,176

Pears, 148

Peas, 121

Pennsylvania German styles, 172

Pennsylvania State College Correspondence School, 50

Pepper, 124, 148

Perennial plants, 127

Perfume, 86

Pickles, dill, 53

Pickling of pigs, 112

Pigs, 66, 102, 112, 167; breeding of, 115; butchering of, 106; diseases of, 104; feeding of, 105, 115; labor time for, 43; manure of, 74

Pimientos, 148

Planning, 9, 11, 28, 69; of gardens, 118

Poke sprouts, 140

Pork, price of, 13, 182

Potato crop, 23

Pottery making, 172

Poultry, 24, 51, 88, 137, 187; cost of, 20; equipment for, 98; investment in, 26; labor time for, 43; profits of, 101; see also Chickens, Hens

Power, consumption of, 98

Preservation of foods, $14^{2}$ 
Pressure-cooking, 143

Prices, food, 13, 102, 169, 182

Problems: in 1932, 3, 186; of meat supply, 12; of servants, 150

Production for use, $3,23,36$, 40, 52; see also Home-use farming, Part-time farming

Production schedules, 68; see also Planning

Profits, 101, 176

Publications, government, 53

Pure Food and Drug Act, 130

Rabbits, 138

Radishes, 121

Raspberries, 124

Recipes, 54, 110, 134

Records, 70, 80, 100, 118

Recreation in the country, 164

Regulations against pig-raising, 103

Rent, 17, 19, 21

Repairs, 18

Rhubarb, 124

Roadside selling, 169

Roots-and-berries school, 11, 56

\section{Salvagers, 105}

Sauerkraut, 54, 148

Sausage, 102, 108

Scrapple, 102, 108, 110

Seasons, 93, 100; and gardens, 121; for butchering, 106; for canning, $142,14^{8}$

Selling: of livestock, 85,187 ; of surplus, 23,166 ; on roadside, 169

Servants, 150

Sheep, 66; course in, 51; labor time for, 43

Smoking of meat, 112

Soap, 134
Social results of part-time farming, 188

Specialization in farming, 176

Spinach, 121

Spraying of trees, 125

Squash, 117, 119

Stockfeed, 63,187 ; course in, 51

Storage of foods, 93,148

Strawberries, 124, 125, 140, 143

Subsistence-homestead idea, $5^{8}$

Sugar, cane, 130; maple, 129

Superstition, value of, 60

Surplus selling, 166

Swine-husbandry, course in, $5^{1}$

Table of debits and credits, 185

Tanning, 132

Tavern House, 17, 114, 154, 159

Taxes, 18

Tea and great-grandfather Tetlow, 117

Temperature: and butter-making, 83; and eggs, 93

Tetlow: children, 4, 162, 168; family, 4,81 ; grandfather, 11 , 176; great-grandfather, 117 ; Henry, 8, 44; Mrs. Henry, 4, $149,151,155$

Textiles, 133, 171

Time: and farming, 40; and textiles, 133; cost of, 32 ; study of, 43

Tobacco, 135

Tomatoes, 120, 124, 144, 146

Tornado, 33

Trailers, $15^{8}$

Trap-nesting, 100

Trees, 131; fruit, 125; maple, 129

Trucks, $15^{8}$

Tuberculin-testing, 77

Turkeys, 137

Turnips, 119

Tusser, Thomas, Five Hundred Points of Husbandry, $5^{6}$ 
200

Undulant fever, 78

U. S. Army, 66

U. S. Department of Agriculture, 21, 54, 88; Diets at Four Levels of Nutritive Content and Cost, 67

Value of the dollar, 185

Van Slyke, Lucius L., 63

Veal, 85

Vegetables, 118, 123; storing of, 148 ; wild, 139; winter, 119 , 124

Vegetarianism, 11

Wages, of hired man, 14

Water cress, 121

Water glass, 93

\section{INDEX}

Water supply, 18, $4^{1}$

Weather: and gardens, 121; for butchering pigs, 106

Weights of eggs, 90

White diarrhoea, 96

Wine, 136; dandelion, 139

Winter vegetables, 119,124

Woodchucks, 139

Woodcutting, labor time for, 43

Woodlot, 131

Woodworking, 175

Wool, 133

Yields: estimates of, 55 ; of eggs, $68,70,99,167$; of kitchen gardens, 122; of milk, 78,81 ;

of pear trees, 125 

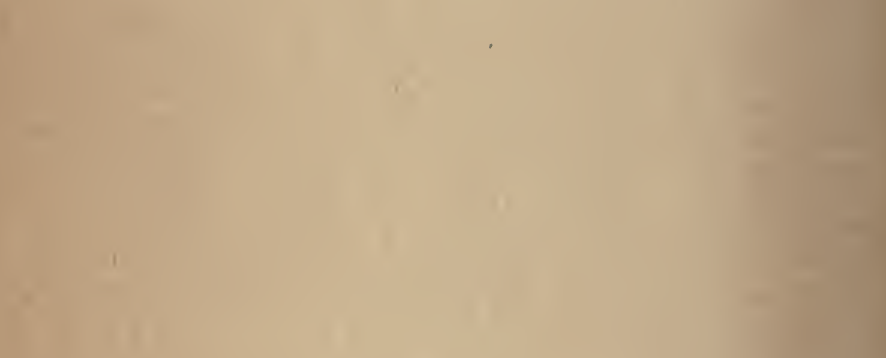

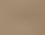

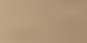

$\sqrt{2}+x^{2}$

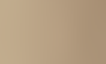

$x=5$
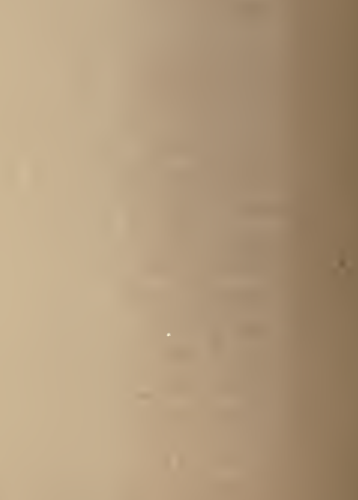
the nuts-and-berries school). And it all costs a fraction of what "store food" would cost. And what is more, starting with his land and his barns, the investment has been negligible. Mr. Tetlow knows what everything has cost, and he does not hesitate to tell you.

Now if your definition of farming is "suffering reduced to a science," this book may contain a shock for you. Farming on a leisure-time basis need not spell drudgery for a woman, or milking-a-cow-at-five-in-the-morning for a man. Most of all, in this practical story of the more abundant life, Mr. Tetlow has written with real charm about a human adventure filled with all kinds of ups and downs but balanced in the end by a completely new joy and rhythm of living. Here is the actual record of how one man made many another city person's dream come true: a home in the country effecting a real saving in the family budget.

Just a few of the subjects the author takes up:

TFarm Drudgery: A Myth

TWhere to Find Out How

TThe Problem, the People, the Place TMust You Keep a Cow?

TPoultry: A Success Story

TWhere Pigs Is Profits

IPitfalls of Accountancy

TThe Orchard and the Garden

TThe Household Chores 
JUST A SAMPLE of the more abundant life HENRY TETLOW has discovered for his familyand which he tells you, too, how to discover, in

\section{WE FARM FOR A HOBBY And Make It Pay}

"As this is written we are close on to Thanksyiving. In the barn are two milch cows yielding a superabundance of tuberculin- and blood-tested whole raw milk. Beside them are two ored heifers and two female calves. In the next twelve months we can count on four more calves, at least one of which will be a vealer (its mother tossed her cap, not over the windmill but over the party-line fence). Alongside these are three sheep that will turn into lamb, and when I say lamb I mean lamb.... There are nineteen pigs, four of which will go to the butcher before Christmas, while three will stay at home to provide us with ham, bacon, lard, sparerib, sausage, scrapple, and souse. There are one hundred and ten hens producing more eggs than we can eat. Before next spring we shall have culled out thirty or forty of the low producers and salvaged them in potpies. These, with the twenty ducks in excess of the brood flock, will supply us with fowl twice a week for the next six months. Currently, until the end of the gunning season, they give place to rabbit and squirrel, pheasant and quail.

"Overhead in the hayloft are fifteen to twenty tons of hay and corn fodder, while out in the corn crib are some six tons of corn with which to feed the livestock through the winter. And although the year's growing season is supposed to be over, the garden still produces lettuce, celery, leeks, broccoli, spinach and cauliflower; while in the cellar or outdoor pits are carrots, beets, cabbages, turnips, potatoes, apples, and pears. And two hundred and fifty quarts of canned fruits and vegetables in the red-room closet!"

“. . . To start home-use farming, at today's prices, it takes about five hundred dollars' worth of livestock, nursery stock, and manu factured equipment."

\section{AND-}

"In 1932, our budget for food and farm was at least $\$ 40.20$ per week.... In the first nine months of 1937 the net weekly budget was exactly $\$ 23$, even though the part of our budget which went for boughten food had risen to an average of $\$ 5.90$ per week. ..."

\section{WILLIAM MORROW A N GOMPANY}

